UC-70

Issued: December 1987

LA--10960-MS

DE88 005707

\title{
Summary of Sorption Measurements Performed with Yucca Mountain, Nevada, Tuff Samples and Water from Well J-13
}

Kimberly W. Thomas

DISCLAIMER

This report was prepared as an account of work sporsored by an agency of the United States Government. Neither the United States Government nor any agency thereof, nor any of their employees, makes any warranty, express or implied, or assumes any legal liability or responsibility for the accuracy, completeness, or usefuliness of any information, apparatus, product, or process disclosed, or represents that its use would not infringe privately owned rights. Reference hereia to any specific commercial product, process, or service by trade name, trademark, manufacturer, or otherwise does not necessarily constitute or imply its endorsernent, recommendation, or favoring by the United States Government or any agency thereof. The views and opinions of authors expressed herein do not necessarily state or reflect those of the Unitød States Government or any agency thereof.
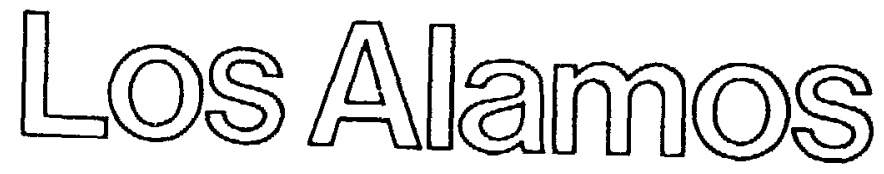

Los Alamos National Laboratory

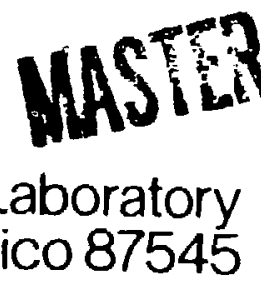




\section{CONTENTS}

ABSTRACT . . . . . . . . . . . . . . . . . . 1

I. INTRODUCTION . . . . . . . . . . . . . . . . . 1

II. EXPERIMENT PROCEDURES . . . . . . . . . . . . . . . . . 8

A. Batch Measurement Technique . . . . . . . . . . . . . . . 8

B. Tracer Preparation. . . . . . . . . . . . . . . . . . . . . 10

C. Sorption Ratio Calculations . . . . . . . . . . . . . . . . . . 11

III. RESULTS . . . . . . . . . . . . . . . . . . . . . . . . . . . . . 12

IV. DISCUSSION ........................ . . 13

A. Sorption as a Function of Tuff Mineralogy . . . . . . . . . . . 13

1. Cesium, Strontium, and Barium . . . . . . . . . . . 16

2. Cerium, Europium, and Tin . . . . . . . . . . . . . . . 16

3. Technetium, Selenium, Uranium, and Neptunium . . . . . . . . . 20

4. Thorium, Plutonium, and Americium . . . . . . . . . . . . . . 20

B. Desorption Experiments: Reversibility . . . . . . . . . . . . . . 21

C. Effects of Elevated Temperature . . . . . . . . . . . . . . . . . 21

D. Effects of Particle Size on Sorptive Behavior . . . . . . . . . . . . 21

E. Comparison of Batch Studies Made Under Atmospheric and Controlled Atmosphere Conditions . . . . . . . . . . . . . . . . . 22

F. Comparison of Sorption Ratios Measured By Batch, Circulating Column, Crushed-Rock Column, Wafer, and Solid-Core Methods . . . . 23

G. Sorption Isotherms . . . . . . . . . . . . . . . . . 28

V. SUMMARY . . . . . . . . . . . . . . . . . . . . . . 29

REFERENCES . . . . . . . . . . . . . . . . . . 30

APPENDIX: BATCH SORPTION RATIOS . . . . . . . . . . . 33 
SUMMARY OF SORPTION MEASUREMENTS PERFORMED

WITH YUCCA MOUNTAIN, NEVADA, TUFF SAMPLES AND WATER

FROM WELL J-13*

by

Kimberly W. Thomas

\begin{abstract}
The sorption studies undertaken from 1977 to 1985 by Los Alamos National Laboratory in support of the Nevada Nuclear Waste Storage Investigations project are summarized, and the data are tabulated in the Appendix. These studies of the sorptive behavior of Yucca Mountain, Nevada, area tuffs have been partly generic in nature (to understand the sorptive behavior of tuff as a function of many variables) and partly site specific (to obtain data for a possible repository site at Yucca Mountain). Sorption has been investigated as a function of mineralogy, temperature, particle size, waste-element concentration, water composition, sorption time, and other variables. The major elements studied were americium, cesium, neptunium, plutonium, thorium, uranium, strontium, technetium, tin, barium, radium, cerium, europium, and selenium.
\end{abstract}

\title{
I. INTRODUCTION
}

Yucca Mountain, Nevada, has been recommended by the US Department of Energy in its Environmental Assessment ${ }^{1}$ as a candidate for site characterization; this characterization will determine the site's suitability as a permanent geologic repository for high-level nuclear waste. Yucca Mountain is located on the southwestern edge of the Nevada Test Site (NTS), on adjacent land controlled by the US Air Force, and on US Bureau of Land Management land (Fig. 1). The repository would be sited in the Topopah Spring Member in the unsaturated zone of Yucca Mountain at an average depth of $300 \mathrm{~m}$ below the mountain surface. The Topopah Spring Member, a compound cooling unit (ash-flow tuff), contains a thick interval of densely welded, divitrified tuff. It is underlain by several other tuff units, including the tuffaceous beds of Calico Hills, the Prow Pass and Bullfrog Members of the Crater Flat tuff, and the Tram and Lithic Ridge Formations. The tuffaceous beds of Calico Hills and the Prow Pass Member locally are above the groundwater table and are strongly zeolitized. 


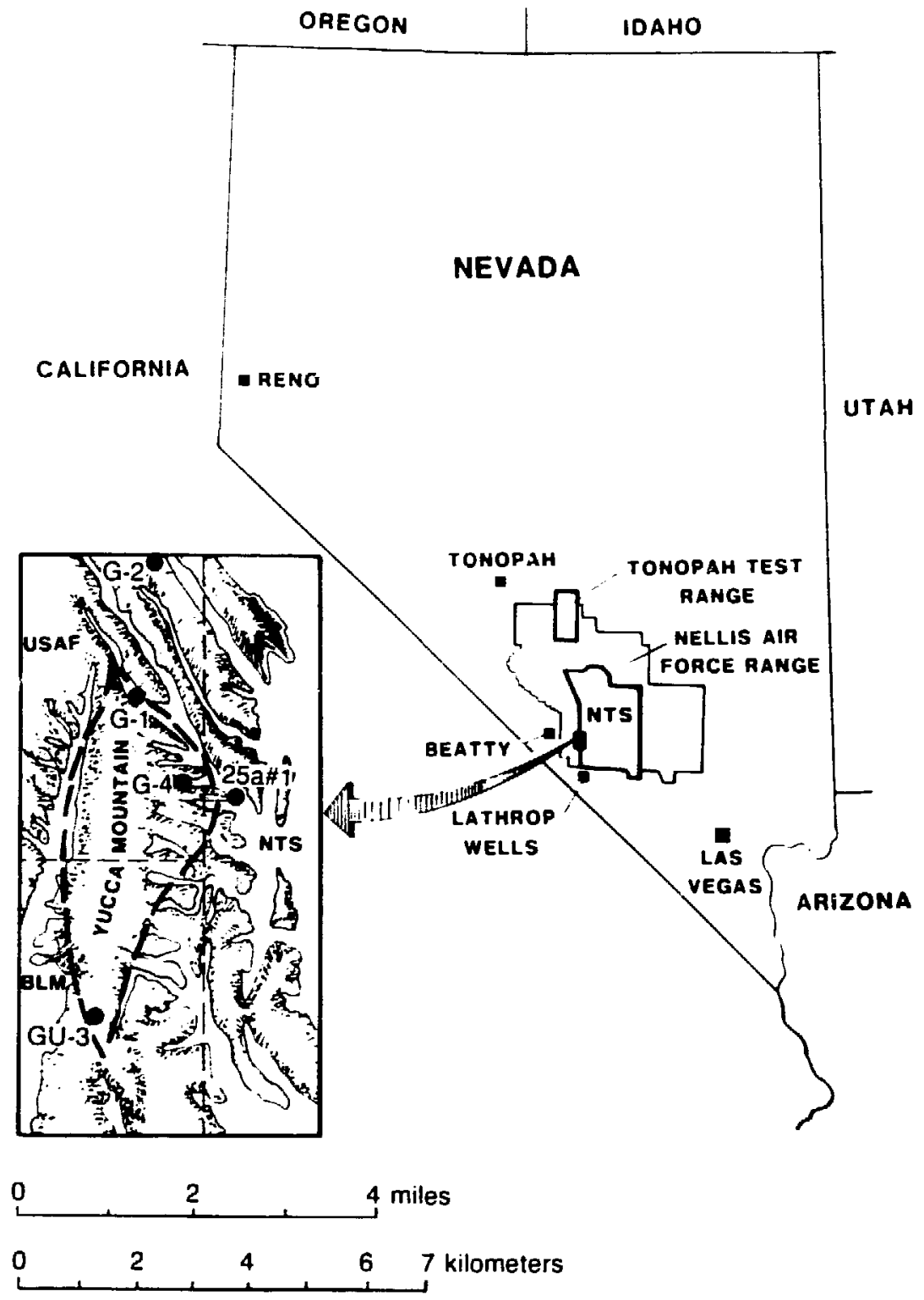

Fig. 1. Yucca Mountain site in southern Nevada. 
The most likely mechanism for transport of radionuclides to the accessible environment is by dissolution of the stored solid-waste form and subsequent transport in water. Movement of water in the unsaturated zone is such a slow process that it is not possible to make direct measurements of radionuclide travel under repository conditions. Therefore, it is necessary to have an understanding of the mechanisms of radionuclide transport and retardation in tuff, as well as a data base of sorptive behavior, to perform the required performance-assessment calculations of possible releases from a repository. These data will be used to satisfy, in part, Key Issue 1 of the NNWSI Project Issue Hierarchy:" "Will the mined geological disposal system at Yucca Mountain isolate the radioactive waste from the accessible environment after closure in accordance with the requirements set forth in 40 CFR Part 191, 10 CFR Part 60, and 10 CFR Part 960?" and its Performance Issue 1.14: "Do the data collected in order to describe the present and expected geochemical characteristics provide the information required by the design and performance issues?" and Information Need 1.14.4: "Radionuclide retardation by sorption processes along flow paths to the accessible environment." The altered tuffs of Yucca Mountain and vicinity, with their high content of zeolites and clays, have great capacity for sorption of radionuclides. As water containing dissolved radionuclides moves away from the repository, it will contact these altered tuffs. Sorption can delay or retard the movement of radionuclides relative to the water flow. Thus, sorption processes can affect whether the Yucca Mountain environment meets the release limits specified by the Environmental Protection Agency (EPA) (40 CFR 191) ${ }^{3}$ and the Nuclear Regulatory Commission (10 CFR 60). ${ }^{4}$ The purpose of the sorption studies is to quantify the contribution of sorption processes toward reducing the transport of radionuclides from the repository to the accessible environment.

The sorption ratio, $R_{d}$, is used as a measure of sorption as a function of many parameters. It is defined as

$$
\mathbf{R}_{\mathbf{d}}=\frac{\text { activity in solid phase per unit mass of solid }}{\text { activity in solution per unit volume of solution }}
$$

and is expressed in units of $\mathrm{m} \ell / \mathrm{g}$. This ratio is often referred to as the distribution coefficient, $K_{d}$. Los Alamos prefers not to use this term, which implies equilibrium, because reversible equilibrium is usually not attained. If equilibrium is attained, then $K_{d}$ is related to a retardation factor, $\mathrm{R}_{\mathrm{f}}$, in a uniform flowing system by

$$
R_{\mathrm{f}}=K_{\mathrm{d}}(\rho / \epsilon)+1
$$

where $\rho$ is the bulk density and $\epsilon$ is the porosity of the rock. 
The sorption studies outlined here were undertaken in support of the Nevada Nuclear Waste Storage Investigations (NNWSI) project. They were performed at the Los Alamos National Laboratory between 1977 and 1985. This report is a summary of work discussed in Refs. 5-16. These studies of the sorptive behavior of the Yucca Mountain area tuffs have been partly generic in nature (tc understand the sorptive behavior of tuff as a function of many variables) and partly site specific (to obtain data for a possible repository site at Yucca Mountain). Sorption has been investigated as a function of mineralogy, temperature, particle size, waste-element concentration, water composition, sorption time, and other variables. The major elements studied were americium, cesium, neptunium, plutonium, thorium, uranium, strontium, technetium, tin, barium, radium, cerium, europium, and selenium. Barium was included as a chemical analogue for radium because ${ }^{226} \mathrm{Ra}$ samples must be handled carefully to avoid releasing the daughter, ${ }^{222} \mathrm{Rn}$, which would cause extensive contamination of low-level counting facilities. Uranium and thorium are longlived parents of radium. Cerium and europium have been included as analogues of any rare-earth elements that may eventually be included in the EPA critical element list. ${ }^{4}$ Selenium is included as a potentially important waste element.

The tuff samples studied have been obtained from various drill holes at Yucca Mountain and its environs (Fig. 2). The origin of the tuff samples and their mineralogic composition have been discussed in earlier reports (Refs. 5 and 17-21). A simple convention was adopted for labeling samples from the various diill holes. The prefix JA-indicates the sample was obtained from Drill Hole J-13; the prefix YM- from Drill Hole UE25a-1; and the prefix G\# from Drill Hole USW-G\#. The four numbers following the "USW-G" prefix give the depth (in feet) from which the sample was obtained.

The water used for the sorption studies was obtained from Well J-13 in western Jackass Flats at the NTS. This water was chosen as the reference groundwater for several reasons. Ideally, water from individual tuff units in Yucca Mountain would have been used; however, there were no producing wells at Yucca Mountain, and there was no way of obtaining formation water from specific tuff units at the time most of these studies were performed. Well J-13 was the nearest producing well. In addition, the approximate production horizon in Well J-13 is the Topopah Spring Member, the site of the proposed repository. (The average cation and anion composition of J-13 water is given in Table I.) Although it was expected that J-13 water would be in equilibrium with the Topopah Spring Tuff, when the water from Well J-13 was contacted with samples of crushed Topopah Spring Tuff, water composition changed. In fact, changes were observed in J-13 water composition when it was contacted with any of the tuff samples of Yucca Mountain (Table II). The changes were relatively minor and showed a trend toward decreasing the concentration of 


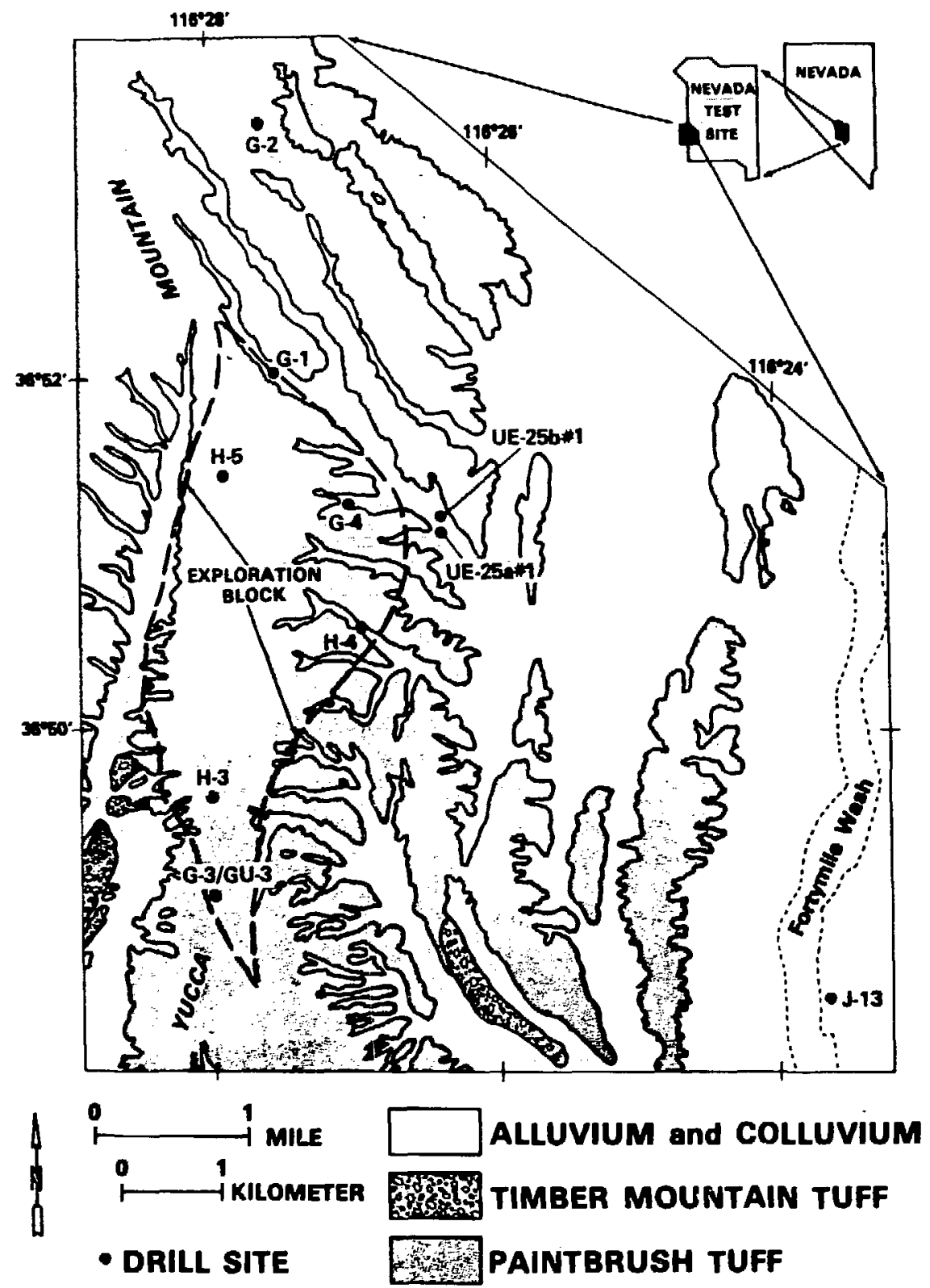

Fig. 2. Yucca Mountain exploration block and drill sites. 
the cations in solution..$^{5,11,12,14}$ The equilibrated waters do not, however, fall outside the bounds of Yucca Mountain water compositions. ${ }^{22}$ There is no conclusive explanation for these changes, but several factors may apply: (1) the J-13 water may not be in equilibrium with the tuff after all; (2) the laboratory temperature is lower by $4^{\circ} \mathrm{C}$ than that in the field; and (3) the $\mathrm{CO}_{2}$ concentration of the water in the laboratory is less than that at depth.

\section{TABLE I}

COMPOSITION OF WELL J-13 GROUNDWATER ${ }^{\mathrm{a}}$

\begin{tabular}{|c|c|c|c|}
\hline Element & $\begin{array}{c}\text { Concentration } \\
(\mathrm{mg} / \ell)\end{array}$ & Anion & $\begin{array}{c}\text { Concentration } \\
(\mathrm{mg} / \ell)\end{array}$ \\
\hline $\mathrm{Ca}$ & 11.5 & $\mathrm{~F}^{-}$ & 2.1 \\
\hline $\mathbf{M g}$ & 1.76 & $\mathrm{Cl}^{-}$ & 6.4 \\
\hline $\mathrm{Na}$ & 45 & $\mathrm{SO}_{4}^{2-}$ & 18.1 \\
\hline $\mathbf{K}$ & 5.3 & $\mathrm{NO}_{2}^{-}$ & N.D. ${ }^{b}$ \\
\hline $\mathrm{Fe}$ & 0.04 & $\mathrm{NO}_{3}^{-}$ & 10.1 \\
\hline $\mathrm{Mn}$ & 0.001 & & \\
\hline $\mathrm{Si}$ & 30.0 & & \\
\hline $\mathrm{Li}$ & 0.06 & $\mathrm{pH}$ & 6.9 \\
\hline Al & 0.03 & & \\
\hline
\end{tabular}

\footnotetext{
arom Ref. 22.

b N.D. = not detected.
}

Most experiments were performed under atmospheric and oxidizing conditions; no effort was made to obtain reducing conditions during the experiments because early data on Yucca Mountain waters suggested that these waters were oxidizing in the field. Recent results indicate that reducing conditions may indeed exist in some places beneath the proposed repository site; ${ }^{18}$ however, the assumption of oxidizing conditions leads to conservative estimates of sorption and precipitation for most, if not all, radionuclides of interest. Over time, the $\mathrm{pH}$ of the water in the laboratory experiments rose to between $\sim 8$ and 8.5, presumably as a result of $\mathrm{CO}_{2}$ loss. Efforts were made to maintain the $\mathrm{pH}$ at $\sim 7$ for those experiments in which the solubility of the element in question was lower in 
TABLE II

COMPOSITION OF WELL J-13 GROUNDWATER AFTER CONTACT WITH TUFF SAMPLES ${ }^{a}$

Composition $(\mathrm{mg} / \ell)$

\begin{tabular}{|c|c|c|c|c|c|c|c|c|c|c|c|c|}
\hline \multirow[b]{2}{*}{ Sample } & & & & & & & & & & & & \\
\hline & $\mathrm{Ca}$ & $\mathrm{Mg}$ & $\mathrm{Na}$ & $\mathrm{K}$ & $\mathrm{Fe}$ & $\mathrm{Mn}$ & $\mathrm{Si}$ & $\underline{F^{-}}$ & $\underline{\mathrm{Cl}^{-}}$ & $\underline{\mathrm{SO}_{4}^{2-}}$ & $\mathrm{NO}_{3}^{-}$ & $\underline{\mathrm{HCO}_{3}^{-}}$ \\
\hline GU3-433 & 9.3 & 2.1 & 49.8 & 9.5 & 0.06 & 0.02 & 22.4 & 2.8 & 9.2 & 19.3 & 7.1 & \\
\hline GU3-855 & 9.3 & 2.14 & 37.5 & 7.8 & 0.010 & 0.014 & 24.1 & 3.5 & 8.7 & 21.0 & & 120 \\
\hline GU3-916 & 9.0 & 2.15 & 37.8 & 9.4 & 0.018 & 0.003 & 23.4 & 2.7 & 8.8 & 20.1 & & 131 \\
\hline GU3-1301 & 11.1 & 1.0 & 45.7 & 6.2 & 0.05 & 0.03 & 25.7 & 2.7 & 8.8 & 19.0 & 8.1 & \\
\hline GU3-1203 & 11.9 & 1.8 & 50.9 & 5.1 & 0.14 & 0.03 & 25.5 & 2.8 & 8.7 & 19.3 & 8.2 & \\
\hline GU3-1436 & 11.1 & 1.45 & 37.8 & 4.2 & 0.017 & 0.022 & 26.2 & 2.6 & 9.3 & 20.02 & & 163 \\
\hline GU3-1531 & 13.4 & 0.87 & 36.9 & 2.4 & $<0.002$ & 0.010 & 26.0 & 2.7 & 8.7 & 19.9 & & 203 \\
\hline G2-547 & 8.7 & 2.5 & 43.3 & 4.3 & 0.04 & 0.02 & 30.0 & 2.7 & 8.1 & 17.3 & 5.8 & \\
\hline G2-723 & 13.2 & 3.0 & 45.2 & 7.4 & 0.06 & 0.02 & 25.8 & 2.4 & 7.5 & 16.6 & 7.6 & \\
\hline G2-1952 & 12.8 & 1.4 & 45.2 & 5.8 & 0.05 & 0.02 & 26.7 & 2.4 & 7.7 & 16.1 & 7.3 & \\
\hline G4-1502 & 0.24 & 0.016 & 50.9 & 3.1 & 0.016 & 0.001 & 23 J & 2.6 & 8.4 & 19.8 & & 127 \\
\hline YM-5 & 15 & 4.1 & 51 & 8.2 & 0.01 & 0.001 & 35 & 2.5 & 7.9 & 23 & & \\
\hline YM-22 & 13 & 2.4 & 54 & 5.3 & 0.01 & 0.001 & 34 & 2.6 & 7.3 & 24 & & \\
\hline YM-30 & 14 & 1.5 & 53 & 2.5 & 0.01 & 0.001 & 30 & 2.5 & 7.0 & 23 & & \\
\hline YM-38 & 14 & 0.1 & 57 & 5.8 & 0.01 & 0.001 & 32 & 2.5 & 7.5 & 26 & & \\
\hline YM-42 & 15 & 0.5 & 59 & 2.2 & 0.04 & 0.001 & 28 & 2.4 & 6.9 & 27 & & \\
\hline YM-45 & 14 & 1.2 & 53 & 5.6 & 0.04 & 0.001 & 34 & 2.5 & 6.8 & & & \\
\hline YM-46 & 15 & 1.1 & 51 & 3.9 & 0.02 & 0.002 & 34 & 2.4 & 7.5 & 24 & & \\
\hline YM-48 & 18 & 1.2 & 50 & 2.5 & 0.03 & 0.03 & 37 & 2.5 & 6.7 & 24 & & \\
\hline YM-49 & 20 & 1.2 & 49 & 2.6 & 0.03 & 0.002 & 36 & 2.5 & 6.9 & 25 & & \\
\hline YM-54 & 14 & 1.4 & 56 & 5.9 & -- & 0.001 & 37 & 2.6 & 6.8 & 24 & & \\
\hline
\end{tabular}

${ }^{a}$ From Refs. 5, 11, and 12. 
the laboratory $\mathrm{pH}$ range than it was at the original $\mathrm{J}-13$ water $\mathrm{pH}$ of $\sim 7$. These experiments were performed in a glove box, and the $\mathrm{pH}$ was kept at 7 by maintaining a sufficient concentration of $\mathrm{CO}_{2}$ in the atmosphere.

\section{EXPERIMENT PROCEDURES}

A variety of techniques have been used to study sorption processes that lead to the removal of radionuclides from solution through interactions with tuff. Such processes, including ion exchange phenomena, chemisorption, and diffusion into the rock matrix, may ultimately end in a variety of precipitation or coprecipitation reactions. The most extensively used procedure in these studies has been a batch technique. Other techniques have been used to verify batch results and to provide additional information on kinetics, solution-to-solid ratios, effects of crushed tuff vs solid core, and other parameters. The batch technique used is described below; other techniques are also discussed and their results are compared with batch results.

\section{A. Batch Measurement Technique}

In these measurements, the distribution of a radionuclide between groundwater and crushed tuff is measured as a function of such parameters as contact time, concentration of sorbing element, particle size, temperature, atmosphere, and mineralogy. A considerable amount of time and effort was expended developing a satisfactory procedure; studies of the actinides have been particularly difficult, both in preparation of traced solution and in separation of aqueous and solid phases. In fact, work is still being done on the preparation of actinides in known, controlled oxidation states.

In the standard batch sorption procedure, the crushed-tuff sample is pretreated by contact with Well J-13 groundwater for at least 2 weeks. The groundwater used to prepare the traced feed solution (the solution containing the radionuclides) is pretreated by contacting it for at least 2 weeks with tuff from the same sample used in the batch measurements. Both the crushed-tuff sample and the pretreated water sample are centrifuged at the end of pretreatment to separate the phases; the pretreated water is filtered through a $0.05-\mu \mathrm{m}$ polycarbonate Nuclepore membrane. This water is then used to prepare the traced feed solutions. Contact of the pretreated tuff sample with the traced feed solutions is started within 2 to $24 \mathrm{~h}$ by adding $20 \mathrm{~m} \ell$ of traced feed to $1 \mathrm{~g}$ of pretreated tuff in a polyetheylene or polycarbonate tube. The two phases are mixed thoroughly, and the sample tube is placed on an orbital shaker and agitated at $200 \mathrm{rpm}$. A discussion of the effect of the solution-to-solid ratio can be found in Ref. 5, pp. 137-142.

Contact times for the batch measurements were varied to study the effect of time on measured sorption coefficients. A standard 6-week contact was chosen for those studies 
where time was not a variable. This choice was a compromise between reaching equilibrium, if that were even possible, and completing the measurements within a reasonable time. The $R_{d}$ measurements $v$ s time indicated a leveling off or at least a very small positive slope sometime after 3 weeks. Twelve weeks (the time required for both sorption and desorption measurements) seemed to be the maximum reasonable time to allow for an experiment, considering the large number of required measurements. At the end of the contact time, the samples are centrifuged for $1 \mathrm{~h}$ at $12000 \mathrm{rpm}(28000 \mathrm{~g})$. The top $15-18 \mathrm{~m} \ell$ of the aqueous phase are removed by pipetting and are transferred to a clean polypropylene or polycarbonate tube. Extreme care must be exercised during the removal of this aqueous sample to ensure that no fine particulate matter is included in the final aqueous phase. Such contamination of the aqueous phase could significantly affect the measured sorption ratio in cases where the activity is strongly sorbed on the solid phase. The development of the centrifugation requirements is discussed in Ref. 5, pp. 44-52.

The removed aqueous phase is centrifuged for $1 \mathrm{~h}$ at $12000 \mathrm{rpm}$. The liquid remaining with the solid phase is removed and saved for $\mathrm{pH}$ measurements. The tube containing the solid phase is weighed and prepared for counting. After the centrifuging, the top 12-16 $\mathrm{m} \ell$ of the aqueous phase are carefully removed, transferred to a clean tube, and centrifuged for $2 \mathrm{~h}$ at $12000 \mathrm{rpm}$. The remaining liquid is added to the $\mathrm{pH}$ sample. After this final centrifugation, the top 9-10 $\mathrm{m} \ell$ are removed and an appropriate aliquot is taken for counting. Any remaining liquid is added to the $\mathrm{pH}$ sample.

After the solid phase has been sampled for counting or when counting is complete, the desorption measurements can begin. Twenty milliliters of tuff-treated water are added to the remaining solid phase. The tube is capped and weighed and the two phases are thoroughly mixed. The sample is placed in a shaker and agitated at $\sim 200 \mathrm{rpm}$ for a predetermined length of time, after which the phases are separated and counted by the same procedures used for the sorption experiments.

Depending upon the element being studied, either the entire solid phase is counted or a fraction is taken. Corrections are made for the amount of aqueous phase still present in the solid sample by carefully weighing the sample while it is wet and after it has been dried. After both the aqueous and solid phases have been counted, subtractions are made from the solid phase data to account for the activity of the entrapped aqueous phase. In cases of extremely low sorption ratios, it is possible to calculate negative sorption ratios resulting from the statistical errors in the counting data or, perhaps, from the assumption that any retained water has the same radionuclide concentration as the aqueous phase. These negative values are typically reported as $0 \mathrm{ml} / \mathrm{g}$; however, the appendix data compilation does report some negative sorption values for technetium. In actual fact, there cannot be 
a negative sorption value because such a value would require the creation of activity; that is, there would be more activity measured after completion of the experiment than was added initially.

The tracer activity in the separated phases is determined in several ways, depending upon the radiations of the radionuclides being studied. For gamma-emitting actinides, the entire solid phase is counted in a $\mathrm{NaI}(\mathrm{Tl})$ well detector. Standards are prepared by using a known amount of the appropriate activity in a geometry and conditions identical to those of

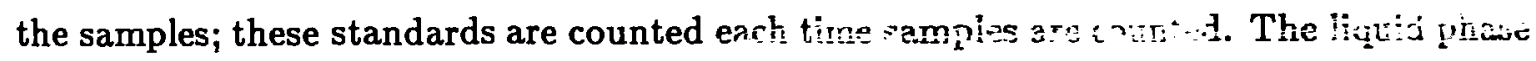
is counted by transferring $3 \mathrm{~m} \ell$ to a counting vial, acidifying with $1 \mathrm{~m} \ell$ of concentrated $\mathrm{HCl}$, and counting both in the $\mathrm{NaI}(\mathrm{Tl})$ well counter and in an automatic gamma scintillation counter. Alternative methods for counting alpha-emitting tracers include radiochemical analysis of both the liquid and the dissolved solid sample, liquid scintillation counting of both fractions, and gross alpha counting. Uranium sorption ratios require only counting of the liquid phase. When the tracer is ${ }^{237} \mathrm{U}$, a portion of the liquid phase is placed in a vial and gamma counted with a $\mathrm{Ge}(\mathrm{Li})$ detector. When natural uranium is the tracer, the liquid samples are counted by a delayed neutron counting method. For the remaining elements, a fraction of the solid phase is dried, weighed, and then counted with a $\mathrm{Ge}(\mathrm{Li})$ counter. Liquid samples are acidified and then $\mathrm{Ge}(\mathrm{Li})$ counted. The sorption ratio, $R_{d}$, is calculated using Eq. (1) above.

\section{B. Tracer Preparation}

Traced feed solutions containing barium, strontium, cesium, cerium, europium, iodine, nickel, cobalt, sodium, tin, iron, manganese, or selenium are prepared using commercially produced nuclides. The final cuncentrations of the elements studied in these feed solutions generally range from $10^{-6}$ to $10^{-9} \mathrm{M}$. The tracer is evaporated at room temperature in a polyethylene or polycarbonate container. After a few drops of $\mathrm{HCl}$ are added, a second evaporation is carried out. The appropriate amount of pretreated groundwater is added, the container is capped, and the traced solution is agitated in a shaker for 1 or 2 days. The traced feed solution is filtered through a $0.05-\mu \mathrm{m}$ Nuclepore membrane just before use.

Exceptions to the above general procedure include technetium, uranium, and the actinides. Because technetium volatilizes when heated in acid solution and is more stable in base, the tracer is delivered in $0.1 \mathrm{M} \mathrm{NH}_{4} \mathrm{OH}$ solution. It is added in a small volume to the appropriate tuff-treated water to produce $10^{-3}$ to $10^{-9} \mathrm{M}$ feed solutions. After dilution, the solution is equilibrated for a few days and passed through a $0.05-\mu \mathrm{m}$ filter just before use.

Uranium feed solutions are made from a dilution of a stock solution; this stock solution is prepared by dissolving a weighed amount of uranyl nitrate in water that has been purified 
with a Millipore deionizing system and filtered through a $0.05-\mu \mathrm{m}$ membrane. The final feed solution is prepared by adding an appropriate amount of uranium stock solution to tuff-treated groundwater, shaking the mixture for as long as a week, and passing it through a $0.05-\mu \mathrm{m}$ filter just before use.

Americium and neptunium feed solutions are prepared by drying tracers in air at room temperature in a polycarbonate or polypropylene container. Before it is dried, the plutonium tracer is treated with $10 \mathrm{M} \mathrm{NaNO}_{2}$ to obtain the (IV) oxidation state; however, as will be discussed later, this treatment does not guarantee the (IV) oxidation state of plutonium. The dried activity is removed from the container by a minimum of three 1-min contacts with the pretreated groundwater using a vibrator or an ultrasonic bath. After each contaci, the tracer is removed to a clean, large polyethylene bottle. Contacts are repeated until tracer is no longer remcved from the drying container. Sufficient rock-equilibrated groundwater is added to the large container to attain the desired volume. Finally, the tracer solution is shaken for 1 to 2 days and filtered as described above just before use.

Because thorium exhibits very low solubility in the $\mathrm{pH}$ range of our normal laboratory experiments, the tracer must be prepared in acid solution and then neutralized to obtain the required $\mathrm{pH}$. Further, the experiments must be performed in the $\mathrm{CO}_{2}$-controlled atmosphere box to maintain the $\mathrm{pH}$ at $\sim 7$. Thorium-230 tracer in $1 \mathrm{MHNO}_{3}$ is added to pretreated groundwater. The $\mathrm{pH}$ is adjusted to $\sim 6$ with $\mathrm{NH}_{4} \mathrm{OH}$ just before filtering, and the experiment is begun immediately in the controlled atmosphere box. The $\mathrm{pH}$ of the samples is monitored, and if the $\mathrm{pH}$ exceeds $\sim 7.2-7.5$, the experiment is terminated and the sorption ratio is calculated. Thorium solubility under these experiment conditions decreases dramatically at $\mathrm{pH}$ values greater than 7.5. The experiments are terminated because sorption ratios measured at higher $\mathrm{pH}$ would not be conservative.

\section{Sorption Ratio Calculations}

As stated earlier, Los Alamos scientists measure a sorption coefficient that does not imply equilibrium: Eq. (1). In fact, Los Alamos data indicate that equilibrium is not achieved in many instances. The sorption ratio is a measurement of an element's distribution between phases under specified conditions, although not necessarily at equilibrium. Sorption from near-neutral groundwater onto rock such as tuff is complicated; it may involve competing cations and complexed or hydzated species. Many equilibria would have to be described in equations leading to the thermodynamic quantities for sorption of an element. Some simplifying assumptions applied in relationships between an equilibrium constant and the distribution coefficieni will be mentioned later and have been discussed in detail in Ref. 5 . 
Average values are calculated for measured sorption ratios because measurements are made in duplicate. The uncertainties associated with averages of sorption data are the standard deviations of the mean $\sigma_{\mathrm{m}}$, defined by

$$
\sigma_{\mathrm{m}}=\frac{\left(\sum d_{i}^{2}\right)^{1 / 2}}{n(n-1)}
$$

where

$d_{i}$ is the deviation from the mean of the $i^{\text {th }}$ experimental value, and

$n$ is the number of values.

The standard deviation of the mean is used rather than the standard deviation of the sample or the population. This practice avoids including zero in the range of uncertainty when, for example, averaging a large range of $R_{d}$ values from individual determinations, all of which indicate a high sorption ratio. The total spread of values averaged in the measurements is often a factor of 5 larger than $\sigma_{\mathrm{m}}$. This spread is the result of the choice of $\sigma_{\mathrm{m}}$ just discussed, the nonweighted averaging, and the simplifying assumption that the samples belong to the same population when areraging results for different times, particle sizes, etc. These uncertainties should not necissarily be used in assessment caiculations as bounds for $K_{d}$ values within a given unit becasse they do not include a complete picture of experiment uncertainties and experiment reproducibility.

A more realistic estimate of the magnitude of the errors in the sorption ratios listed in the Appendix would be $\pm 50 \%$. This estimate is arrived at by considering the many analytical measurements made during the experiments, and, more importantly, the observed reproducibility over time, from one sorption measurement to another. This is not a rigorously determined error, but represents a "best estimate" by the scientists responsible for making the sorption measurements.

\section{RESULTS}

All the sorption and desorption data collected are listed in the Appendix. This listing represents data reported in Refs. 5-17 as well as more recent, unpublished results. It is an unrefined data set; for example, data are included that were generated while the experiment conditions and procedures were being developed. Thorough examination of such data has shown that some of these measurements are not reliable and should not be used for performance assessment calculations. Systematic identification of suspect data is currently in progress. The refined data set will be available as part of the Reference Data Base for Yucca Mountain that is being compiled by Sandia National Laboratories. The 
complete data set will be available in the Tuff Data Base at Sandia, and explanations will be provided for data that are not included in the Reference Data Base.

Parameters reported in the Appendix include contact time (in days), atmospheric conditions, concentration of the sorbing element (in moles/liter), particle-size range of the crushed tuff (particle minimum to particle maximum in micrometers), and temperature (in $\left.{ }^{\circ} \mathrm{C}\right)$. The headings "srd 1 " and "srd2" and "drd1" and "drd2" represent duplicate sorption and desorption ratios, respectively. When duplicate measurements are averaged, which is how these ratios are usually reported, the standard deviation of the mean is used to represent an error estimate. In some cases, ratios may be reported as greater than some value. These values are the result of poor counting statistics that can occur in cases of very high sorption ratios where very little activity is left in the aqueous solution. Occasionally, negative sorption ratios are calculated-again, the result of poor counting statistics. Although negative values have no realistic meaning, they are reported when duplicate measurements have been made to properly reflect the error involved in those measurements. When only one measurement is available, a negative value is reported as " 0 ".

Table III lists the four major rock groups used to classify the tuff sample mineralogy: (1) devitrified assemblage-composed primarily of quartz and alkali feldspar; (2) zeolitized-dominated by an alteration assemblage of zeolites; (3) glass-high percentage of original glass in sample (not devitrified or altered to zeolites); and (4) clays-clays are the major alteration assemblage. Each of the major groups can be further classified according to the subgroups listed in the table. In Table IV, the tuff samples are categorized according to these mineralogic types. Greater detail on tuff mineralogy is contained in Refs. 5 and 14-21. Available cation-exchange capacities (CEC) are given in Table V.

\section{DISCUSSION}

\section{A. Sorption as a Function of Tuff Mineralogy}

One of the primary objectives of these studies is to determine if sorption ratios can be correlated with tuff mineralogy. Although a comprehensive, statistical analysis of the data has not yet been performed, some observations can be made about sorption as a function of tuff mineralogy, and these observations are given below. All comments refer to sorption coefficients measured at 6-week contact times, under ambient temperature, and atmosphere and on 75- to 500- $\mu \mathrm{m}$ particles, unless otherwise stated. A large number of radionuclides other than those discussed below have been tested with selected tuff samples. There are not enough data to draw conclusions, but the available data are included in this report. 


\section{TABLE III}

\section{CLASSIFICATION OF TUFF SAMPLES}

FOUR MAJOR ROCK GROUPS

1. DEVITRIFIED

composed primarily of quartz and alkali feldspar

\section{ZEOLITIZED}

dominated by an alteration assemblage of zeolites

\section{GLASS}

high percentage of original glass in sample (not devitrified or altered to zeolites)

\section{CLAYS}

clays are the major alteration assemblage

\section{SUBGROUPS}

1. DEVITRIFIED $-<10 \%$ clays, $<10 \%$ zeolites

DEVIT $1->10 \%$ clays, $<10 \%$ zeolites

DEVIT2- $<10 \%$ clays, $>10 \%$ zeolites

2. ZEOLITIZED - $>\mathbf{2 0 \%}$ zeolites, $<10 \%$ clays, $<10 \%$ glass

ZEOLIT1 $->\mathbf{2 0 \%}$ zeolites, $>\mathbf{1 0} \%$ clays, $<10 \%$ glass

ZEOLIT2- $>20 \%$ zeolites, $<10 \%$ clays, $>10 \%$ glass

3. GLASS $->40 \%$ glass, $<10 \%$ clays, $<10 \%$ zeolites

GLASS1- $>40 \%$ glass, $>10 \%$ clays, $<10 \%$ zeolites

GLASS2- $>40 \%$ glass, $<10 \%$ clays, $>10 \%$ zeolites

4. CLAYS $->40 \%$ clays 
TABLE IV

CLASSIFICATION OF YUCCA MOUNTAIN TUFf SAMPLES

\begin{tabular}{|c|c|c|}
\hline DEVITRIFIED & DEVIT1 & DEVIT2 \\
\hline G1-1883 & G1-2901 & YM-30 \\
\hline G1-1982 & JA-32 & \\
\hline G1-2333 & YM-54 & \\
\hline \multicolumn{3}{|l|}{ G1-2363 } \\
\hline \multicolumn{3}{|l|}{ G1-2410 } \\
\hline \multicolumn{3}{|l|}{ G1-2476 } \\
\hline \multicolumn{3}{|l|}{ G1-2840 } \\
\hline \multicolumn{3}{|l|}{ G1-2854 } \\
\hline \multicolumn{3}{|l|}{ G1-2954 } \\
\hline \multicolumn{3}{|l|}{ GU3-0433 } \\
\hline \multicolumn{3}{|l|}{ GU3-0855 } \\
\hline \multicolumn{3}{|l|}{ GU3-0916 } \\
\hline \multicolumn{3}{|l|}{ GU3-1531 } \\
\hline \multicolumn{3}{|l|}{ YM-22 } \\
\hline \multicolumn{3}{|l|}{ YM-45 } \\
\hline \multicolumn{3}{|l|}{ YM-46 } \\
\hline ZEOLITIZED & ZEOLIT1 & ZEOLIT2 \\
\hline G1-1436 & G1-2233 & YM-48 \\
\hline G1-1854 & G1-2689 & \\
\hline G1-2278 & G1-2698 & \\
\hline G1-2289 & G1-3116 & \\
\hline G2-1952 & G2-3933 & \\
\hline \multicolumn{3}{|l|}{ G2-2017 } \\
\hline \multicolumn{3}{|l|}{ G4-1502 } \\
\hline \multicolumn{3}{|l|}{ G4-1608 } \\
\hline \multicolumn{3}{|l|}{ GU3-1937 } \\
\hline \multicolumn{3}{|l|}{ JA-26 } \\
\hline \multicolumn{3}{|l|}{ JA-28 } \\
\hline \multicolumn{3}{|l|}{ YM-38 } \\
\hline YM-42 & & \\
\hline
\end{tabular}


TABLE IV (cont)

GLASS

G1-1292

GU3-1203

GU3-1301

GU3-1436

CLAYS

G1-3658

JA-08

JA-37
GLASS1

G2-0547

JA-18

YM-49

UNCLASSIFIED

G2-0723 (40\% calcite)

1. Cesium, Strontium, and Barium. A positive correlation has been shown between zeolite content and sorption of simple cations such as cesium, strontium, and barium (used as an analogue of radium). ${ }^{5}$ This result is not surprising because zeolites are strong cation exchangers. Strontium, cesium, and barium show very high sorption for a sample that is $40-60 \%$ smectite (G1-3658), but they do not exhibit high sorption with another highsmectite sample (JA-08). A third sample (JA-37) has a large percentage of smectite in the core material; however, the sorption studies were performed on a fraction from which much of the clay had been removed. The sorption ratios for these elements on JA-37 are very similar to those obtained with sample JA-08. Sorption on glass samples having $<10 \%$ zeolites (GLASS anc GLASS1) is as much as one order of magnitude lower than for zeolitized samples. However, sorption on GLASS2 samples ( $>10 \%$ zeolites) appears to be the same as sorption on zeoiitized samples. Devitrified samples exhibit the same or, often in the case of strontium, less sorption than the glass samples containing no zeolites. Again, the effect of zeolites can be seen in the case of the DEVIT2 sample YM-30 (>10\% zeolites), which shows higher sorption than any of the other devitrified samples. In summary, these elements sorb strongly on zeolitic tuffs and less so on glass and devitrified samples. The results for smectite are inconclusive.

2. Cerium, Europium, and Tin. Correlations of sorption with mineralogy for cerium, europium, and tin and those elements whose discussions follow are much less evident than 
TABLE V

CATION-EXCHANGE CAPACITIES ${ }^{a, b}$

CEC CEC by

Particle

Sample $(\mu \mathrm{m})$

JA-8 75-500

JA-18

JA-18

JA-26

JA-28

JA-32

JA-32

JA-37

JA-37

YM-5

YM-22

YM-22

YM-30

YM-38

YM-38

$Y M_{x}-42$

YM-45

YM-46

YM-48

YM-49

YM-49

YM-54

G1-1292

G1-1436

G1-1854

G1-1854

G1-1883

G1-1982

G1-1982
Size

106-150

355-500

$<75$

75-500

150-180

250-355

$<106$

150-180

75-500

75-500

$<75$

75-500

$<500$

75-500

75-500

106-500

75-500

106-500

106-250

75-500

75-500

$\mathrm{NH}_{4} \mathrm{OAc}$

(meq/100 g)

28.4

78.7

69.8

3.3

3.6

2.8

2.5

26.7

23.8

23.6

0.8

1.4

8.7

151.7

122.0

52.7

5.5

3.8

46.0

111.9

118.7

2.3

75-500

$<500$

$<75$

75-500

$<106$

$<38$

$<500$
Sum

Cations $^{c}$

(meq/100
(\%)

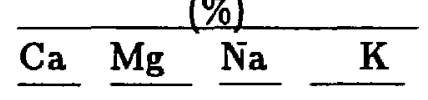

Extractable Acidity of CEC

(\%) 
TABLE V (cont)

\begin{tabular}{|c|c|c|c|c|c|c|c|c|}
\hline \multirow[b]{2}{*}{ Sample } & \multirow{2}{*}{$\begin{array}{c}\text { Particle } \\
\text { Size } \\
(\mu \mathrm{m}) \\
\end{array}$} & \multirow{2}{*}{$\begin{array}{c}\text { CEC } \\
\text { by } \\
\mathrm{NH}_{4} \mathrm{OAc} \\
(\mathrm{meq} / 100 \mathrm{~g})\end{array}$} & \multirow{2}{*}{$\begin{array}{c}\text { CEC by } \\
\text { Sum } \\
\text { Cations }^{\mathrm{c}} \\
\text { (meq/100 g) } \\
\end{array}$} & \multicolumn{4}{|c|}{$\begin{array}{c}\text { Sum of Bases } \\
(\%)\end{array}$} & \multirow{2}{*}{$\begin{array}{c}\text { Extractable } \\
\text { Acidity } \\
\text { of CEC } \\
(\%) \\
\end{array}$} \\
\hline & & & & $\mathrm{Ca}$ & $\mathbf{M g}$ & $\mathrm{Na}$ & $\bar{K}$ & \\
\hline G1-2233 & $<38$ & 55.6 & $(136.0)$ & 19 & 0.4 & 57 & 24 & - \\
\hline G1-2233 & $<500$ & 88.2 & $(90.5)$ & 19 & 0.3 & 57 & 23 & - \\
\hline G1-2233 & $106-500$ & 68.6 & $(70.7)$ & 18 & 0.1 & 59 & 22 & - \\
\hline G1-2289 & $<500$ & 132.4 & (144.3) & 37 & 0.1 & 53 & 9 & - \\
\hline G1-2334 & $<38$ & 6.8 & 7.5 & 64 & 7 & 23 & 7 & tr \\
\hline G1-2334 & 75-355 & 5.0 & (5.5) & 53 & 2 & 38 & 7 & - \\
\hline G1-2334 & $355-500$ & 3.6 & (4.2) & 60 & 2 & 31 & 7 & - \\
\hline G1-2363 & $<500$ & 4.8 & 8.0 & 74 & 1 & 25 & tr & 1 \\
\hline G1-2410 & $106-500$ & 0.4 & 4.9 & 78 & - & 22 & - & - \\
\hline G1-2476 & $75-500$ & 0.4 & 3.8 & 49 & - & 41 & 11 & 3 \\
\hline G1-2698 & $<500$ & 116.4 & (118.9) & 15 & 0.3 & 69 & 15 & - \\
\hline G1-2840 & $<38$ & 6.3 & (7.3) & 71 & 4 & 18 & 7 & - \\
\hline G1-2840 & $<106$ & 5.1 & (6.2) & 61 & 2 & 31 & 6 & - \\
\hline$\therefore 1-2840$ & $150-355$ & 3.9 & (4.8) & 67 & tr & 29 & 4 & - \\
\hline G1-2840 & $75-500$ & 0.3 & 43 & 74 & - & 24 & 3 & - \\
\hline G1-2840 & 355-500 & 3.4 & (3.8) & 76 & 3 & 16. & 5 & - \\
\hline G1-2854 & $75-500$ & 0.9 & 3.8 & 74 & - & 24 & 3 & - \\
\hline G1-2901 & $<500$ & 0.5 & - & ()$^{f}$ & $(-)$ & $(1.2)$ & $(0.3)$ & $(-)$ \\
\hline G1-3116 & $<500$ & 23.8 & 28.4 & 24 & 0.4 & 72 & 4 & 0.4 \\
\hline G1-3658 & $<500$ & 50.8 & (57.4) & 37 & 5 & 57 & 1 & - \\
\hline G2-332 & $<500$ & 73.6 & (78.3) & $81^{e}$ & 16 & 1 & 1 & - \\
\hline G2-339 & $<500$ & 29.8 & 36.3 & 79 & 18 & 1 & 2 & 8 \\
\hline G2-547 & 75-500 & 33.7 & 36.1 & 76 & 13 & 6 & 5 & 8 \\
\hline G2-723 & $<500$ & 9.9 & - & ()$^{g}$ & $(1.3)$ & $(0.6)$ & $(0.8)$ & - \\
\hline G2-770 & $<500$ & 2.9 & 2.8 & 40 & 8 & 20 & 32 & 11 \\
\hline G2-1951 & $<500$ & 139.1 & 138.0 & 48 & 3 & 25 & 25 & 1 \\
\hline G2-1952 & 75-500 & 123.5 & 124.0 & 46 & 0.4 & 30 & 23 & 1 \\
\hline G2-2000 & $<500$ & 120.9 & 50 & 2 & 30 & 18 & $\mathbf{1}$ & \\
\hline G2-3308 & $<500$ & 42. & 3.3 & 47 & - & 41 & 13 & 3 \\
\hline
\end{tabular}


TABLE V (cont)

\begin{tabular}{|c|c|c|c|c|c|c|c|c|}
\hline \multirow[b]{2}{*}{ Sample } & \multirow{2}{*}{$\begin{array}{c}\text { Particle } \\
\text { Size } \\
(\mu \mathrm{m})\end{array}$} & \multirow{2}{*}{$\begin{array}{c}\text { CEC } \\
\text { by } \\
\mathrm{NH}_{4} \mathrm{OAc} \\
(\mathrm{meq} / 100 \mathrm{~g}) \\
\end{array}$} & \multirow{2}{*}{$\begin{array}{c}\text { CEC by } \\
\text { Sum } \\
\text { Cations }^{c} \\
\text { (meq/100 g) } \\
\end{array}$} & \multicolumn{4}{|c|}{$\begin{array}{c}\text { Sum of Bases } \\
(\%)\end{array}$} & \multirow{2}{*}{$\begin{array}{c}\text { Extractable } \\
\text { Acidity } \\
\text { of CEC } \\
(\%) \\
\end{array}$} \\
\hline & & & & $\mathrm{Ca}$ & $\mathrm{Mg}$ & $\mathrm{Na}$ & $\mathbf{K}$ & \\
\hline G2-3933 & $75-500$ & 7.1 & - & ()$^{h}$ & $(6.2)$ & (4.1) & $(1.0)$ & - \\
\hline GU3-433 & $<500$ & 1.9 & 2.6 & 35 & 10 & 30 & 25 & 23 \\
\hline GU3-855 & $<500$ & 3.1 & 4.4 & 45 & 13 & 24 & 18 & 14 \\
\hline GU3-855 & $75-500$ & 2.9 & 4.5 & 49 & 13 & 21 & 18 & 13 \\
\hline GU3-916 & $75-500$ & 3.1 & 3.9 & 38 & 15 & 26 & 21 & 13 \\
\hline GU3-1203 & $75-500$ & 2.3 & 2.3 & 70 & 9 & 13 & 9 & - \\
\hline GU3-1301 & $75-500$ & 1.1 & 1.2 & 73 & - & 18 & 9 & 8 \\
\hline GU3-1437 & $75-500$ & 2.7 & 2.5 & 64 & - & 24 & 12 & - \\
\hline GU3-1531 & $75-500$ & 11.9 & 12.7 & 77 & 1 & 14 & 8 & 6 \\
\hline GU3-1937 & $<500$ & 150.39 & 149.3 & 10 & - & 54 & 35 & 1 \\
\hline G3-3005 & $<500$ & 3.9 & - & ()$^{e}$ & $(1.5)$ & $(0.7)$ & - & \\
\hline G3-4868 & $<500$ & - & - & ()$^{f}$ & - & - & - & - \\
\hline G3-4907 & $<500$ & 7.1 & $(11.8)$ & 54 & 1 & 40 & 5 & - \\
\hline G4-1502 & $75-500$ & 157.8 & $163.8^{\prime}$ & 14 & - & 46 & 41 & 1 \\
\hline
\end{tabular}

\footnotetext{
a From Refs. 5 and 13.

${ }^{b}$ Blank = not determined; dash $=$ not detected.

c Values in parentheses represent only the sum of bases; extractable acidity was not determined.

$d$ Values in parentheses are in meq/100 $\mathrm{g}$.

e Trace $\mathrm{CaCO}_{3}$.

f $3 \% \mathrm{CaCO}_{3}$.

g $29 \% \mathrm{CaCO}_{3}$.

${ }^{h} 1 \% \mathrm{CaCO}_{3}$.
}

those for the simple cations. Cerium sorption coefficierits for zeolitized tuff are generally very high, $>10000 \mathrm{~m} \ell / \mathrm{g}$. Data from a single clay sample gave an $R_{\mathrm{d}}$ of $>1000 \mathrm{~m} \ell / \mathrm{g}$. There does not appear to be much difference between sorption on glass (coefficients of $\sim 100 \mathrm{~m} \ell / \mathrm{g}$ or more) and on devitrified samples (coefficients of several hundred milliliters per gram).

Europium sorption coefficients on zeolitized samples are also high: $>1000$ and often $>10000 \mathrm{~m} \ell / \mathrm{g}$. The few clay samples indicate an $R_{d}$ of $>1000 \mathrm{~m} \ell / g$. The lowest sorption coefficients for europium are measured on glass samples with sorption coefficients $\sim 100$ $\mathrm{m} \ell / \mathrm{g}$. Devitrified samples give ratios $\geq 500 \mathrm{~m} \ell / \mathrm{g}$ and generally $>2000 \mathrm{~m} \ell / \mathrm{g}$. 
There are not enough measurements of tin to draw any correlations of sorption with mineralogy. However, the tin sorption coefficients measured to date on the four main mineralogic types are several hundred milliliters per gram.

3. Technetium, Selenium, Uranium, and Neptunium. Far ail intents and purposes, technetium sorption coefficients under oxidizing conditions on all the tuff mineralogies studied are extremely low: $<1 \mathrm{~m} \ell / \mathrm{g}$; to $t$ s conservative, they should be considered zero. Technetium sorption measured wider a nitrogen atmosphere (Sec. IV.E) gave significantly higher sorption coefficisnits: $4 \mathrm{ml} / \mathrm{g}$ or more. These conditions, however, were not representative of those expected at Yucca Mountain and should not be used for performance ssiessment calculations.

Selenium and uranium do not differ much in their sorption behavior. Sorption coefficients for these two elements on zeolitized tuff are $\sim 5 \mathrm{m \ell} / \mathrm{g}$. Uranium gave an $R_{d}$ of $4 \mathrm{~m} \ell / \mathrm{g}$ on a clay sample, but no data are available for selenium on clay. Glassy samples give sorption coefficients of $\sim 3 \mathrm{~m} \ell / \mathrm{g}$ for selenium and range from 0 to $20 \mathrm{~m} \ell / \mathrm{g}$ for uranium. Devitrified samples for uranium are $\sim 2 \mathrm{~m} \ell / \mathrm{g}$; they range from 3 to $30 \mathrm{~m} \ell / \mathrm{g}$ for selenium, and most values are $\sim 10$. When sorption coefficients were measured for these elements under a controlled- $\mathrm{CO}_{2}$ atmosphere (see Sec. IV.E), uranium sorption increased, but selenium sorption showed no significant clange.

Neptunium does not display any significant differences in sorption among the four major rock groups. The sorption coefficients measured under oxidizing conditions for neptunium are $\sim 5 \mathrm{~m} \ell / \mathrm{g}$. No significant changes in sorption were noted under the $\mathrm{CO}_{2}$ atmosphere.

4. Thorium, Plutonium, and Americium. Because thorium solubility is expected to be low at the laboratory $\mathrm{pH}$ of 8-8.5, most of the thorium sorption measurements were made in the controlled- $\mathrm{CO}_{2}$ atmosphere where the $\mathrm{pH}$ was maintained at 7 . Sorption times were sometimes shorter than 6 weeks. No correlations with mineralogy are evident for thorium. The sorption coefficients measured for zeolitized, glassy, and devitrified tuff exceed several hundred milliliters per gram. No data are available for clay.

Considerable time and effort already has been devoted to understanding actinide speciation at neutral $\mathrm{pH}$. We are now attempting to investigate actinide sorption by preparing tracers in known oxidation states. The data contained in this document were obtained by preparing the actinide tracers as described in Sec. II.B. Although this method was intended to prepare the actinides (plutonium in particular) in a single oxidation state, it is not always successful. Tests on the plutonium tracer revealed that $\mathrm{Pu}(\mathrm{IV}),(\mathrm{V})$, and (VI) can be present in our tracer. Therefore, the plutonium sorption data presented here 
represent a grand-average sorption ratio for these three oxidation states of plutonium. Our current effort is aimed at studying sorption of specific oxidation states of plutonium.

Plutonium sorption values for zeolitized tuff range from 60 to $1600 \mathrm{~m} \ell / \mathrm{g}$. The limited clay data yield an $R_{\mathrm{d}}$ of $\sim 500 \mathrm{~m} \ell / \mathrm{g}$, and glass and devitrified samples give sorption coefficients $>100 \mathrm{~m} \ell / \mathrm{g}$. Some of the variation in the data for similar rock types may be a result of tracer preparation anomalies.

Americium does not display any correlation of sorption with mineralogy. With two exceptions, americium sorption coefficients exceed $1000 \mathrm{~m} \ell / \mathrm{g}$. These exceptions are the devitrified tuffs JA-32 and YM-54, which have sorption ratios of $80 \mathrm{~m} \ell / \mathrm{g}$ and $150 \mathrm{~m} \ell / \mathrm{g}$, respectively.

\section{B. Desorption Experiments: Reversibility}

If equilibrium were established, and if observed $R_{d}$ values for tuffs were true $K_{d}$ values, the same $R_{d}$ values should be obtained from desorption and sorption experiments. These $\mathbf{R}_{\mathbf{d}}$ values, however, are usually not the same, and the desorption values are almost always higher. Some of these differences arise from the large ranges in individual determinations; the averaging process, which assumed that the samples represent the same population, may not have been appropriate for such cases. Desorption ratios greater than the corresponding sorption ratios may also indicate kinetic problems or that precipitation has occurred. Other results may represent truly irreversible sorption. If such is the case, the use of these $R_{d}$ measurements would underestimate retardation because of the contribution of irreversible sorption onto tuff. However, if precipitation is occurring, then the measured sorption ratio has overestimated the amount of sorption actually taking place. Desorption ratios lower than the related sorption ratios may indicate dissolution of a precipitate whose solubility was exceeded during the sorption experiment. To rule out such explanations, sorption and desorption isotherms must be measured.

\section{Effects of Elevated Temperature}

The effects of $70^{\circ} \mathrm{C}$ temperatures compared to those of room temperature are discussed in Ref. 5. The values at $70^{\circ} \mathrm{C}$ are generally similar to but higher than those at room temperature by factors up to 5 . A regression modeling of the strontium, cesium, barium, cerium, and europium data indicates a very positive correlation of increasing $R_{d}$ with elevated temperature. The limited data for $85^{\circ} \mathrm{C}$ also show higher sorption. (See Ref. 5, page 110.)

\section{Effects of Particle Size on Sorptive Behavior}

Particle-size effects on sorption ratios are discussed in Ref. 5. It was concluded that the presence of very fine particles $(<38 \mu \mathrm{m}$ ) could lead to larger sorption ratios (by factors of 2 to 5), especially for samples of devitrified tuff. As a result, only particles in 
the 75- to $500-\mu \mathrm{m}$ range are currently used for sorption experiments. Errors caused by excluding these fine particles should result in $R_{d}$ values that are too low and are, therefore, conservative. A large body of data does exist, however, for particle sizes $<500 \mu \mathrm{m}$, which includes very fine particles. (Wherever these $R_{d}$ values are used in discussions, the particle size is noted.)

A regression model analysis of data for barium, cerium, cesium, strontium, and europium and tuff samples from G1-1883, G1-1982, G1-2289, G1-2363, G1-3658, JA-18, JA-32, JA-37, YM-22, YM-38, YM-45, YM-48, YM-49, and YM-54 showed no particlesize effects among four particle-size ranges studied: 106 to 150,106 to 500, 250 to 500, and 355 to $500 \mu \mathrm{m}$. Data from the 75- to $500-\mu \mathrm{m}$ range will be included in a later analysis, but the above result indicates that particle size is not a major factor in our data set.

E. Comparison of Batch Studies Made Under Atmospheric and ControlledAtmosphere Conditions

Because reducing conditions are expected for some groundwater/rock systems, the sorptive behavior of some elements in such systems may differ from their behavior under normal atmospheric conditions. A summary of sorption values measured under a nitrogen atmosphere ( $\leq 0.2 \mathrm{ppm}$ oxygen and $\leq 20 \mathrm{ppm} \mathrm{CO} \mathrm{CO}_{2}$ ) is given in Ref. 5 , and a comparison with laboratory atmosphere results is given in Table VI. Because it has a low $\mathrm{CO}_{2}$ content, this $\mathrm{N}_{2}$ atmosphere is not necessarily representative of deep geologic systems, but it does represent a nonoxidizing atmosphere. With the exception of manganese and tin, sorption ratios for elements measured under the nitrogen conditions were either the same as or slightly higher than those in the more oxidizing conditions of the laboratory atmosphere. Therefore, the laboratory atmosphere measurements, with the exceptions noted, underestimate the sorption ratio compared to measurements under these less oxidizing conditions.

Experiments performed in the laboratory ai Los Alamos display a gradual increase in $\mathrm{pH}$ to values of 8-8.5. This increase is assumed to be a result of loss of $\mathrm{CO}_{2}$ from solution. In an effort to maintain the $\mathrm{pH}$ of some sorption experiments at a level closer to 7 , which is the field $\mathrm{pH}$ of $\mathrm{J}-13$ well water, a controlled-atmosphere box was des:grict to keep the $\mathrm{pH}$ of a sample of $\mathrm{J}-13$ water at $\sim 7$ by increasing the amount of $\mathrm{CO}_{2}$ in the atmosphere whenever necessary. The resulting atmosphere is enriched in $\mathrm{CO}_{2}$ by $\sim 5 \%$.

Sorption ratios have been measured for uranium, neptunium, selenium, and thorium in the $\mathrm{CO}_{2}$-controlled atmosphere. Uranium is the only element studied that showed a significant difference in sorption behavior between controlled and ambient atmospheres; ambient conditions ( $\mathrm{pH} \sim 8.8$ ) gave sorption ratios factors of 3 to 8 times lower than those measured under the controlled conditions (Ref. 16). We conclude that the sorption 
TABLE VI

COMPARISON OF SORPTION RATIOS $\left(R_{\mathrm{d}}\right)$ MEASURED UNDER AMBIENT

ATMOSPHERE AND CONTROLLED-ATMOSFHERE CONDITIONS ${ }^{\mathrm{a}, \mathrm{b}}$

\begin{tabular}{cl} 
Element & Effect on $R_{d}$ Value \\
\cline { 2 - 2 } & \\
$\mathrm{Cs}$ & None \\
$\mathrm{Sr}$ & None \\
$\mathrm{Ba}$ & None \\
$\mathrm{C} e$ & None \\
$\mathrm{Eu}$ & None \\
$\mathrm{Na}$ & None \\
$\mathrm{Se}$ & None \\
$\mathrm{Mn}$ & Lower in CA (factors of 3 to 4) \\
$\mathrm{Sn}$ & Lower in CA (factor of 2) \\
$\mathrm{Am}$ & None \\
$\mathrm{Pu}$ & Higher in CA (factor of 2) \\
$\mathrm{Tc}$ & Higher in CA (factor of $\geq 10$ ) \\
$\mathrm{U}$ & Higher in CA (factors of 2 to 3) \\
$\mathrm{Np}$ & Higher in CA (factor of 2)
\end{tabular}

a From Ref. 5.

b $\mathrm{CA}=$ controlled atmosphere: nitrogen, $\leq 0.2$ ppm oxygen, and $\leq 20 \mathrm{ppm} \mathrm{CO}_{2}$

c With YM-38 (zeulitized) tuff only; otherwise there is no eif fect.

ratios measured in the laboratory under ambient conditions will yield conservative, that is, underestimated sorption ratios; however, we will continue to monitor sorption behavior under these controlled conditions, especially for elements that have an $R_{d}$ of $<10 \mathrm{~m} \ell / g$. F. Comparison of Sorption Ratios Measured by Batch, Circulating Column, Crushed-Rock Column, Wafer, and Solid-Core Methods

Critics have charged that batch measurements on crushed tuff consistently overestimate sorption ratios by large factors. This is not the case, although there may be a bias toward higher batch values. Agreement among various sorption ratio methods is good when sorption times are comparable. Recent evidence does suggest, however, that kinetics may be an important factor. Previous disagreements may have resulted from comparisons between long-term batch and short-term column measurements. 
Batch sorption and circulating column measurements generally agree within a factor of 2, as is shown in Table VII. The circulating column method uses a column that holds the solid phase stationary and prevents possible contribution from self-grinding, which may be present in the batch measurements. The eluent is recirculated through the column until the experiment is terminated. The large disagreements for americium with sample JA-37 and barium with sample YM-22 remain unexplained. However, the presence of very fine clay particles in the batch sample JA-37, which has a relatively high concentration of smectite, could lead to a high sorption value. Crushed-rock columns do not recirculate the eluent, and the radioisotopes to be studied are loaded as a spike onto the column. The contact time of the eluent with the column material is determined by the flow rate. The rock-to-solution ratio is $\sim 3: 1$ for the columns as compared to 1:20 for the batch measurements. Results for strontium, cesium, and barium are cornpared for batch and crushed-rock methods in Table VIII. The value in parentheses represents the factor by which the listed method exceeds the other. Again, the agreement is good for these three elements.

TABLE VII

COMPARISON OF AVERAGE SORPTION RATIOS FROM BATCH AND CIRCULATING-SYSTEM SORPTION MEASUREMENTS ${ }^{a}$

\begin{tabular}{|c|c|c|c|c|c|}
\hline & \multicolumn{5}{|c|}{ Ratio of Batch $R_{d}$ to Circulating-System $R_{d}$} \\
\hline & $\mathbf{S r}$ & Cs & $\mathrm{Ba}$ & Am & $\mathbf{P u}$ \\
\hline $\begin{array}{l}\mathrm{JA}-37^{\mathrm{a}} \\
\text { YM-49 }\end{array}$ & $0.74(0.04)^{b}$ & $0.03(0.03)$ & $0.88(0.18)$ & 8.2(3.3) & $\begin{array}{c}1.4(0.3) \\
0.40(0.15)\end{array}$ \\
\hline $\begin{array}{l}\text { YM-22 } \\
\text { YM-54 }\end{array}$ & $\begin{array}{l}2.0(0.2) \\
1.3(0.2)\end{array}$ & $\begin{array}{c}0.59(0.09) \\
1.3(0.3)\end{array}$ & $\begin{array}{l}7.5(0.7) \\
1.6(0.6)\end{array}$ & & \\
\hline G1-1883 & & & & $1.4(0.1)$ & $1.4(0.4)$ \\
\hline
\end{tabular}


TABLE VIII

SUMMARY OF DIFFERENCES IN SORPTION RATIOS BETWEEN

CRUSHED-ROCK COLUMN AND BATCH MEASUREMENTS ${ }^{a}$

\begin{tabular}{|c|c|c|c|}
\hline Column & ${ }^{85} \mathrm{Sr}$ & ${ }^{137} \mathrm{Cs}$ & ${ }^{133} \mathrm{Ba}$ \\
\hline YM54 & $0^{b}$ & 0 & 0 \\
\hline YM38 & & $\mathrm{C}>\mathrm{B}(1.45)$ & \\
\hline YM22 & $\mathrm{C}>\mathrm{B}^{\mathrm{c}}$ & 0 & $\mathrm{C}<\mathrm{B}^{\mathrm{c}}$ \\
\hline JA-37 & $\mathrm{C}<\mathrm{B}(2.08)$ & $\mathrm{C}>\mathrm{B}(1.36)^{\mathrm{c}}$ & \\
\hline JA-32 & 0 & & \\
\hline G1-3658 & $\mathrm{C}<\mathrm{B}(11.8)$ & $\mathrm{C}<\mathrm{B}(1.18)$ & $\mathrm{C}<\mathrm{B}(1.91)$ \\
\hline G1-3116 & $\mathrm{C}<\mathrm{B}$ & $\mathrm{C}<\mathrm{B}$ & {$[0]$} \\
\hline G1-2901 & $\mathrm{C}<\mathrm{B}$ & $\mathrm{C}<\mathrm{B}$ & $\mathrm{C}<\mathrm{B}$ \\
\hline G1-2476 & $\mathrm{C}<\mathrm{B}$ & {$[\mathrm{C}<\mathrm{B}]$} & $\mathrm{C}<\mathrm{B}$ \\
\hline G1-2363 & 0 & $\mathrm{C}<\mathrm{B}$ & $\mathrm{C}<\mathrm{B}$ \\
\hline G1-2233 & {$[0]$} & {$[\mathrm{C}>\mathrm{B}]$} & {$[0]$} \\
\hline G1-1982 & 0 & 0 & $\mathrm{C}<\mathrm{B}(1.18)$ \\
\hline G1-1883 & 0 & 0 & $\mathrm{C}<\mathrm{B}(123)$ \\
\hline G1-1292 & 0 & {$[\mathrm{C}>\mathrm{B}]$} & {$[\mathrm{C}<\mathrm{B}]$} \\
\hline
\end{tabular}

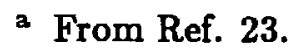

b " 0 " indicates that the column $R_{\mathrm{d}}$ value fell within the range of measured batch values or that the ranges overlapped (if more than one column measurement was made). Brackets indicate that the column $R_{d}$ value(s) was obtained by sectioning the column. $C<B$ or $C>B$ indicates that the column $R_{d}$ value was less than or greater than the batch $R_{d}$ value. If a number follows in parentheses, it is the factor by which column and batch values differ. Numbers are not given when only batch data on unwashed fractions are available for comparison; the apparent difference between column and batch values may not be real.

c $\mathrm{C}=\mathrm{B}$ when results from the circulating type of batch measurements are included. 
The results are quite different, however, for neptunium, plutonium, and americium. Sorption ratios determined from the crushed-rock columns are significantly lower than those determined by the batch method. From $10-50 \%$ of the input radionuclide activity appeared with the solvent front or quite close to it for the column runs. Table IX lists the tuffs studied and their batch and column sorption values. The amount of actinide in these experiments is generally $\sim 10^{-8} \mathrm{M}$. Thorough checks of the columns showed that their behavior was reproducible and that they were otherwise operating correctly. Several short-term batch experiments were performed to discover if there were kinetic effects. Tuff USW GU-3-1301 had previously yielded sorption values of $1500-2000 \mathrm{~m} \ell / \mathrm{g}$ for 6 -week contact periods, but the results for batch contact times of $6 \mathrm{~h}, 24 \mathrm{~h}$, and 8 days were 54, 84 , and $2000 \mathrm{~m} \ell / \mathrm{g}$, respectively. ${ }^{15}$

Several explanations may account for the appearance of the actinides in the effluent with the solvent front. A contact time longer than a few hours may be required for sorption of all the input species. This theory is consistent with the short-term batch results. The species originally present in the feed solution may not sorb completely but may change slowly over a period of days to a more sorbable species. In addition, the activity appearing with the solvent front may be due to colloid-size particles carrying sorbed radioactivity as they wash from the column.

Speciation changes are certainly possible with plutonium, but that explanation does not seem to be applicable to americium, which presumably exists in only one oxidation state. Colloidal transport of the activity seems a less likely explanation in light of a followup experiment using one column that was flooded with colloids and another column from which all colloids had been removed. Both columns behaved similarly, but the colloid column eluted somewhat less activity. We concluded that because large quantities of colloidal material did not appreciably change the elution behavior, the presence of relatively small amounts of colloidal material could not cause the breakthrough of any large fraction of the input activity. However, other colloidal transport experiments are continuing.

The evidence thus far indicates that actinide sorption may involve one or more timedependent steps. More experimental work should be directed toward resolving the uncertainties associated with this kinetic effect. It may be necessary to modify models of actinide transport to include the possibility that source material could move farther over short time periods than would be predicted solely on the basis of long-term batch measurements.

A third method using intact tuff wafers can be compared to batch techniques. Thin (2- to 3-mm thick) tuff wafers are suspended in pretreated groundwater that has a rockto-solution ratio of 1:20-the same as that for batch experiments. The sorption ratios 
TABLE IX

KINETIC STUDIES OF SORPTION COLUMNS ${ }^{\mathrm{a}}$

\begin{tabular}{|c|c|c|c|c|c|}
\hline \multirow{2}{*}{ Experiment } & \multirow[b]{2}{*}{ Tuff } & \multirow[b]{2}{*}{ Type } & \multirow[b]{2}{*}{ Constituents } & \multicolumn{2}{|c|}{$R_{d}$ Values } \\
\hline & & & & Batch & Column \\
\hline \multirow[t]{5}{*}{ Plutonium } & JA-37 & Welded & $\begin{array}{l}\text { Clay, glass, } \\
\text { feldspar, cristobolite }\end{array}$ & $4 \times 10^{2}$ & 4 \\
\hline & YM-49 & $\begin{array}{l}\text { Partially } \\
\text { welded }\end{array}$ & & & \\
\hline & USW G1-1883 & $\begin{array}{l}\text { Partially } \\
\text { welded }\end{array}$ & $\begin{array}{l}\text { Feldspar, quartz, } \\
\text { cristobolite }\end{array}$ & $8 \times 10^{1}$ & 0.3 \\
\hline & U12G & Zeolitized & $\begin{array}{l}\text { Clinoptilolite, } \\
\text { feldpar }\end{array}$ & $3 \times 10^{2}$ & 0.5 \\
\hline & USW G1-1292 & Welded & Glass, feldspar, & $6 \times 10^{2 b}$ & $<1$ \\
\hline \multirow[t]{3}{*}{ Americium } & USW G1-1292 & Welded & $\begin{array}{l}\text { Glass, feldspar, } \\
\text { cristobolite }\end{array}$ & $3 \times 10^{4 b}$ & $<1$ \\
\hline & USW G1-1436 & Zeolitized & $\begin{array}{l}\text { Clinoptilolite, } \\
\text { quartz, cristobolite, } \\
\text { feldspar }\end{array}$ & $2 \times 10^{3}$ & $<1$ \\
\hline & USW GU3-1301 & Vitric & $\begin{array}{l}\text { Glass, feldspar, } \\
\text { cristobolite, quartz }\end{array}$ & & $<1$ \\
\hline \multirow[t]{3}{*}{ Neptunium } & JA-37 & Welded & $\begin{array}{l}\text { Clay, glass, } \\
\text { feldspar, cristobolite }\end{array}$ & $2 \times 10^{1}$ & 4 \\
\hline & YMA-49 & $\begin{array}{l}\text { Partially } \\
\text { welded }\end{array}$ & $\begin{array}{l}\text { Glass, feldspar, } \\
\text { clinoptilolite }\end{array}$ & 8 & 2 \\
\hline & USW G1-1883 & $\begin{array}{l}\text { Partially } \\
\text { welded }\end{array}$ & $\begin{array}{l}\text { Feldspar, quartz, } \\
\text { cristobolite }\end{array}$ & 6 & 0.5 \\
\hline
\end{tabular}

arom Ref. 15.

${ }^{\mathrm{b}}$ Estimated value.

measured after 4 weeks of contact are compared to those of batch measurements in Table X. The agreement differs by much less than a factor of 2 in all cases.

A few solid-core experiments have been performed. Strontium gave a sorption ratio within a factor of $\sim 2.5$ of the ratio for batch results, and plutonium gave values within a factor of 10 (Ref. 5). These results are considered in reasonable agreement because of the large uncertainties in the solid-core data. 
When we compare batch and wafer experiments on the same time scale, we conclude that use of the batch technique is valid for tuff sorption measurements. It appears, however, that a kinetic factor is present in the sorption process. This kinetic effect must be investigated further, and it may be necessary to incorporate it into modeling codes for actinide transport.

TABLE X

$\mathrm{R}_{d}$ COMPARISON: TUFF WAFERS vs CRUSHED TUFF ${ }^{2}$

\begin{tabular}{|c|c|c|c|}
\hline Tuff Sample & Element & $\begin{array}{c}\mathrm{R}_{\mathrm{d}} \text { (Wafer) } \\
(\mathrm{m} \ell / \mathrm{g}) \\
\end{array}$ & $\begin{array}{c}R_{d} \text { (Batch) } \\
(\mathrm{m} \ell / \mathrm{g})\end{array}$ \\
\hline \multirow[t]{3}{*}{ G1-1883 (sorption) } & $\mathbf{S} \mathbf{r}$ & 27 & 22 \\
\hline & Cs & 230 & 190 \\
\hline & $\mathbf{B a}$ & 210 & 180 \\
\hline \multirow[t]{3}{*}{ G1-1982 (sorption) } & $\mathrm{Sr}$ & 80 & 62 \\
\hline & Cs & 1000 & 1200 \\
\hline & $\mathrm{Ba}$ & 800 & 800 \\
\hline \multirow[t]{2}{*}{ G1-1436 (desorption) } & $\mathbf{S} \mathbf{r}$ & 96500 & 87000 \\
\hline & Cs & 14900 & 24000 \\
\hline
\end{tabular}

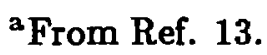

\section{G. Sorption Isotherms}

One of the key purposes for measuring the dependence of sorption coefficients on sorbing element concentration (isotherms) is to provide the information necessary to accurately model retardation of waste elements under various source-term and groundwater conditions. Thermodynamic parameters, such as equilibrium constants, can sometimes be extracted from isotherm data, thus providing a data base for correlating sorption coefficients with other variables of interest. In most transport codes, sorption is treated as a linear isotherm; that is, the sorption coefficient does not depend upon the element concentration. This treatment should be appropriate for ion-exchange equilibrium at tracer levels with zeolitic tuffs; however, it may not hold for nonzeolitized tuffs. In these cases, it may be necessary to consider other approaches such as Langmuir, Freundlich, or massaction isotherms. Additionally, it is not unexpected that hysteresis will be observed when desorption isotherms are measured. If such is the case, isotherm measurements take on an 
even greater importance. According to Genuchten and Cleary, ${ }^{24}$ the exclusion of hysteresis effects in the calculation of concentration distributions can cause serious discrepancies between the actual a- 1 calculated distributions. In other words, predictive models of sorption will need to account for hysteresis effects, which must be experimentally measured. A discussion of isotherm data and calculations for Yucca Mountain tuff samples is contained in Ref. 5. Recent isotherm measurements for neptunium are included in this data set but have not been analyzed to determine which type of isotherm may apply. The tuff samples used for these studies are G4-1608 and GU3-433.

Sorption isotherm measurements can be useful in other ways. Preliminary statistical analysis of some of our sorption data revealed that often trends could not be predicted because there are too many variables. Frequently, the analysis could narrow the problem down to two variables-one of which was commonly concentration. Using data obtained from isotherm measurements, we have been able in many cases to rule out concentration as a contributing factor. As stated in Sec. B (Desorption Experiments), isotherm measurements are necessary to rule out the possibility that precipitation contributed to the measured sorption ratio.

\section{SUMMARY}

Los Alamos has compiled an extensive sorption data base for radionuclides on Yucca Mountain tuff; these data, when refined, will contribute to estimations of the movement and transport of radionuclides in groundwater at Yucca Mountain. This data base will grow as the Project continues its investigations of Yucca Mountain. The next major addition to this data base will be information being collected on the effect of groundwater composition on sorption ratios. Additional effects still to be determined include sorption of other radionuclides, sorption on colloids and bacteria and ıneir subseçuent transport, other effects of bacteria on sorption (such as the release of complexing agents), sorption under Vadose groundwater conditions, and sorption isotherms.

\section{ACKNOWLEDGEMENTS}

The following people made significant contributions to the data collection and the interpretations used in this report. Sorption experiments: B. P. Bayhurst, M. R. Cisneros, W. R. Daniels, S. D. Knight, F. O. Lawrence, A. J. Mitchell, R. S. Rundberg, and K. Wolfsberg; water chemistry: A. E. Ogard and P. L. Wanek; mineralogy/petrology: D. L. Bish, B. M. Crowe, and D. T. Vaniman; statistical evaluation and data interpretation: R. Beckman, B. M. Crowe, and R. S. Rundberg; column experiments: N. A. Raybold, E. N. Treher, and J. L. Thompson; and speciation of actinides: D. E. Hobart, T. W. Newton, P. Palmer, and V. L. Rundberg. 


\section{REFERENCES}

1. "Environmental Assessment, Yucca Mountain Site, Nevada Research and Development Area, Nevada," Vol. I-II, DOE/RW-0073 (May 1986).

2. "Nevada Nuclear Waste Storage Investigation Site Characterization Plan," Secs. 8.1, 8.2, US Department of Energy (in preparation); Office of Geologic Repositories, "Issues Hierarchy for a Mined Geologic Disposal System," OGR-B-10, US Department of Energy, Office of Civilian Repository Waste Management (1986).

3. Code of Federal Regulations, Title 10, Energy, Part 60: "Disposal of High-Level Radioactive Wastes in Geologic Repositories," US Government Printing Office, Washington, DC (1983).

4. Code of Federal Regulations, Part 191: "Environmental Standards for the Management and Disposal of Spentor Nuclear Field, High-Level and Transuranic Radioactive Wastes: Final Rule," Federal Register Vol. 50, No. 182 (September 19, 1985).

5. W. R. Daniels, K. Wolfsberg, R. S. Rundberg, A. E. Ogard, J. F. Kerrisk, C. J. Duffy, et al., "Summary Report on the Geochemistry of Yucca Mountain and Environs," Los Alamos National Laboratory report LA-9328-MS (December 1982).

6. W. R. Daniels, K. Wolfsberg, D. T. Vaniman, and B. R. Erdal, Eds., "Research and Development Related to the Nevada Nuclear Waste Storage Investigations, January 1-March 31, 1982," Los Alamos National Laboratory report LA-9327-PR (October 1982).

7. K. Wolfsberg, W. R. Daniels, B. R. Erdal, and D. T. Vaniman, Comps., "Research and Development Related to the Nevada Nuclear Waste Storage Investigations, April 1June 30, 1982," Los Alamos National Laboratory report LA-9484-PR (October 1982).

8. W. R. Daniels, B. R. Erdal, and D. T. Vaniman, Comps., "Research and Development Related to the Nevada Nuclear Waste Storage Investigations, July 1-September 30, 1982," Los Alamos National Laboratory report LA-9577-PR (March 1983).

9. A. E. Ogard, W. R. Daniels, and D. T. Vaniman, Comps., "Research and Development Related to the Nevada Nuclear Waste Storage Investigations, October 1-December 31, 1982," Los Alamos National Laboratory report LA-9666-PR (May 1983).

10. K. Wolfsberg, D. T. Vaniman, and A. E. Ogard, Comps., "Research and Development Related to the Nevada Nuclear Wasie Storage Investigations, January 1-March 31, 1983," Los Alamos National Laboratory report LA-9793-PR (June 1983).

11. A. E. Ogard, K. Wolfsberg, and D. T. Vaniman, Comps., "Research and Development Related to the Nevada Nuclear Waste Storage Investigations, April 1-June 30, 1983," Los Alamos National Laboratory report LA-9846-PR (December 1983). 
12. E. A. Bryant and D. T. Vaniman, Comps., "Research and Development Related to the Nevada Nuclear Waste Storage Investigations, July 1-September 30, 1983," Los Alamos National Laboratory report LA-10006-PR (July 1984).

13. K. Wolfsberg and D. T. Vaniman, "Research and Development Related to the Nevada Nuclear Waste Storage Investigations, October 1-December 31, 1983, " Los Alamos National Laboratory report LA-10032-PR (August 1984).

14. B. Crowe and D. T. Vaniman, Comps., "Research and Development Related to the Nevada Nuclear Waste Storage Investigations, January 1-March 31, 1984," Los Alamos National Laboratory report LA-10154-PR (February 1985).

15. R. S. Rundberg, A. E. Ogard, and D. T. Vaniman, Comps., "Research and Development Related to the Nevada Nuclear Waste Storage Investigations, April 1-June 30, 1984," Los Alamos National Laboratory report LA-10297-PR (May 1985).

16. A. E. Ogard and D. T. Vaniman, Comps., "Research and Development Related to the Nevada Nuclear Waste Storage Investigations, July 1-September 30, 1984," Los Alanuos National Laboratory report LA-10299-PR (May 1985).

17. D. L. Bish, D. T. Vaniman, F. M. Byers, Jr., and D. E. Broxton, "Summary of the Mineralogy-Petrology of Tuffs of Yucca Mountain and Secondary-Phases of Thermal Stability in Tuffs," Los Alamos National Laboratory report LA-9321-MS (November 1982).

18. D. Broxton, D. Vaniman, F. Caporuscio, B. Arney, G. Heiker, "Detailed Petrographic Descriptions and Microprobe Data for Drill Holes USW-G2 and UE25b-1H, Yucca Mountain, Nevada," Los Alamos National Laboratory report LA-9324-MS (November 1982).

19. S. S. Levy, "Petrology of Samples from Drill Holes USW H-3, H-4, and H-5, Yucca Mountain, Nevada," Los Alamos National Laboratory report LA-9706-MS (April 1983).

20. D. Vaniman, D. Bish, D. Broxton, F. Byers, G. Heiken, B. Carlos, E. Semarge, F. Caparuscio, and R. Gooley, "Variations in Authigenic Mineralogy and Sorptive Zeolite Abundance at Yucca Mountain, Nevada, Based on Studies of Drill Cores USW GU-3 and G-3," Los Alamos National Laboratory report LA-9707-MS (April 1983).

21. R. G. Warren, F. M. Byers, and F. Caporuscio, "Petrography and Mineral Chemistry of Units of the Topopah Spring, Calico Hills and Crater Flat Tuffs, and Older Volcanic Units, with Emphasis on Samples from Drill Hole USW G-1, Yucca Mountain, Nevada," Los Alamos National Laboratory report LA-10003-MS (June 1984). 
22. A. E. Ogard and J. F. Kerrisk, "Groundwater Chemistry Along Flow Paths Between a Proposed Repository Site and the Accessible Environment," Los Alamos National Laboratory report LA-10188-MS (November 1984).

23. E. N. Treher and N. A. Raybold, "The Elution of Radionuclides Through Columns of Crushed Rock from the Nevada Test Site, " Los Alamos National Laboratory report LA-9329-MS (October 1982).

24. M. Th. van Genuchten and R. W. Cleary, "Movement of Solutes in Soil: ComputerSimulated and Laboratory Results," in Soil Chemistry B: Physico-Chemical Models, G. H. Bolt, Ed. (Elsevier Scientific Publishing Co. Amsterdam, The Netherlands, 1982). 


\section{APPENDIX}

BATCH SORPTION RATIOS FOR TUFFS OF THE YUCCA MOUNTAIN AREA AND WELL J-13 WATER 


\section{GLOSSARY}

element $=$ chemical symbol for the element in question

temp $=$ temperature at which the measurements were made (room $\sim 25 \pm 3^{\circ} \mathrm{C}$ )

Atm $=$ atmosphere

air = ambient atmosphere

ca = controlled atmosphere: $\mathrm{N}_{2} ; \leq 0.2 \mathrm{ppm} \mathrm{O}_{2} ; \leq 20 \mathrm{ppm} \mathrm{\textrm {CO } _ { 2 }}$

$\mathrm{CO}_{2}=$ atmosphere enriched in $\mathrm{CO}_{2} \sim 5 \%$; $\mathrm{pH}$ of $\mathrm{J}-13$ groundwater was maintained at $\sim 7$

Stime $=$ time of sorption measurements in days

$\operatorname{srd} 1 / \mathrm{srd} 2=$ sorption ratios measured in duplicate

dtime $=$ time of desorption measurement in days

$\mathrm{drd} 1 / \mathrm{drd} 2=$ desorption ratios measured in duplicate

conc $=$ concentration of sorbing element in Molarity

$\mathrm{pmin} / \mathrm{pmax}=$ the minimum and maximum particle size in $\mu \mathrm{m}$ of the crushed tuff 
BATCH SORPTION RATIOS FOR TUFFS OF THE YUCCA

MOUNTAIN AREA AND WELL J-13 WATER

Element Temp Atm Stime srd1 srd2 dtime drd1 drd2

\section{Core}

G1-1292

\begin{tabular}{|c|c|c|c|c|c|c|c|c|c|c|}
\hline \multirow[t]{2}{*}{$\mathrm{Ba}$} & room & air & 21.000 & 1800.0 & 2200.0 & 42.000 & 1700.0 & 1400.0 & $7.00-6$ & 500. \\
\hline & & & 42.000 & 2800.0 & 1500.0 & 21.000 & 1400.0 & 15000.0 & $7.00-6$ & 500. \\
\hline \multirow[t]{2}{*}{$\mathrm{Ce}$} & room & air & 21.000 & 54.0 & 79.0 & 42.000 & 1200.0 & 510.0 & $7.00-8$. & 500. \\
\hline & & & 42.000 & 82.0 & 50.0 & 21.000 & 610.0 & 94.0 & $7.00-8$ & 500. \\
\hline \multirow[t]{2}{*}{ Cs } & room & air & 21.000 & 390.0 & 450.0 & 42.000 & 560.0 & 500.0 & $3.00-9$ & 500. \\
\hline & & & 42.000 & 500.0 & 380.0 & 21.000 & 470.0 & 520.0 & 3.00-9. & 500. \\
\hline \multirow[t]{2}{*}{ Eu } & room & air & 21.000 & 140.0 & 160.0 & 42.000 & 780.0 & 510.0 & $1.00-7$ & 500. \\
\hline & & & 42.000 & 160.0 & 100.0 & 21.000 & 490.0 & 620.0 & $1.00-7$ & 500. \\
\hline $\mathbf{R a}$ & room & air & 42.000 & 1500.0 & 1400.0 & & & & $3.60-7.75$ & 500. \\
\hline \multirow[t]{2}{*}{$\mathbf{S} \mathbf{r}$} & room & air & 21.000 & 200.0 & 200.0 & 42.000 & 120.0 & 110.0 & $2.00-7$ & 500. \\
\hline & & & 42.000 & 220.0 & 190.0 & 21.000 & 110.0 & 130.0 & 2.00-7. & 500. \\
\hline Th & room & air & 84.000 & 566.0 & 389.0 & & & & $5.40-8.75$ & 500. \\
\hline $\mathrm{U}$ & room & air & 42.000 & 0.2 & -1.6 & & & & $5.00-6.75$ & 500. \\
\hline
\end{tabular}

$\underline{\text { Core }}$

G1-1436

$\begin{array}{llllllllllll}\text { Ba } & \text { room } & \text { air } & 21.000 & 150000.0 & 140000.0 & 42.000 & 300000.0 & 110000.0 & 8.00-6 . & 500 . \\ & & & 42.000 & 93000.0 & 210000.0 & 21.000 & 450000.0 & 500000.0 & 8.00-6 . & 500 . \\ & & & & & & & & & & & \\ \text { Ce } \quad \text { room } & \text { air } & 21.000 & 58000.0 & 62000.0 & 42.000 & 5900.0 & 5500.0 & 1.00-7 . & 500 . \\ & & & 42.000 & 41000.0 & 74000.0 & 21.000 & 8000.0 & 7200.0 & 1.00-7 . & 500 .\end{array}$ 


\section{Element Temp Atm Stime srd1 srd2 dtime drd1 drd2 Conc pmin pmax}

Core

G1-1436

\begin{tabular}{|c|c|c|c|c|c|c|c|c|c|c|c|}
\hline $\mathrm{Cs}$ & room & air & 21.000 & 7000.0 & 7900.0 & 42.000 & 29000.0 & 18000.0 & 3.00-9. & & 500. \\
\hline & & & 42.000 & 7400.0 & 9000.0 & 21.000 & 26000.0 & 23000.0 & 3.00-9. & & 500. \\
\hline Eu & room & air & 21.000 & 30000.0 & 32000.0 & 42.000 & 4200.0 & 4500.0 & $1.00-7$ & & 500. \\
\hline & & & 42.000 & 25000.0 & 34000.0 & 21.000 & 6500.0 & 6100.0 & $1.00-7$ & & 500. \\
\hline $\mathbf{a}$ & room & air & 42.000 & 79000.0 & 130000.0 & & & & $3.60-7$ & 75. & 500. \\
\hline Se & room & air & 42.000 & 11.0 & 14.0 & & & & $1.00-10$ & 75. & 500. \\
\hline $\mathbf{s r}$ & room & air & 21.000 & 31000.0 & 36000.0 & 42.000 & 100000.0 & 55000.0 & $1.00-7$ & & 500. \\
\hline & & & 42.000 & 33000.0 & 45000.0 & 21.000 & 110000.0 & 83000.0 & $1.00-7$ & & 500. \\
\hline & room & air & 42.000 & 12.0 & 10.0 & & & & $5.00-6$ & 75. & 500 \\
\hline
\end{tabular}

Core

G1-1854

Ba room air 21.00063000 .0

$21.000 \quad 34000.0$

$42.000 \quad 48000.0$

$42.000 \quad 34000.0$

Cs room air $21.000 \quad 15000.0$

21.00011000 .0

$42.000 \quad 15000.0$

42.00010000 .0

Eu room air $21.000>130000.0$

21.000120000 .0

$42.000>110000.0$

$42.000 \quad 14000.0$

$\begin{array}{ll}42.000 & 140000.0 \\ 42.000 & 130000.0 \\ 21.000 & 250000.0 \\ 21.000 & 87000.0\end{array}$

$42.000 \quad 14000.0$

$42.000 \quad 11000.0$

21.00018000 .0

$21.000 \quad 15000.0$

$42.000 \quad 4800.0$

$\mathbf{4 2 . 0 0 0} \quad 3000.0$

$21.000 \quad 6500.0$

$21.000 \quad 4800.0$
1.00-7. 1.00-7. 75. 500 . 1.00-7. 75 .

1.00-7. 75. 500 .

4.00-9.

75.

4.00-9. 75. 500 .

4.00-9. 75 .

4.00-9. 75. 500 .

3.00-8. 75 .

3.00-8. 75. 500 .

3.00-8. 75 .

3.00-8. 75. 500 . 
Element Temp Atm Stime srd1 srd2 dtime drd1 drd2 Conc pmin pmax

\section{Core}

G1-1854

Sr room air

$$
\begin{array}{ll}
21.000 & 71000.0 \\
21.000 & 32000.0 \\
42.000 & 92000.0 \\
& \\
42.000 & 43000.0
\end{array}
$$

\begin{tabular}{|c|c|c|c|c|c|c|c|c|c|c|}
\hline \multirow[t]{3}{*}{ Am } & room air & 21.000 & 4200.0 & & 84.000 & 5900.0 & & $1.00-7$ & 106. & 250. \\
\hline & & 42.000 & 4500.0 & & 63.000 & 6900.0 & & $1.00-7$ & 106. & 250. \\
\hline & & 84.000 & 5300.0 & & 21.000 & 8900.0 & & $1.00-7$ & 106. & 250. \\
\hline \multirow[t]{8}{*}{$\mathbf{B a}$} & room air & 21.000 & 750.0 & & & & & $7.00-6$ & & 38. \\
\hline & & 21.000 & 230.0 & & & & & $7.00-6$. & & 38. \\
\hline & & 21.000 & 4300.0 & 250.0 & 42.000 & 440.0 & 420.0 & $8.00-6$ & & 500. \\
\hline & & 21.000 & 210.0 & & & & & $7.00-6$ & 38. & 106. \\
\hline & & 21.000 & $200: 0$ & & & & & $7.00-6$ & 38. & 106. \\
\hline & & 21.000 & 160.0 & & & & & $7.00-6$ & 106. & 500. \\
\hline & & 21.000 & 160.0 & & & & & $7.00-6$ & 106. & 500. \\
\hline & & 42.000 & 480.0 & 490.0 & 21.000 & 450.0 & 460.0 & $8.00-6$ & & 500. \\
\hline \multirow[t]{2}{*}{$\mathrm{Ce}$} & room air & 21.000 & 150.0 & 150.0 & 42.000 & 2000.0 & 2100.0 & $7.00-8$ & & 500. \\
\hline & & 42.000 & 300.0 & 250.0 & 21.000 & 2200.0 & 2300.0 & $7.00-8$ & & 500. \\
\hline \multirow[t]{4}{*}{$\mathrm{Cs}$} & room air & 21.000 & 720.0 & & & & & $4.00-9$ & & 38. \\
\hline & & 21.000 & 310.0 & & & & & $4.00-9$ & & 38. \\
\hline & & 21.000 & 380.0 & 350.0 & 42.000 & 420.0 & 430.0 & $3.00-9$ & & 500. \\
\hline & & 21.000 & 200.0 & & & & & $4.00-9$ & 38. & 106. \\
\hline \multirow[t]{4}{*}{$\mathrm{Cs}$} & room air & 21.000 & 180.0 & & & & & $4.00-9$ & 38. & 106. \\
\hline & & 21.000 & 180.0 & & & & & $4.00-9$ & 106. & 500. \\
\hline & & 21.000 & 190.0 & & & & & $4.00-9$ & 106. & 500. \\
\hline & & 42.000 & 440.0 & 440.0 & 21.000 & 430.0 & 440.0 & $3.00-9$ & & 500. \\
\hline
\end{tabular}

Core

G1-1883

$\begin{array}{lll}3.00-8 . & & 75 . \\ 3.00-8 . & 75 . & 500 . \\ 3.00-8 . & & 75 . \\ & & \\ 3.00-8 . & 75 . & 500 .\end{array}$

$21.000 \quad 51000.0$

3.00-8. 75. 500.

\section{G1.1883}


Element Temp Atm Stime srd1 srd2 dtime drd1 drd2 Conc pmin pmax

\section{Core}

G1-1883

\begin{tabular}{|c|c|c|c|c|c|c|c|c|c|c|c|}
\hline \multirow[t]{8}{*}{$\mathbf{E u}$} & room & air & 21.000 & 650.0 & & & & & $3.00-8$ & & 38. \\
\hline & & & 21.000 & 370.0 & & & & & $3.00-8$ & & 38. \\
\hline & & & 21.000 & 180.0 & 180.0 & 42.000 & 1300.0 & 1500.0 & $1.00-7$ & 500. & \\
\hline & & & 21.000 & 110.0 & & & & & $3.00-8$ & 38. & 106. \\
\hline & & & 21.000 & 120.0 & & & & & $3.00-8$ & 38. & 106. \\
\hline & & & 21.000 & 150.0 & & & & & $3.00-8$ & 106. & 500. \\
\hline & & & 21.000 & 170.0 & & & & & $3.00-8$ & 106. & 500. \\
\hline & & & 42.000 & 330.0 & 300.0 & 21.000 & 1300.0 & 1300.0 & $1.00-7$ & & 500. \\
\hline \multirow[t]{3}{*}{$\mathrm{Mn}$} & room & air & 14.000 & 160.0 & & 28.000 & 140.0 & & $1.00-11$ & & 500. \\
\hline & & & 14.000 & 120.0 & & & & & $1.00-11$ & & 500. \\
\hline & & & 28.000 & 140.0 & 390.0 & 14.000 & 160.0 & 950.0 & $1.00-11$ & & 500. \\
\hline \multirow[t]{2}{*}{$\mathrm{Na}$} & room & air & 14.000 & 0.93 & 3.0 & 28.000 & 4.2 & 1.3 & $2.00-3$ & & 500. \\
\hline & & & 28.000 & 3.7 & 1.6 & 14.000 & 3.8 & 1.7 & $2.00-3$ & & 500. \\
\hline \multirow[t]{3}{*}{$\mathrm{Np}_{\mathrm{p}}$} & room & air & 21.000 & 5.3 & & 84.000 & 24.0 & & $9.00-11$ & 106. & 250. \\
\hline & & & 42.000 & 6.9 & & 63.000 & 29.0 & & $9.00-11$ & 106. & 250. \\
\hline & & & 91.000 & 7.1 & & 21.000 & 56.0 & & $9.00-11$ & 106. & 250. \\
\hline \multirow[t]{3}{*}{$\mathbf{P u}$} & room & air & 21.000 & 51.0 & & 84.000 & 830.0 & & $4.00-12$ & 106. & 250. \\
\hline & & & 42.000 & 52.0 & 91.0 & 56.000 & 740.0 & 1100.0 & $4.00-12$ & 106 & 250. \\
\hline & & & 91.000 & 82.0 & 107.0 & 21.000 & 960.0 & 850.0 & $4.00-12$ & 106. & 250. \\
\hline \multirow[t]{2}{*}{$\mathbf{S e}$} & room & air & 14.000 & 1.5 & & 28.000 & 60.0 & 20.0 & $1.00-9$ & & .500. \\
\hline & & & 28.000 & 16.0 & 3.6 & 14.000 & 72.0 & 30.0 & $1.00-9$ & & 500. \\
\hline \multirow[t]{2}{*}{ Sn } & room & air & 14.000 & 230.0 & & 28.000 & 2600.0 & 2100.0 & $8.00-9$ & & 500. \\
\hline & & & 28.000 & 620.0 & 290.0 & 14.000 & 2400.0 & 2700.0 & $8.00-9$ & & 500. \\
\hline \multirow[t]{4}{*}{ Sr } & room & air & 21.000 & 80.0 & & & & & 3.00-7. & & 38. \\
\hline & & & 21.000 & 26.0 & & & & & 3.00-7. & & 38. \\
\hline & & & 21.000 & 58.0 & 59.0 & 42.000 & 58.0 & 56.0 & $2.00-7$ & & 500. \\
\hline & & & 21.000 & 22.0 & & & & & 3.00-7. & 38. & 106. \\
\hline
\end{tabular}


Element Temp Atm Stime srd1 srd2 dtime drd1 drd2 Conc pmin pmax

\section{Core}

G1-1883

$21.000 \quad 22.0$

21.00022 .0

$21.000 \quad 22.0$

$42.000 \quad 57.0$
3.00-7. 38. 106.

3.00-7. 106. 500 .

3.00-7. 106. 500 .

$\begin{array}{lllll}58.0 & 21.000 & 60.0 & 62.0 & 2.00-7\end{array}$

\section{Core}

G1-1982

\begin{tabular}{|c|c|c|c|c|c|c|c|c|c|c|c|}
\hline \multirow[t]{10}{*}{$\mathbf{B a}$} & room & air & 14.000 & 10000.0 & & & & & $4.00-6$ & & 38. \\
\hline & & & 14.000 & 670.0 & & & & & $4.00-6$ & 38. & 75. \\
\hline & & & 14.000 & 570.0 & & & & & $4.00-6$ & 75. & 250. \\
\hline & & & 14.000 & 690.0 & & & & & $4.00-6$ & 250. & 500. \\
\hline & & & 21.000 & 10000.0 & & & & & $4.00-6$ & & 38. \\
\hline & & & 21.000 & 2500.0 & 2200.0 & 42.000 & 2600.0 & 3100.0 & $4.00-6$ & & 500. \\
\hline & & & 21.000 & 840.0 & & & & & $4.00-6$ & 38. & 75. \\
\hline & & & 21.000 & 780.0 & & & & & $4.00-6$ & 75. & 50. \\
\hline & & & 21.000 & 780.0 & & & & & $4.00-6$ & 250. & 500. \\
\hline & & & 42.000 & 3100.0 & 3200.0 & 21.000 & 2800.0 & 2600.0 & $4.00-6$ & & 00. \\
\hline \multirow[t]{2}{*}{$\mathrm{Ce}$} & room & air & 21.000 & 520.0 & 450.0 & 42.000 & 5900.0 & 5600.0 & $1.00-7$ & & 00. \\
\hline & & & 42.000 & 640.0 & 600.0 & 21.000 & 9400.0 & 7200.0 & $1.00-7$ & & 00. \\
\hline \multirow[t]{7}{*}{$\mathrm{Cs}$} & rrom & air & 14.000 & 3800.0 & & & & & $3.00-9$ & & 38. \\
\hline & & & 14.000 & 1200.0 & & & & & 3.00-9. & 38. & 75. \\
\hline & & & 14.000 & 960.0 & & & & & $3.00-9$ & 75. & 50. \\
\hline & & & 14.000 & 1200.0 & & & & & $3.00-9$ & 250. & 0. \\
\hline & & & 21.000 & 3500.0 & & & & & $3.00-9$ & & 38. \\
\hline & & & 21.000 & 1400.0 & 1400.0 & 42.000 & 2900.0 & 2000.0 & $3.00-9$ & & \\
\hline & & & 21.000 & 1300.0 & & & & & $3.00-9$ & 38. & 75. \\
\hline \multirow[t]{3}{*}{ Cs } & room & air & 21.000 & 1100.0 & & & & & $3.00-9$ & 75. & \\
\hline & & & 23.000 & 1200.0 & & & & & $3.00-9$ & 250. & \\
\hline & & & 42.000 & 1800.0 & 1800.0 & 21.000 & 2100.0 & 2100.0 & 3.00-9. & & \\
\hline
\end{tabular}




\section{Element Temp Atm Stime ord1 ard2 dtime drd1 drd2 Conc pmin pmax}

\section{Core}

G1-1982

Eu room air 14.0001200 .0

14.000530 .0

$14.000 \quad 610.0$

14.000860 .0

$21.000 \quad 2500.0$

$21.000 \quad 1500.0$

21.000880 .0

$21.000 \quad 1300.0$

21.0001100 .0

$42.000 \quad 2000.0$

$\begin{array}{lll}1300.0 \quad 42.000 & 6100.0 \\ 1900.0 & 21.000 \quad 800.0\end{array}$

$\begin{array}{llllll}\text { Se } & \text { room air } & 42.000 & 2.7 & 2.4\end{array}$

Sr room air $14.000 \quad 1200.0$

$14.000 \quad 59.0$

$14.000 \quad 49.0$

$14.000 \quad 51.0$

$21.000 \quad 1200.0$

$21.000 \quad 430.0$

$21.000 \quad 66.0$

Sr room air $21.000 \quad 53.0$

$21.000 \quad 66.0$

$42.000 \quad 450.0$

$\begin{array}{lllll}U & \text { room air } \quad 42.000 \quad 2.5\end{array}$ $\begin{array}{lll}450.0 & 21.000 & 310.0\end{array}$

$2.3 \quad 42.000$
1.00-7. 38.

1.00-7. 38. 75 .

1.00-7. 75. 250.

1.00-7. 250. 500 .

1.00-7. 38.

1.00-7. 500.

1.00-7. 38. 75 .

1.00-7. 75. 250.

1.00-7. 250. 500 .

1.00-7. 500 .
1.80-11. 75. 500 .

2.00-7. 38.

2.00-7. 38. 75 .

2.00-7. 75. 250 .

2.00-7. 250. 500 .

2.00-7.

38.

430.0

$42.000 \quad 340.0$

330.0

2.00-7. 500.

2.00-7. 38. 75 .

2.00-7. 75. 250 .

2.00-7. 250. 500 .

$310.0 \quad 2.00-7 . \quad 500$.

$4.1 \quad 2.70-6.75 . \quad 500$.

Core

G1-2233

Ba room air $21.000 \quad 200000.0 \quad 210000.0 \quad 42.000 \quad 460000.0 \quad 100000.0 \quad 6.02-6$. 500. $\begin{array}{lllllll}42.000 & 330000.0 & 250000.0 & 21.000 & 160000.0 & 220000.0 & 6.00-6 .\end{array}$ 500.

$\begin{array}{lllllllll}\text { Ce room air } & 21.000 & 840.0 & 1300.0 & 42.000 & 59000.0 & 14000.0 & 7.00-8 \text {. }\end{array}$ 500. $\begin{array}{lllllll}42.000 & 2100.0 & 1200.0 & 21.000 & 2200.0 & 4900.0 & 7.00-8 .\end{array}$ 500. 
Element Temp Atm Stime srd1 srd2 dtime drd1 drd2 Conc pmin pmax

Core

G1-2233 $\begin{array}{llllllllll}\text { Cs room air } & 21.000 & 13000.0 & 11000.0 & 42.000 & 31000.0 & 29000.0 & 3.00-9 . & 500 . \\ & & 42.000 & 15000.0 & 14000.0 & 21.000 & 6500.0 & 25000.0 & 3.00-9 . & 500 .\end{array}$

$\begin{array}{llllllllll}\text { Eu room air } & 21.000 & 520.0 & 920.0 & 42.000 & 3900.0 & 9400.0 & 9.00-8 . & 500 .\end{array}$

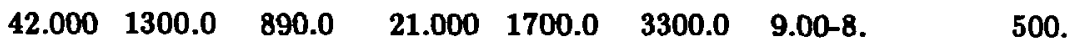

$\begin{array}{llllllll}\text { Mn room air } & 14.000 & 5800.0 & 28.000 & 9300.0 & 2.00-11 & 500 .\end{array}$

$\begin{array}{llllll}21.000 & 6800.0 & 28.000 & 10000.0 & 2.00-11 . & 500 \text {. }\end{array}$

$28.0006400 .0 \quad 2.00-11 . \quad 500$.

$28.0005000 .0 \quad 2.00-11$.

$\begin{array}{lllllllll}\text { room ca } & 14.000 & 2600.0 & 2300.0 & 28.000 & 1600.0 & 1400.0 & 2.00-11 . & 500 .\end{array}$

$\begin{array}{llllllll}28.000 & 550.0 & 710.0 & 14.000 & 3400.0 & 2800.0 & 2.00-11 . & 500 .\end{array}$

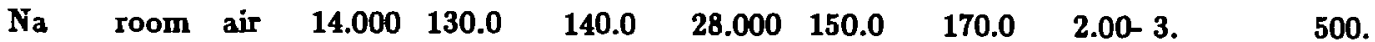

$28.000150 .0 \quad 2.00-3 . \quad 500$.

$28.000140: 0 \quad 2.00-3 . \quad 500$.

$\begin{array}{lllllllll}\text { room ca } & 14.000 & 140.0 & 150.0 & 28.000 & 150.0 & 170.0 & 2.00-3 . & 500 \text {. }\end{array}$

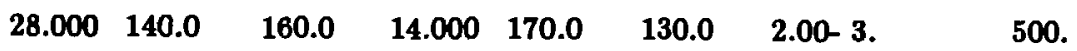

$\begin{array}{llllllll}\text { Se room air } & 14.000 & 16.0 & 28.000 & 51.0 & 1.00-9 . & 500 .\end{array}$

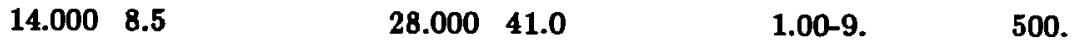

$\begin{array}{llll}28.000 & 8.7 & 1.00-9 . & 500 .\end{array}$

$28.00010 .0 \quad 1.00-9 . \quad 500$.

$\begin{array}{llllll}42.000 & 1.8 & 1.7 & 1.80-11 . & 75 . & 500 .\end{array}$

$\begin{array}{lllllllllll}\text { room ca } & 14.000 & 6.6 & 21.0 & 28.000 & 63.0 & 72.0 & 1.00-9 . & 500 . \\ & & 28.000 & 9.5 & 18.0 & 14.000 & 200.0 & 58.0 & 1.00-9 . & 500 . \\ \text { Co2 } & 56.000 & .8 & 1.2 & & & & 1.80-10 . & 75 . & 500 .\end{array}$

$\begin{array}{llllllllll}\text { Sn } & \text { room air } & 14.000 & 480.0 & 840.0 & 28.000 & 650.0 & 500.0 & 3.00-8 . & 500 .\end{array}$

$28.000250 .0 \quad 3.00-8 . \quad 500$.

$28.000280 .0 \quad 3.00-8 . \quad 500$. 


\section{Element Temp Atm Stime srd1 srd2 dtime drd1 drd2 Conc pmin pmax}

\section{Core}

G1-2233

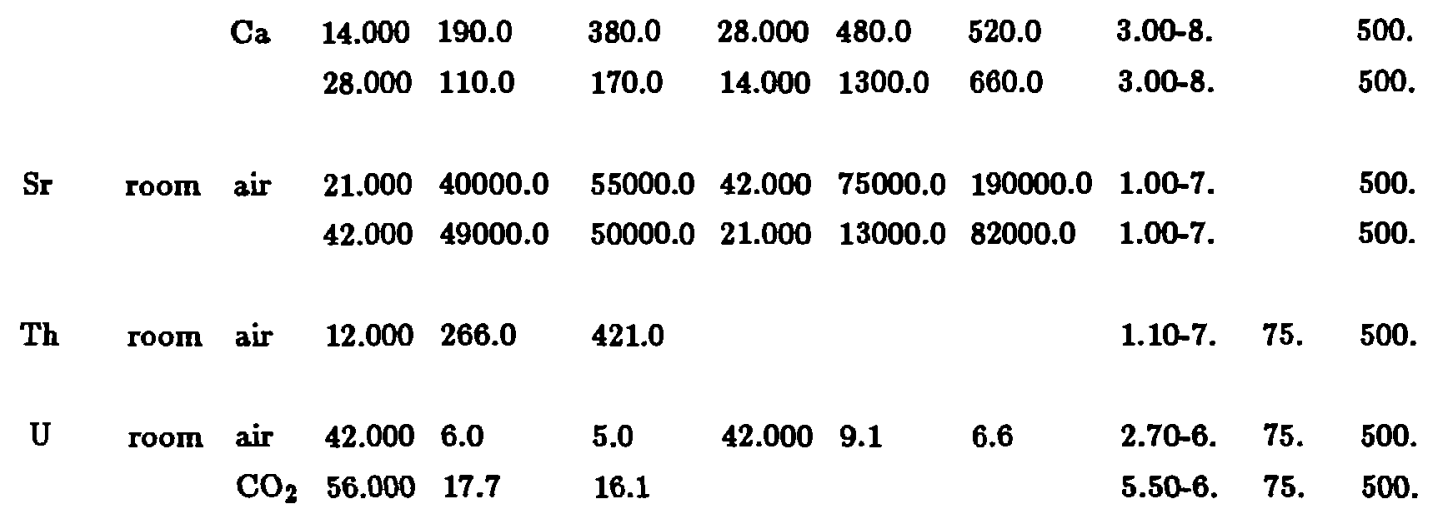

Core

G1-2278

$\begin{array}{lllllllll}\text { Mn room air } & 14.000 & 10000.0 & 10000.0 & 28.000 & 10000.0 & 10000.0 & 1.00-11 . & 500\end{array}$

\section{Core \\ G1-2289}

$\begin{array}{rll}\text { Ba room air } \quad 21.000 & 110000.0 \\ & 21.000 & 170000.0 \\ 21.000 & 54000.0 \\ 21.000 & 48000.0 \\ 21.000 & 90000.0 \\ 21.000 & 70000.0\end{array}$

Cs room air $21.000 \quad 43000.0$

$21.000 \quad 27000.0$

$21.000 \quad 34000.0$

21.00029000 .0

21.00072000 .0

$21.000 \quad 12000.0$

Eu room air $21.000 \quad 1400.0$

$21.000 \quad 1600.0$

21.000780 .0
1.00- 7 . $\quad 38$.

1.00- 7 . $\quad 38$.

1.00- 7. 38. 106.

1.00- 7. 38. 106.

1.00-7. 106. 500 .

1.00-7. 106. 500 .

4.00-9.

38.

4.00- 9.

38.

4.00- 9 . 38. 106.

4.00- 9 . 38. 106 .

4.00- 9. 106. 500 .

4.00-9. 106. 500 .

2.00-8.

38.

2.00- 8 .

38.

2.00-8. 38. 106 . 


Element Temp Atm Stime srd1 srd2 dtime drd1 drd2 Conc pmin pmax

\section{Core}

G1-2289

$$
\begin{array}{ll}
21.000 & 820.0 \\
21.000 & 810.0
\end{array}
$$

\begin{tabular}{|c|c|c|c|c|}
\hline room air & 14.000230 .0 & 220.0 & 28.000 & 230.0 \\
\hline
\end{tabular}

Mn room air $28.000 \quad 6000.0 \quad 7300.0 \quad 14.000>10000.0>10060.0 \quad 1.00-11.500$.

$\begin{array}{lllllll}28.000 & 230.0 & 230.0 & 14.000 & 260.0 & 270.0 & 3.00-3\end{array}$

Ra room air $\quad 42.000 \quad 70000.0 \quad 22000.0$

Se room air

$\begin{array}{lllll}14.000 & 24.0 & 8.8 & 28.000 & 21.0 \\ 28.000 & 10.0 & 12.0 & 14.000 & 58.0 \\ 42.000 & 9.0 & 8.0 & & \end{array}$

Sn room air

14.0001100 .0

28.000550 .0

560.0

640.0

$28.000 \quad 1000.0$

$14.000 \quad 1400.0$

1000.0

Sr room ai

$$
\begin{array}{ll}
21.000 & 12000.0 \\
21.000 & 17000.0 \\
21.000 & 6300.0 \\
21.000 & 6400.0 \\
21.000 & 8400.0 \\
21.000 & 7800.0
\end{array}
$$

$\begin{array}{lllll}\text { Th } & \text { room air } & 12.000 & 140.0 & 146.0\end{array}$

$\begin{array}{llllll}\mathrm{U} & \text { room } & \text { air } & 42.000 & 2.5 & 2.6\end{array}$

21.000820 .0

21.000810 .0
1500.0

2.00-8. 106 . 500 .

2.00-8. 106. 500 .

3.60-7. $75 . \quad 500$.

32.0

8.00-10.

500.

8.00-10.

500.

1.00-10. 75. 500 .

1.00-8.

500.

1.00-8.

500.

3.00-8.

38.

3.00-8.

38.

3.00-8. 38. 106.

3.00-8. 38. 106.

3.00-8. 106. 500 .

3.00-8. 106. 500 .

5.90-8. $75 . \quad 500$.

5.00-6. 75. 500 .

2.00-8 106 . 500 .

$2.00-8$ 106. 500 . 
Element Temp Atm Stime srd1 srd2 dtime drd1 drd2 Conc pmin pmax

\section{$\underline{\text { Core }}$}

G1-2333

\begin{tabular}{|c|c|c|c|c|c|c|c|c|}
\hline \multirow[t]{4}{*}{$\mathrm{Ba}$} & room air & 21.000 & 1900.0 & 42.000 & 1700.0 & $3.00-7$ & & 75. \\
\hline & & 21.000 & 1200.0 & 42.000 & 1400.0 & $3.00-7$ & 75. & 500. \\
\hline & & 42.000 & 1800.0 & 21.000 & 1600.0 & $3.00-7$ & & 75. \\
\hline & & 42.000 & 1100.0 & 21.000 & 1100.0 & $3.00-7$ & 75. & 500. \\
\hline \multirow[t]{4}{*}{ Cs } & room air & 21.000 & 1700.0 & 42.000 & 1400.0 & 5.00-9. & & 75. \\
\hline & & 21.000 & 1200.0 & 42.000 & 1100.0 & 5.00-9. & 75. & 500. \\
\hline & & 42.000 & 1500.0 & 21.000 & 1300.0 & $5.00-9$ & & 75. \\
\hline & & 42.000 & 1100.0 & 21.000 & 1000.0 & $5.00-9$ & 75. & 500. \\
\hline \multirow[t]{4}{*}{$\mathbf{E u}$} & room air & 21.000 & 2000.0 & 21.000 & 1200.0 & $3.00-8$ & & 75. \\
\hline & & 21.000 & 1400.0 & 42.000 & 9800.0 & $3.00-8$ & 75. & 500. \\
\hline & & 42.000 & 3100.0 & 21.000 & 11000.0 & $3.00-8$ & & 75. \\
\hline & & 42.000 & 2900.0 & 21.000 & 6800.0 & $3.00-8$ & 75. & 500. \\
\hline \multirow[t]{4}{*}{$\mathrm{Sr}$} & room air & 21.000 & 220.0 & 42.000 & 160.0 & $1.00-6$ & & 75. \\
\hline & & 21.000 & 150.0 & 42.000 & 130.0 & $1.00-6$ & 75. & 500. \\
\hline & & 42.000 & 220.0 & 21.000 & 160.0 & $1.00-6$ & & 75. \\
\hline & & 42.000 & 140.0 & 21.000 & 110.0 & $1.00-6$ & 75. & 500. \\
\hline
\end{tabular}

Core

G1-2363

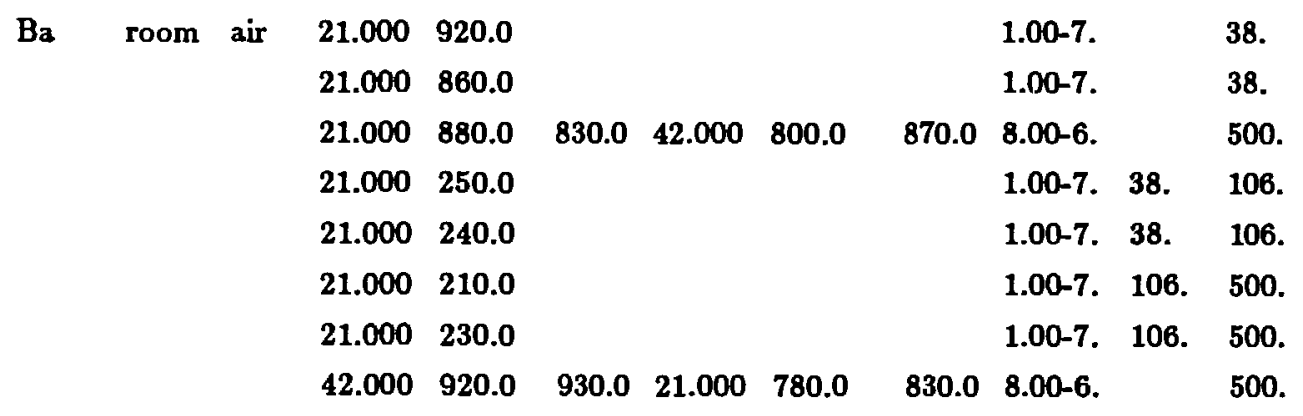


Element Temp Atm Stime srd1 srd2 dtime drd1 drd2 Conc pmin pmax

\section{Core}

G1-2363

\begin{tabular}{|c|c|c|c|c|c|c|c|c|c|c|}
\hline \multirow[t]{2}{*}{$\mathrm{Ce}$} & \multirow[t]{2}{*}{ room air } & 21.000 & 290.0 & 270.0 & 42.000 & 140000.0 & 120000.0 & \multicolumn{2}{|l|}{$3.00-8$} & \multirow{2}{*}{$\begin{array}{l}500 . \\
500 .\end{array}$} \\
\hline & & 42.000 & 370.0 & 310.0 & 21.000 & 139999.0 & 130000.0 & $3.00-8$ & & \\
\hline \multirow[t]{8}{*}{ Cs } & room air & 21.000 & 1400.0 & & & & & $4.00-9$ & & 38. \\
\hline & & 21.000 & 1300.0 & & & & & 4.00-9. & & 38. \\
\hline & & 21.000 & 1300.0 & 1200.0 & 42.000 & 1200.0 & 1300.0 & $7.00-9$ & & 500. \\
\hline & & 21.000 & 520.0 & & & & & 4.00-9. & 38. & 106. \\
\hline & & 21.000 & 550.0 & & & & & $4.00-9$ & 38. & 106. \\
\hline & & 21.000 & 380.0 & & & & & 4.00-9. & 106. & 500. \\
\hline & & 21.000 & 410.0 & & & & & $4.00-9$ & 106. & 500. \\
\hline & & 42.000 & 1400.0 & 1400.0 & 21.000 & 1200.0 & 1200.0 & 7.00-9. & & 500. \\
\hline
\end{tabular}

Eu room air $21.000 \quad 5600.0$

5.00-8. $\quad 38$.

$21.0005400 .0 \quad 3.00-8 . \quad 38$.

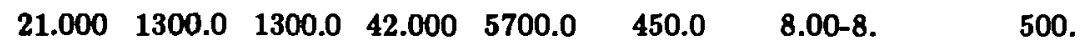

$\begin{array}{llllll}21.000 & 790.0 & 5.00-8 . & 38 . & 106 .\end{array}$

$21.000780 .0 \quad$ 5.00-8. 38.106.

$\begin{array}{llllll}21.000 & 580.0 & 5.00-8 . & 106 . & 500 \text {. }\end{array}$

$21.000780 .0 \quad 5.00-8 . \quad 106.500$.

$\begin{array}{llllllll}42.000 & 1900.0 & 1600.0 & 21.000 & 5900.0 & 6700.0 & 8.00-8 . & 500 \text {. }\end{array}$

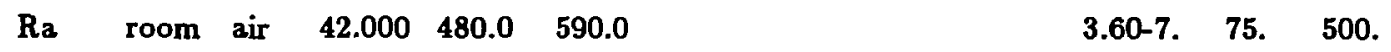

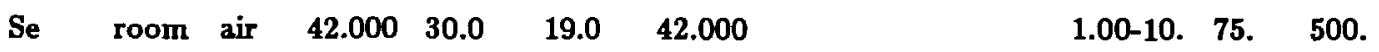

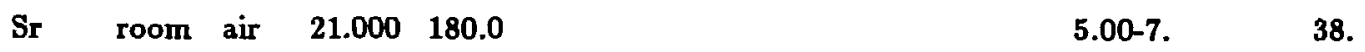

$21.000170 .0 \quad 5.00-7 . \quad 38$.

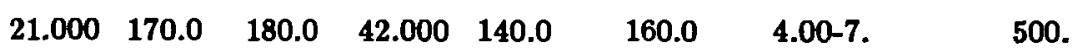

$21.00074 .0 \quad 5.00-7 . \quad 38 . \quad 106$.

$21.00062 .0 \quad 5.00-7.38 . \quad 106$.

$21.00058 .0 \quad 5.00-7 . \quad 106.500$.

$21.00061 .0 \quad 5.00-7 . \quad 106.500$.

$\begin{array}{llllllll}42.000 & 170.0 & 170.0 & 21.000 & 1400.0 & 150.0 & 4.00-7 & 500 .\end{array}$ 
Element Temp Atm Stime srd1 srd2 dtime drd1 drd2 Conc pmin pmax

Core

G1-2363

$\begin{array}{cccccc}\text { Th } & \text { room } & \text { air } & 12.000 & 940.0 & 1484.0 \\ \text { U } & \text { room } & \text { air } & 42.000 & -0.7 & 0.5\end{array}$

6.50-8. 75. 500 .

5.00-6. 75. 500 .

Core

G1-2410

$$
\begin{array}{lll}
\text { Ba room air } & 21.000 & \\
& 21.000 & \\
& 42.000 & 3000.0 \\
& 42.000 & 1800.0
\end{array}
$$

Cs room air $21.000 \quad 2000.0$

$21.000 \quad 1200.0$

$42.000 \quad 2000.0$

$42.000 \quad 1300.0$

Eu room air $21.000 \quad 390.0$

$21.000 \quad 360.0$

$42.000 \quad 440.0$

$42.000 \quad 510.0$

Sr room air $21.000 \quad 280.0$

$21.000 \quad 170.0$

$42.000 \quad 280.0$

$42.000 \quad 170.0$
$42.000 \quad 3000.0$

$42.000 \quad 1900.0$

$21.000 \quad 3000.0$

$21.000 \quad 1600.0$

$42.000 \quad 1800.0$

$42.000 \quad 1200.0$

$21.000 \quad 1800.0$

$1.000 \quad 1000.0$

$42.000 \quad 10000.0$

42.0008700 .0

$21.000 \quad 5700.0$

$21.000 \quad 3300.0$

42.000250 .0

$42.000 \quad 150.0$

$21.000 \quad 240.0$

21.000130 .0

2.00-7

75.

2.00-7. 75 . 500 .

2.00-7.

75.

2.00-7. 75. 500 .

4.00-9.

75.

4.00-9. 75. 500 .

4.00-9.

75.

4.00-9. 75. 500 .

2.00-8.

75.

2.00-8. 75. 500 .

2.00-8.

75.

2.00-8. 75. 500 .

4.00-7.

75.

4.00-7. 75. 500 .

4.00-7.

75.

4.00-7. 75 . 500 .

\section{Core}

G1-2476

$\begin{array}{rrr}\text { Ba room air } \quad 21.000 & 480.0 \\ & 21.000 & 370.0 \\ & 42.000 & 520.0 \\ & 42.000 & 400.0\end{array}$

$42.000 \quad 3200.0$

1.00-7.

75.

$42.000 \quad 3800.0$

1.00-7. 75 . 500 .

$21.000 \quad 3500.0$

1.00-7.

75.

$21.000 \quad 3600.0$

1.00-7. 75. 500. 


Element Temp Atm Stime srd1 srd2 dtime drd1 drd2 Conc pmin pmax

Core

G1-2476

\begin{tabular}{|c|c|c|c|c|c|c|c|c|c|}
\hline \multirow[t]{4}{*}{ Cs } & room & air & 21.000 & 810.0 & 42.000 & 1600.0 & 5.00-9. & & 75. \\
\hline & & & 21.000 & 660.0 & 42.000 & 1500.0 & $5.00-9$ & 75. & 500. \\
\hline & & & 42.000 & 920.0 & 21.000 & 1800.0 & 5.00-9. & & 75. \\
\hline & & & 42.000 & 740.0 & 21.000 & 1500.0 & $5.00-9$ & 75. & 500. \\
\hline \multirow[t]{4}{*}{ Eu } & room & air & 21.000 & 4600.0 & 42.000 & 9300.0 & $6.00-8$ & & 75. \\
\hline & & & 21.000 & 3300.0 & 42.000 & 15000.0 & $6.00-8$ & 75. & 500. \\
\hline & & & 42.000 & 5100.0 & 21.000 & 12000.0 & $6.00-8$ & 75. & \\
\hline & & & 42.000 & 3100.0 & 21.000 & 15000.0 & $6.00-8$ & 75. & 500. \\
\hline \multirow[t]{4}{*}{ Sr } & room & air & 21.000 & 49.0 & 42.000 & 200.0 & $9.00-7$ & & 75. \\
\hline & & & 21.000 & 41.0 & 42.000 & 210.0 & $9.00-7$ & 75. & 50. \\
\hline & & & 42.000 & 51.0 & 21.000 & 220.0 & $9.00-7$ & & 5. \\
\hline & & & 42.000 & 40.0 & 21.000 & 200.0 & $9.00-7$ & 75. & 500. \\
\hline
\end{tabular}

\section{Core}

G1-2689

$\begin{array}{cccccccccccc}\text { U } & \text { room } & \text { air } & 42.000 & 4.2 & 4.5 & 42.000 & 1.3 & 1.7 & 2.70-6 . & 75 . & 500 . \\ \text { Ba } & \text { room } & \text { air } & 21.000 & 61000.0 & 56000.0 & 42.000 & 47000.0 & 390000.0 & 8.00-6 . & 500 . \\ & & & 42.000 & 77000.0 & 58000.0 & 21.000 & 62000.0 & 270000.0 & 8.00-6 . & 500 . \\ & & & & & & & & & & \\ \text { Ce } & \text { room } & \text { air } & 21.000 & 220.0 & 170.0 & 42.000 & 2800.0 & 2400.0 & 1.00-7 . & 500 . \\ & & & 42.000 & 270.0 & 310.0 & 21.000 & 1600.0 & 1200.0 & 1.00-7 . & 500 . \\ & & & & & & & & & & & \\ \text { Cs } & \text { room } & \text { air } & 21.000 & 8200.0 & 7400.0 & 42.000 & 15000.0 & 16000.0 & 5.00-9 . & 500 . \\ & & & 42.000 & 8500.0 & 6600.0 & 21.000 & 20000.0 & 17000.0 & 5.00-9 . & 500 . \\ & & & & & & & & & & \\ \text { Eu } & \text { room } & \text { air } & 21.000 & 180.0 & 130.0 & 42.000 & 2100.0 & 1900.0 & 4.00-7 . & 500 . \\ & & & 42.000 & 230.0 & 260.0 & 21.000 & 1000.0 & 850.0 & 4.00-7 . & 500 .\end{array}$


Element Temp Atm Stime srd1 srd2 dtime drd1 drd2 Cone pmin pmax

\section{Core}

G1-2689

$\begin{array}{llllllllllll}\text { Se } & \text { room } & \mathrm{CO}_{2} & 42.000 & 2.82 & 2.59 & & & & 1.90-9 & 75 . & 500 . \\ & & & & & & & & & & & \\ \mathrm{Sr} & \text { room } & \text { air } & 21.000 & 49000.0 & 39000.0 & 42.000 & 200000.0 & 170000.0 & 2.00-7 . & 500 . \\ & & & 42.000 & 43000.0 & 37000.0 & 21.000 & 350000.0 & 130000.0 & 2.00-7 . & 500 . \\ & & & & & & & & & & & \\ \text { U } & \text { room } & \mathrm{CO}_{2} & 42.000 & 17.9 & 18.6 & & & & 1.07-6 & 75 . & 500 .\end{array}$

Core

G1-2840

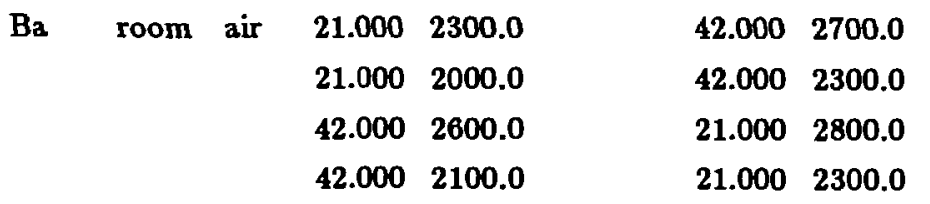

Cs $\quad$ room air $21.000 \quad 49.0 \quad 45.0$

$21.000 \quad 65.0 \quad 68.0$

$21.000 \quad 24.0 \quad 25.0$

$21.000 \quad 182.0 \quad 179.0$

$21.000 \quad 371.0 \quad 366.0$

$\begin{array}{lll}21.000 & 942.0 & 961.0\end{array}$

$\begin{array}{lll}21.000 & 1330.0 & 1580.0\end{array}$

$\begin{array}{lll}21.000 & 1430.0 & 1130.0\end{array}$

$\begin{array}{lll}21.000 & 19.0 \quad 21.0\end{array}$

$21.00078 .0 \quad 81.0$

$21.00031 .0 \quad 32.0$

$\begin{array}{lll}21.000 & 1170.0 & 1060.0\end{array}$

21.0002800 .0

$21.000 \quad 2400.0$

$42.000 \quad 2500.0$

42.0002000 .0 $\begin{array}{ll} & \\ & \\ & \\ & \\ & \\ & \\ & \\ & \\ & \\ & \\ & \\ 42.000 & 2500.0 \\ 42.000 & 2000.0 \\ 21.000 & 2500.0 \\ 21.000 & 2100.0\end{array}$
2.00-7.

75.

2.00-7. 75 . 500 .

2.00-7.

75.

2.00-7. 75 . 500 .

6.30-5. 75. 500 .

1.60-5. 75 . 500 .

6.30-4. 75 . 500 .

1.60-6. 75. 500 .

6.30-7. 75. 500 .

1.30-7. 75. 500 .

6.98-9. 75. 500 .

1.80-9. 75. 500 .

1.30-3. 75. 500 .

6.30-6. 75. 500 .

1.60-4. 75. 500 .

6.30-8. 75. 500 .

5.00-9.

75.

5.00-9. 75 . 500 .

5.00-9. 75 .

5.00-9. 75. 500 . 


\section{Core}

G1-2840

\begin{tabular}{|c|c|c|c|c|c|c|c|c|c|c|c|}
\hline \multirow[t]{4}{*}{ Eu } & \multirow[t]{4}{*}{ room } & \multirow[t]{4}{*}{ air } & 21.000 & \multicolumn{2}{|l|}{5000.0} & 42.000 & \multicolumn{2}{|l|}{12000.0} & \multicolumn{2}{|l|}{$3.00-8$} & \multirow{2}{*}{$\begin{array}{l}75 . \\
500 .\end{array}$} \\
\hline & & & 21.000 & 4500.0 & & 42.000 & 8000.0 & & $3.00-8$ & 75. & \\
\hline & & & 42.000 & 6200.0 & & 21.000 & 7900.0 & & $3.00-8$ & & 75. \\
\hline & & & 42.000 & 5300.0 & & 21.000 & 7900.0 & & $3.00-8$ & 75. & 500. \\
\hline \multirow[t]{2}{*}{$\mathrm{Se}$} & room & air & 42.000 & 2.8 & 3.4 & & & & $1.80-11$ & 75. & 500. \\
\hline & & $\mathrm{CO}_{2}$ & 56.000 & 1.5 & 1.9 & & & & $1.80-10$ & 75. & 500. \\
\hline Sn & room & air & 42.000 & 124.0 & 442.0 & 42.000 & 910.0 & 650.0 & $2.00-8$ & 75. & 500. \\
\hline \multirow[t]{8}{*}{$\mathrm{Sr}$} & room & air & 21.000 & 61.7 & 61.2 & & & & $2.80-6$ & 75. & 500. \\
\hline & & & 21.000 & 9.2 & 9.7 & & & & $1.40-3$ & 75. & 500. \\
\hline & & & 21.000 & 39.5 & 38.1 & & & & $2.10-4$ & 75. & 500. \\
\hline & & & 21.000 & 47.0 & 51.0 & & & & $7.70-5$ & 75. & 500. \\
\hline & & & 21.000 & 30.5 & 30.7 & & & & $3.30-4$ & 75. & 500. \\
\hline & & & 21.000 & 55.3 & 56.4 & & & & $2.40-5$ & 75. & 500. \\
\hline & & & 21.000 & 56.7 & 57.1 & & & & $1.20-5$ & 75. & 500. \\
\hline & & & 21.000 & 59.0 & 57.0 & & & & 8.10-7. & 75. & 500. \\
\hline \multirow[t]{8}{*}{$\mathbf{S} \mathbf{r}$} & room & air & 21.000 & 21.9 & 19.9 & & & & $6.00-4$ & 75. & 500. \\
\hline & & & 21.000 & 14.8 & 15.9 & & & & $8.50-4$ & 75. & 500. \\
\hline & & & 21.000 & 46.6 & 47.3 & & & & $8.30-5$ & 75. & 500. \\
\hline & & & 21.000 & 59.6 & 63.6 & & & & $1.40-6$ & 75. & 500. \\
\hline & & & 21.000 & 170.0 & & 42.000 & 150.0 & & $1.00-6$ & & 75. \\
\hline & & & 21.000 & 160.0 & & 42.000 & 130.0 & & $1.00-6$ & 75. & 500. \\
\hline & & & 42.000 & 170.0 & & 21.000 & 160.0 & & $1.00-6$ & & 75. \\
\hline & & & 42.000 & 159.0 & & 21.000 & 130.0 & & $1.00-6$ & 75. & 500. \\
\hline Th & room & $\mathrm{CO}_{2}$ & 42.000 & 3900 & 2600 & & & & $2.20-7$ & 75. & 500. \\
\hline \multirow[t]{2}{*}{$\mathrm{U}$} & room & air & 42.000 & 0.3 & 0.7 & 42.000 & & & $2.70-6$ & 75. & 500. \\
\hline & & $\mathrm{CO}_{2}$ & 56.000 & 3.9 & 4.5 & & & & $5.50-6$ & 75. & 500. \\
\hline
\end{tabular}


Element Temp Atm Stime srd1 srd2 dtime drd1 drd2 Conc pmin pmax

Core

G1-2854

\begin{tabular}{|c|c|c|c|c|c|c|c|c|c|}
\hline \multirow[t]{4}{*}{$\mathbf{B a}$} & \multirow[t]{4}{*}{ room } & \multirow[t]{4}{*}{ air } & 21.000 & 1600.0 & 42.000 & 3700.0 & $1.00-7$ & & 75. \\
\hline & & & 21.000 & 950.0 & 42.000 & 1300.0 & $1.00-7$ & \multirow[t]{2}{*}{75.} & 500. \\
\hline & & & 42.000 & 6500.0 & 21.000 & 1600.0 & $1.00-7$ & & 75. \\
\hline & & & 42.000 & 1000.0 & 21.000 & 1300.0 & $1.00-7$ & 75. & 500. \\
\hline \multirow[t]{4}{*}{$\mathrm{Cs}$} & \multirow[t]{4}{*}{ room } & \multirow[t]{4}{*}{ air } & 21.000 & 1700.0 & 42.000 & 1900.0 & 5.00-9. & & 75. \\
\hline & & & 21.000 & 1200.0 & 42.000 & 1100.0 & $5.00-9$ & \multirow[t]{2}{*}{75 . } & 500. \\
\hline & & & 42.000 & 510.0 & 21.000 & 1300.0 & 5.00-9. & & 75. \\
\hline & & & 42.000 & 950.0 & 21.000 & 1200.0 & 5.00-9. & 75. & 500. \\
\hline \multirow[t]{4}{*}{$\mathbf{E u}$} & \multirow[t]{4}{*}{ room } & \multirow[t]{4}{*}{ air } & 21.000 & 1100.0 & 42.000 & 7200.0 & $2.00-8$ & & 75. \\
\hline & & & 21.000 & 1100.0 & 42.000 & 4800.0 & $2.00-8$ & \multirow[t]{2}{*}{75.} & 500. \\
\hline & & & 42.000 & 2600.0 & 21.000 & 3100.0 & $2.00-8$ & & 75. \\
\hline & & & 42.000 & 1500.0 & 21.000 & 5200.0 & $2.00-8$ & 75. & 500. \\
\hline \multirow[t]{4}{*}{ Sr } & \multirow[t]{4}{*}{ room } & \multirow[t]{4}{*}{ air } & 21.000 & 120.0 & 42.000 & 130.0 & $5.00-7$ & & 75. \\
\hline & & & 21.000 & 94.0 & 42.000 & 96.0 & 5.00-7 & \multirow[t]{2}{*}{75.} & 300. \\
\hline & & & 42.000 & 60.0 & 21.000 & 92.0 & $5.00-7$ & & 75. \\
\hline & & & 42.000 & 93.0 & 21.000 & 97.0 & 5.00-7. & 75. & 600. \\
\hline
\end{tabular}

\section{Core}

G1-2901

$$
\begin{array}{llllllllllll}
\text { Ba } & \text { room } & \text { air } & 21.000 & 1900.0 & 1200.0 & 42.000 & 1900.0 & 2000.0 & 1.00-6 . & 500 . \\
& & & 42.000 & 1900.0 & 1900.0 & 21.000 & 2000.0 & 2000.0 & 1.00-6 . & 500 . \\
& & & & & & & & & & \\
\text { Ce } \quad \text { room } & \text { air } & 21.000 & 40000.0 & 35000.0 & 42.000 & 38000.0 & 40000.0 & 9.00-9 . & 500 . \\
& & & 42.000 & 45000.0 & 49000.0 & 21.000 & 37000.0 & 40000.0 & 9.00-9 . & 500 . \\
& & & & & & & & & & \\
\text { Cs } \quad \text { room } & \text { air } & 21.000 & 1400.0 & 950.0 & 42.000 & 1300.0 & 1400.0 & 6.00-9 . & 500 . \\
& & & 42.000 & 1400.0 & 1400.0 & 21.000 & 1400.0 & 1400.0 & 6.00-9 . & 500 .
\end{array}
$$




\section{Core}

G1-2901

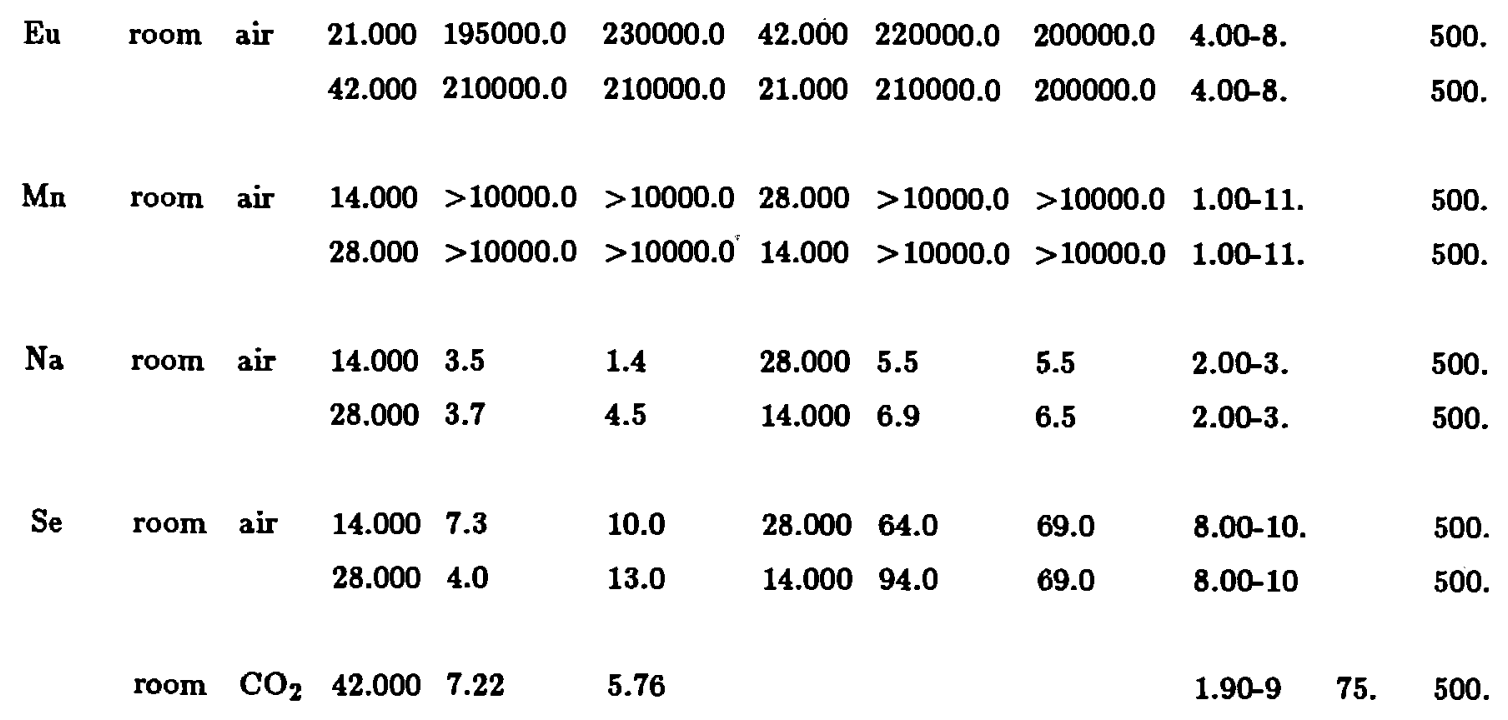

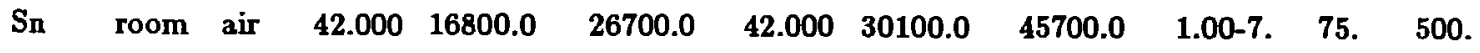 $14.000>10000.0>10000.028 .000>10000.0>10000.0$ 6.c.s.9. 500 . $28.000>10000.0>10000.014 .000>10000.0>10000.0 \quad 6.00-9$. $\quad 500$.

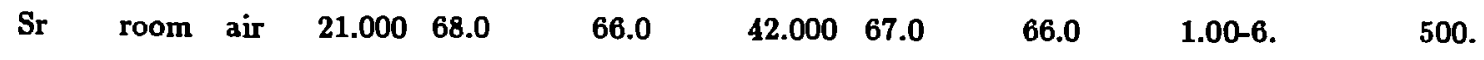

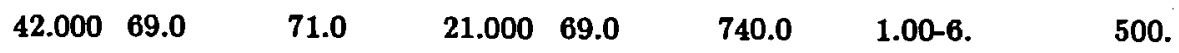

$\begin{array}{llllllll}\text { Th room } & \mathrm{CO}_{2} & 42.00 & 3700 & 3400 & 1.60-7 & 75 . & 500 .\end{array}$

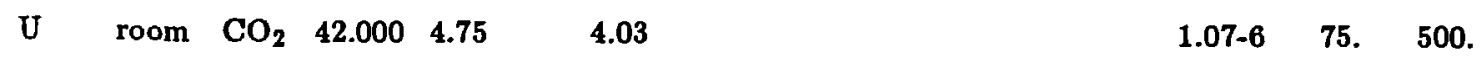

\section{Core}

G1-3116

$\begin{array}{llllllllll}\text { Ba room } & \text { air } & 21.000 & 120000.0 & 130000.0 & 42.000 & 23000.0 & 709999.0 & 9.00-6 . & 500 . \\ & & 42.000 & 120000.0 & 130000.0 & 21.000 & 280000.0 & 190000.0 & 9.00-6 . & 500\end{array}$ 
Element Temp Atm Stime srd1 srd2 dtime drd1 drd2 Conc pmin pmax

\section{Core}

G1-3116

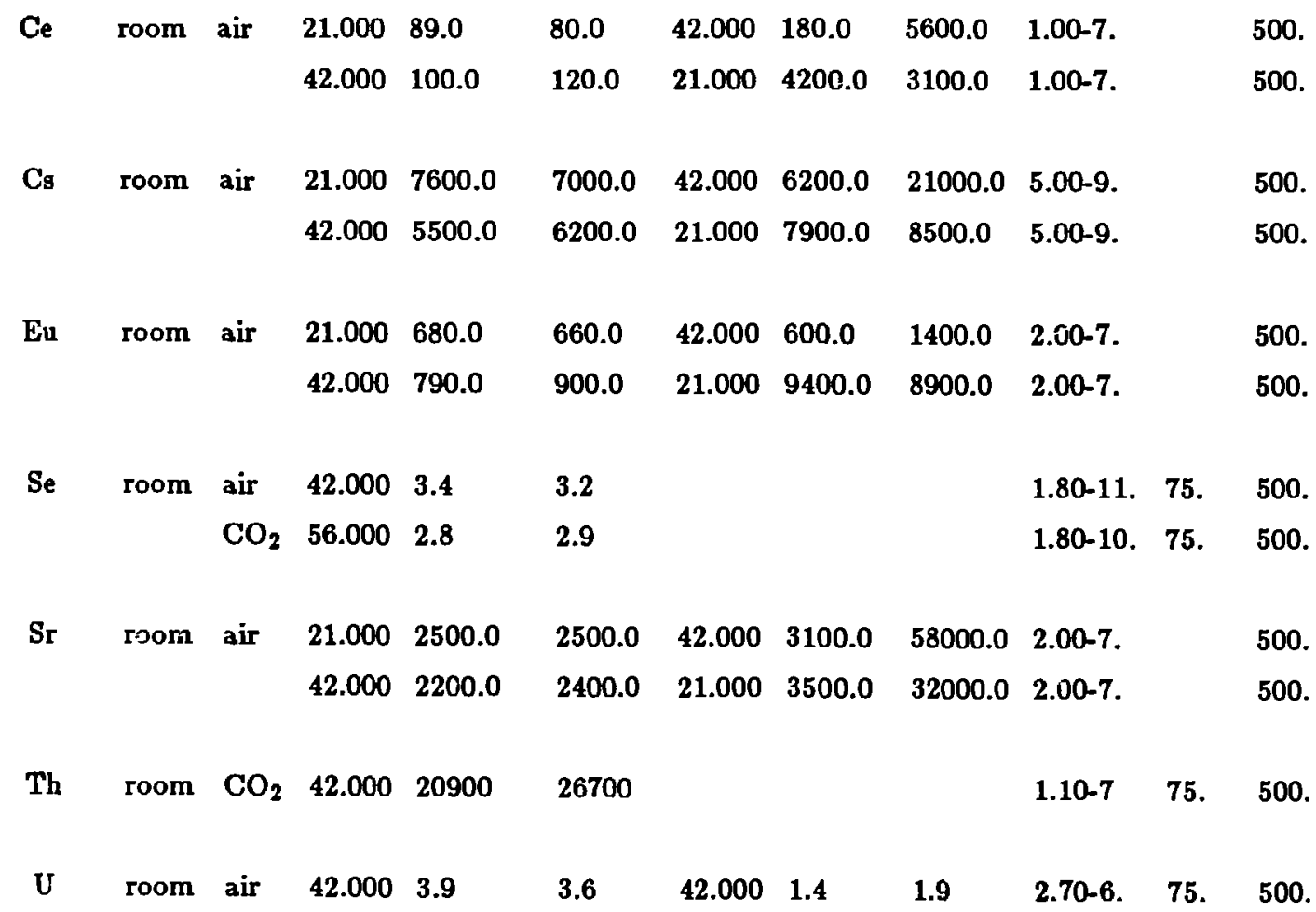

Core

G1-3658

\begin{tabular}{|c|c|c|c|c|c|c|c|c|c|}
\hline $\mathrm{Ba}$ room air & 21.000 & 120000.0 & & & & & $9.00-6$ & & 38. \\
\hline & 21.000 & 190000.0 & & & & & $9.00-6$. & & 38. \\
\hline & 21.000 & 8700.0 & 12000.0 & 42.000 & 3100.0 & 16000.0 & $9.00-6$ & & 500. \\
\hline & 21.000 & 100000.0 & & & & & $9.00-6$ & 38. & 106. \\
\hline & 21.000 & 90000.0 & & & & & $9.00-6$ & 38. & 106. \\
\hline & 21.000 & 130000.0 & & & & & $9.00-6$ & 106. & 500. \\
\hline & 21.000 & 140000.0 & & & & & $9.00-6$ & 106. & 500. \\
\hline & 42.000 & 12000.0 & 9000.0 & 21.000 & 19000.0 & 2100.0 & $9.00-6$ & & 500. \\
\hline
\end{tabular}

$\begin{array}{llllllllll}\text { Ce room air } & 21.000 & 640.0 & 630.0 & 42.000 & 790.0 & 6800.0 & 2.00-7 . & 500 .\end{array}$

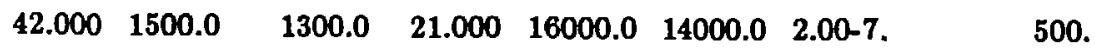


Element Temp Atm Stime srd1 srd2 dtime drd1 drd2 Conc pmin pmax

\section{Core}

G1-3658

Core

$\begin{array}{lllllllll}21.000 & 180000.0 & & & & 7.00-9 . & 38 . \\ 21.000 & 140000.0 & & & & 8.00-9 . & 38 . \\ 21.000 & 7800.0 & 8200.0 & 42.000 & 18000.0 & 10000.0 & 7.00-9 . & 500 . \\ 21.000 & 61000.0 & & & & 7.00-9 . & 38 . & 106 . \\ 21.000 & 70000.0 & & & 7.00-9 . & 38 . & 106 . \\ 21.000 & 49000.0 & & & 7.70-9 . & 106 . & 500 . \\ 21.000 & 50000.0 & & & & 7.00-9 . & 106 . & 500 . \\ 42.000 & 8500.0 & 7700.0 & 21.000 & 10000.0 & 11000.0 & 7.00-9 . & 500 .\end{array}$

$\begin{array}{lllll}\text { Eu room air } & 21.000 & 150000.0 & 4.00-7\end{array}$

$21.000160000 .0 \quad 4.00-7 . \quad 38$.

$\begin{array}{llllllll}21.000 & 510.0 & 490.0 & 42.000 & 700.0 & 6700.0 & 4.00-7 . & 500 .\end{array}$

$21.0004100 .0 \quad 4.00-7.33 .106$.

$21.0004800 .0 \quad$ 4.00-7. 38. 106.

$21.0004900 .0 \quad 4.00-7.106 .500$.

$21.0005700 .0 \quad 4.00-7.106 .500$.

$\begin{array}{llllllll}42.000 & 1200.0 & 1000.0 & 21.000 & 15000.0 & 12000.0 & 4.00-7 . & 500 \text {. }\end{array}$

$\begin{array}{llllll}\text { Sr } & \text { room air } & 21.000 & 98000.0 & 3.00-7 & 38\end{array}$

$21.000160000 .0 \quad 3.00-7 . \quad 38$.

$\begin{array}{llllllll}21.000 & 10000.0 & 14000.0 & 42.000 & 3500.0 & 14000.0 & 3.00-7 . & 500 .\end{array}$

$21.000140000 .0 \quad 3.00-7.38 .106$.

$21.000120000 .0 \quad 3.00-7.38 .106$.

$21.000130000 .0 \quad 3.00-7.106 .500$.

$21.000130000 .0 \quad 3.00-7.106 .500$.

$\begin{array}{llllllll}42.000 & 12000.0 & 11000.0 & 21.000 & 14000.0 & 17000.0 & 3.00-7 . & 500 \text {. }\end{array}$

G2-0547

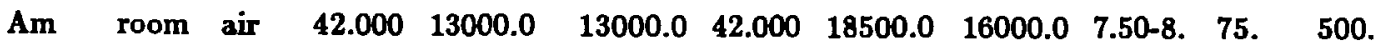




Element Temp Atm Stime srd1 srd2 dtime drd1 drd2 Conc pmin pmax

\section{Core}

G2-0547

\begin{tabular}{|c|c|c|c|c|c|c|c|c|c|c|}
\hline $\mathrm{Ba}$ & room & air & 42.000 & 3460.0 & 3520.0 & 42.000 & 3069.0 & 2740.0 & 7.30-8. & \\
\hline $\mathrm{Cs}$ & room & air & 42.000 & 11900.0 & 14800.0 & 42.000 & 9450.0 & 8360.0 & $4.80-9$ & \\
\hline Eu & room & air & 42.000 & 360.0 & 414.0 & 42.000 & 1070.0 & 2330.0 & 5.90-8. & \\
\hline $\mathrm{Pu}$ & room & air & 42.000 & 1100.0 & 1300.0 & 42.000 & 1100.0 & 1300.0 & 4.80-8. & 75. \\
\hline $\mathrm{Se}$ & room & air & 42.000 & 3.0 & 1.0 & & & & $1.00-10$ & 75. \\
\hline Sr & room & air & 42.000 & 256.0 & 275.0 & 42.000 & 217.0 & 195.0 & $2.60-6$ & \\
\hline Tc & room & air & 42.000 & 0.031 & -0.056 & 42.000 & 0 & 0 & $1.90-11$. & \\
\hline U & room & air & 42.000 & 9.4 & 9.5 & & & $5.00-6$ & & 75. \\
\hline
\end{tabular}

\section{$\underline{\text { Core }}$}

G2-0723

$\begin{array}{lllllllllll}\text { Am room air } \quad 42.000 & 930000.0 & 840000.0 & 42.000 & >999999.0 & >999999.0 & 9.30-8 . & 75 . & 500 \text {. }\end{array}$

$\begin{array}{llllllllll}\text { Ba room air } & 42.000 & 3930.0 & 3080.0 & 42.000 & 4200.0 & 4217.0 & 7.00-8 & 500 .\end{array}$

$\begin{array}{llllllllll}\text { Cs room air } & 42.000 & 4620.0 & 3530.0 & 42.000 & 4280.0 & 4276.0 & 5.00-9 & 500 .\end{array}$

$\begin{array}{lllllllll}\text { Eu room air } & 42.000 & 10000.0 & 10000.0 & 42.000 & 10000.0 & 10000.0 & 3.00-8 . & 500 \text {. }\end{array}$

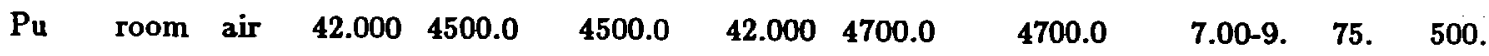

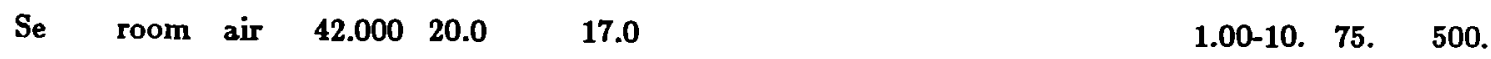

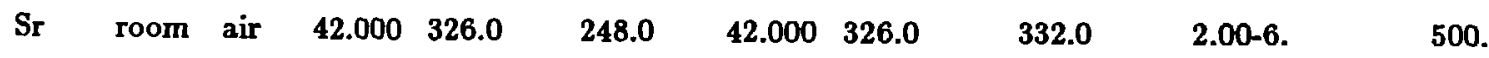


Element Temp Atm Stime srd1 srd2 dtime drd1 drd2 Conc pmin pmax

\section{Core}

G2-0723

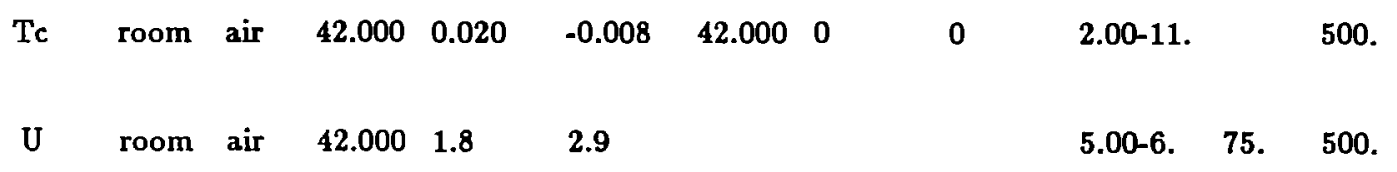

\section{Core}

G2-1952

\begin{tabular}{|c|c|c|c|c|c|c|c|c|c|c|c|}
\hline Am & room & air & 42.000 & 1700.0 & 1500.0 & 42.000 & 7100.0 & 8100.0 & $1.40-7$ & 75. & 500. \\
\hline & & & 42.000 & 1850.0 & 1700.0 & 42.000 & 4000.0 & 3800.0 & $1.40-7$ & 75. & 500. \\
\hline $\mathrm{Ba}$ & room & air & 42.000 & 21500.0 & 28700.0 & 42.000 & 46050.0 & 34400.0 & $7.00-8$ & & 500. \\
\hline ss & room & air & 42.000 & 61300.0 & 63400.0 & 42.000 & 47070.0 & 44650.0 & $5.00-9$ & & 500. \\
\hline Eu & room & air & 42.000 & 75.0 & 103.0 & 42.000 & 1770.0 & 1470.0 & $7.00-8$ & & 500. \\
\hline $\mathrm{Np}$ & room & air & 42.000 & 2.8 & 2.6 & 42.000 & 17.0 & 13.0 & 7.10-9. & 75. & 300. \\
\hline u & room & air & 42.000 & 72.0 & 80.0 & 42.000 & 460.0 & 380.0 & $3.20-8$ & 75. & 500. \\
\hline & & & 42.000 & 57.0 & 55.0 & $\mathbf{4 2 . 0 0 0}$ & 310.0 & 250.0 & $3.20-8$ & 75. & 500. \\
\hline Se & room & air & $\mathbf{4 2 . 0 0 0}$ & 2.0 & 1.0 & & & & $1.00-10$ & 75. & 500. \\
\hline $\mathrm{Sr}$ & room & air & 42.000 & 1940.0 & 2560.0 & 42.000 & 4390.0 & 4080.0 & $2.00-6$ & & 500. \\
\hline$[\mathrm{c}$ & room & air & $\mathbf{4 2 . 0 0 0}$ & -0.039 & 0.022 & & & & $2.00-11$ & 75. & 500. \\
\hline & room & a & כ0 & -0 & 0.6 & & & & $5.00-6$ & . & \\
\hline
\end{tabular}

Core

G2-2017

$\begin{array}{lllllllll}\text { Se room } & \text { air } & 42.00 & 1.42 & 1.12 & 1.90-9 & 75 . & 500 . \\ & \mathrm{CO}_{2} & 42.000 & 4.97 & 4.48 & 1.90-9 & 75 . & 500 .\end{array}$


Element Temp Atm Stime srd1 srd2 dtime drd1 drd2 Conc pmin pmax

\section{Core}

G2-2017
Th room $\mathrm{CO}_{2} \quad 42.00 \quad 2000 \quad 4400$
1.00-7 75 . 500 .

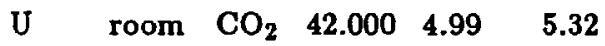
1.07-6 75. 500 .

Core

G2-3933

\begin{tabular}{|c|c|c|c|c|c|c|c|c|c|c|c|}
\hline Am & room & air & 42.000 & 7000.0 & 6200.0 & 42.000 & 12000.0 & 11000.0 & $8.80-8$ & 75. & 500. \\
\hline $\mathbf{B a}$ & room & air & 42.000 & 1240.0 & 2220.0 & 42.000 & 905.0 & 1300.0 & $6.00-8$ & & 500. \\
\hline Cs & room & air & 42.000 & 1580.0 & 3490.0 & 42.000 & 1105.0 & 1750.0 & 5.00-9. & & 500. \\
\hline Eu & room & air & 42.000 & 887.0 & 2230.0 & 42.000 & 1950.0 & 4060.0 & $6.00-8$ & & 500. \\
\hline $\mathbf{P u}$ & room & air & 42.000 & 1600.0 & 1600.0 & 42.000 & 650.0 & 330.0 & $4.10-8$ & 75. & 500. \\
\hline Sr & room & air & 42 & 192.0 & 299.0 & 42.000 & 117.0 & 164.0 & $2.00-6$ & & 500. \\
\hline Tc & room & air & 42 & 0.042 & 0.167 & 42.000 & 0 & 0 & & 7.5 & 500. \\
\hline I & room & air & 42.000 & -1.4 & 0.9 & & & & & 75. & \\
\hline
\end{tabular}

Core

G4-1502

$\begin{array}{lllll}\text { Am room air } & .042 & 470.0 & 510.0 \\ & & .167 & 720.0 & 710.0 \\ & & 1.000 & 1000.0 & 1200.0 \\ & 2.000 & 1200.0 & 1200.0 \\ & & 3.000 & 1500.0 & 1400.0 \\ & & & \\ & & & \\ & & & \end{array}$

1.30-8. 75. 500 .

1.30-8. 75. 500 .

1.30-8. 75. 500.

1.30-8. 75. 500 .

1.30-8. 75. 500 .

1.30-8. 75. 500 . 
Element Temp Atm Stime srd1 srd2 dtime drd1 drd2 Conc pmin pmax

Core

G4-1502

\begin{tabular}{|c|c|c|c|c|c|c|c|c|c|}
\hline \multirow[t]{6}{*}{$\mathrm{Np}$} & room air & 42 & 4.6 & 4.8 & $42.000 \quad 13.0$ & 10.0 & $1.00-10$ & 75. & 500. \\
\hline & & 91 & 5.2 & 3.6 & & & $1.00-10$ & 75. & 500. \\
\hline & & 182 & 5.2 & 5.2 & & & $1.00-10$ & 75 . & 500. \\
\hline & & 273 & 5.7 & 5.5 & & & $1.00-10$ & 75 . & 500. \\
\hline & & 368 & 5.8 & 5.8 & & & $1.00-10$ & 75. & 500. \\
\hline & & 460 & 5.8 & 5.8 & & & $1.00-10$ & 75. & 500. \\
\hline \multirow[t]{9}{*}{$\mathbf{P u}$} & room air & .042 & 19.0 & 20.0 & & & $3.10-8$ & 75. & 500. \\
\hline & & .167 & 24.0 & 21.0 & & & $3.10-8$ & 75. & 500. \\
\hline & & 1.000 & 26.0 & 28.0 & & & $3.10-8$. & 75. & 500. \\
\hline & & 2.000 & 36.0 & 31.0 & & & $3.10-8$. & 75. & 500. \\
\hline & & 3.000 & 31.0 & 38.0 & & & $3.10-8$. & 75. & 500. \\
\hline & & 7.000 & 36.0 & 37.0 & & & $3.10-8$ & 75. & 500. \\
\hline & & 21.000 & 34.0 & 34.0 & & & $3.10-8$ & 75. & 500. \\
\hline & & 42.000 & 44.0 & 43.0 & & & $3.10-8$. & 75. & 500. \\
\hline & & 42.000 & 56.0 & 62.0 & & & $1.50-7$ & 75 . & 500. \\
\hline
\end{tabular}

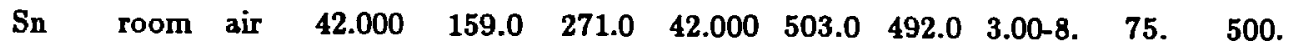

$\begin{array}{llllllll}\text { Tc room air } & 42.000 & 0.042 & -0.003 & 8.00-10 . & 75 . & 500 \text {. }\end{array}$

$\begin{array}{llllll}91.000 & 0.06 & -0.038 & 8.00-10 . & 75 . & 500 .\end{array}$

$\begin{array}{llllll}182.000 & -0.085 & -0.09 & 8.00-10 . & 75 . & 500 .\end{array}$

$\begin{array}{llllll}273.000 & -0.06 & -0.05 & 8.00-10 . & 75 . & 500 .\end{array}$

$\begin{array}{lllllll}366.000 & 0.001 & -0.015 & 8.00-10 . & 75 . & 500 .\end{array}$

$\begin{array}{llllll}480.000 & -0.08 & -0.03 & 8.00-10 . & 75 . & 500 .\end{array}$

\section{Core}

G4-1608

$\begin{array}{llllllllll}\mathrm{Np} \quad \text { room air } & 42 & 6.1 & 6.6 & & 3.50-11 . & 75 . & 500 . \\ & \mathrm{CO}_{2} & 42 & 4.7 & & 5.1 & 7.60-6 . & 75 . & 500 . \\ & & 42 & 5.2 & 5.5 & & 2.70-11 . & 75 . & 500 . \\ & & 42 & 2.0 & 2.7 & & 6.60-4 . & 75 . & 500 .\end{array}$


Element Temp Atm Stime srd1 srd2 dtime drd1 drd2 Conc pmin pmax

Core

G4-1608

$\begin{array}{rlll}\mathrm{Np} \quad \text { room } \mathrm{CO}_{2} & 42 & 5.2 & 4.7 \\ & 42 & 3.4 & 3.1 \\ & 42 & 1.3 & 0.58 \\ 42 & 4.4 & 5.9 \\ 42 & 4.5 & 5.4 \\ 42 & 3.5 & 3.2 \\ 42 & 4.8 & \\ 42 & 6.0 & 4.7 \\ 42 & 3.0 & 7.8\end{array}$

7.50-7. 75.500 .

3.40-5. 75. 500 .

3.00-4. 75. 500 .

3.90-7. 75. 500 .

3.70-6. 75. 500 .

6.70-5. 75. 500 .

7.50-8. 75. 500 .

3.90-8. 75. 500 .

4.30-9. 75. 500

$\begin{array}{rrrl}\mathrm{Pa} \quad \text { room } \mathrm{CO}_{2} & 42 & 5.3 & 10.1 \\ & 42 & 3.8 & 4.1 \\ & 42 & 3.3 & 4.1 \\ & 42 & 5.0 & 5.0 \\ & 42 & 3.4 & 5.3 \\ & 42 & 8.4 & 8.0\end{array}$

5.00-13. 75. 500 .

1.00-12. 75. 500 .

5.00-14. 75. 500 .

5.00-12. 75 . 500.

1.00-11. 75 . 500 .

1.00-13. 75. 500 .

$\begin{array}{llllll}\text { Se } & \text { room } & \text { air } & 42 & 14.8 & 15.7\end{array}$

1.90-9 75. 500.

1.90-9 75. 500 .

$\begin{array}{llllll}\text { Th } & \text { room } & \mathrm{CO}_{2} & 42 & 17900 & 22700\end{array}$

1.50-7 75. 500 .

$\begin{array}{llllll}\mathrm{U} & \text { room } & \text { air } & 42 & 12.6 & 11.4\end{array}$

1.07-6 75. 500 .

$\begin{array}{llll}\mathrm{CO}_{2} & 42 & 20.5 & 22.2\end{array}$

1.07-6 75. 500 .

Core

GU3-0433

$\begin{array}{lllllllllll}\text { Am room } & \text { air } & 42 & 3300.0 & 2900.0 & 42.000 & 9500.0 & 6000.0 & 2.10-7 . & 75 . & 500 .\end{array}$

$\begin{array}{lllllllll}42 & 3500.0 & 3800.0 & 42.000 & 7800.0 & 14000.0 & 2.10-7 . & 75 . & 500 .\end{array}$

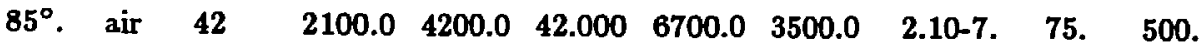


Element Temp Atm Stime srd1 srd2 dtime drd1 drd2 Conc pmin pmax

\section{Core}

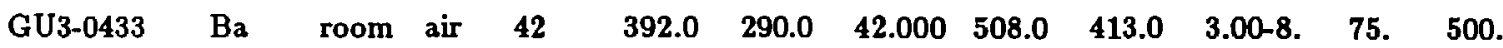

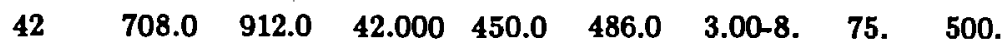

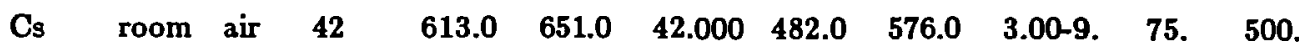

$\begin{array}{lllllllll}42 & 436.0 & 370.0 & 42.000 & 531.0 & 499.0 & 3.00-9 & 75 . & 500 .\end{array}$

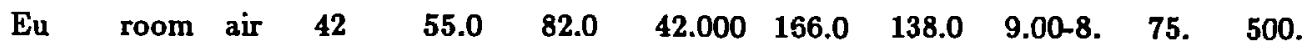

$\begin{array}{lllllllll}42 & 86.0 & 113.0 & 42.000 & 103.0 & 144.0 & 9.00-8 . & 75 . & 500 .\end{array}$

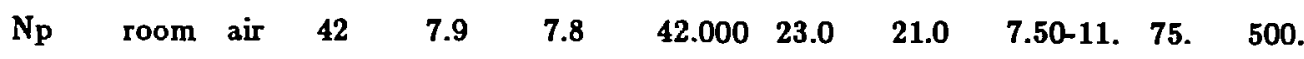

$\begin{array}{rlllllll} & 42 & 13.0 & 14.0 & 3.00-11 . & 75 . & 500 . \\ \mathrm{CO}_{2} & 42 & 0.82 & 0.67 & 8.2-12 . & 75 . & 500 . \\ & 42 & 9.6 & 2.6 & 2.3-8 & 75 . & 500 . \\ 42 & 6.2 & 6.1 & 4.4-8 & 75 . & 500 . \\ 42 & 5.5 & 4.3 & 2.4-7 & 75 . & 500 . \\ 42 & 5.3 & 5.1 & 5.0-7 & 75 . & 500 . \\ 42 & 4.6 & 5.0 & 2.2-6 & 75 . & 500 . \\ 42 & 3.4 & 4.9 & 4.3-6 & 75 . & 500 . \\ 42 & 0.60 & 0.17 & 2.1-5 & 75 . & 500 . \\ 42 & 2.6 & 1.6 & 4.8-5 & 75 . & 500 .\end{array}$

$\begin{array}{lllllllllll}\mathrm{Pu} & \text { room air } & 42 & 340.0 & 500.0 & 42 & 960.0 & 810.0 & 2.60-8 . & 75 . & 500 .\end{array}$ $\begin{array}{lllllllll}42 & 240.0 & 240.0 & 42 & 100.0 & 890.0 & 2.60-8 . & 75 . & 500 .\end{array}$

$\begin{array}{lllllllllll}85^{\circ} \text {. air } & 42 & 1700.0 & 1800.0 & 42 & 4500.0 & 7800.0 & 2.60-8 . & 75 . & 500 .\end{array}$

$\begin{array}{lllllllllll}\text { Sr } & \text { room air } & 42 & 56.0 & 66.0 & 42 & 39.0 & 49.0 & 2.00-6 . & 75 . & 500 \text {. }\end{array}$

$\begin{array}{lllllllll}42 & 31.6 & 28.2 & 42 & 36.0 & 32.0 & 2.00-6 . & 75 . & 500 .\end{array}$

$\begin{array}{lllll}\text { Tc room air } & 42 & 0.05 & -0.004\end{array}$

75. 500 .

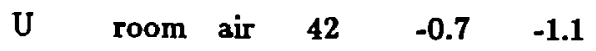

75. 500 . 
Element Temp Atm Stime ord1 srd2 dtime drd1 drd2 Conc pmin pmax

Core

GU3-0855
Se room air $42 \quad 10(4)$
75. 500 .
$\mathrm{U} \quad$ room air $\quad 42 \quad 10(0.1)$
75. 500 .

$\underline{\text { Core }}$

GU3-0916

\begin{tabular}{|c|c|c|c|c|c|c|c|c|c|c|c|}
\hline \multirow[t]{6}{*}{$\mathbf{N p}_{\mathbf{p}}$} & room & air & 42 & 4.8 & 4.9 & 42.000 & 35.0 & 32.0 & $6.00-11$ & 75. & 500. \\
\hline & & & 91 & 5.1 & 5.4 & & & & $6.00-11$ & 75. & 500. \\
\hline & & & 182 & 5.6 & 5.2 & & & & $6.00-11$ & 75. & 500. \\
\hline & & & 273 & 5.1 & 5.1 & & & & $6.00-11$ & 75. & 500. \\
\hline & & & 366 & 6.8 & 6.8 & & & & $6.00-11$ & 75. & 500. \\
\hline & & & 457 & 7.2 & 9.6 & & & & $6.00-11$ & 75. & 500. \\
\hline \multirow[t]{2}{*}{$\mathbf{P u}$} & room & air & 42 & 280.0 & 230.0 & 42.000 & 720.0 & 640.0 & $1.00-7$ & 75. & 500. \\
\hline & & & 42 & 190.0 & 180.0 & 42.000 & 280.0 & 240.0 & $9.50-8$. & 75. & 500. \\
\hline \multirow[t]{6}{*}{$\mathrm{Tc}$} & room & air & 42 & 0.50 & 0.94 & & & & $6.00-10$ & 75. & J. \\
\hline & & & 91 & 0.33 & 1.3 & & & & $6.00-10$ & 75. & \\
\hline & & & 183 & 0.81 & 0.44 & & & & $6.00-10$ & 75. & \\
\hline & & & 273 & 0.14 & 0.11 & & & & $6.00-10$ & 75. & \\
\hline & & & 366 & 0.13 & 0.32 & & & & $6.00-10$ & 75. & \\
\hline & & & 480 & 0.08 & 0.17 & & & & $6.00-10$ & 75. & \\
\hline
\end{tabular}

Core

GU3-1203

$\begin{array}{rrrrrrrrrrrr}\text { Am } & \text { room } & \text { air } & 42 & 1400.0 & 1200.0 & 42 & 900.0 & 1800.0 & 2.10-7 . & 75 . & 500 . \\ & & & 42 & 860.0 & 970.0 & 42 & 990.0 & 1400.0 & 2.10-7 . & 75 . & 500 . \\ & & & & & & & & & & \\ & 85^{\circ} . & \text { air } & 42, & 4200.0 & 4300.0 & 42 & 7200.0 & 10500.0 & 2.10-7 . & 75 . & 500 . \\ & & & & & & & & & & & \\ \text { Ba room air } & 42 & 600.0 & 42 & & 750.0 & 700.0 & 4.00-8 . & 75 . & 500 .\end{array}$


Element Temp Atm Stime grd1 srd2 dtime drd1 drd2 Conc pmin pmax

\section{Core}

GU3-1203

$\begin{array}{llllllllll}\text { Cs } & \text { room } & 42 & 380.0 & 330.0 & 42 & 450.0 & 330.0 & 4.00-9 . & 75 .\end{array}$

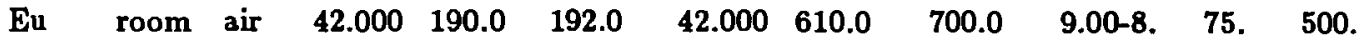

$\begin{array}{lllllllllll}\mathrm{Np} & \text { room } & \text { air } & 42.000 & 2.8 & 2.6 & 42.000 & 42.0 & 57.0 & 7.70-11 . & 75 .\end{array}$

$\begin{array}{llllllll} & 42.000 & 0.5 & 0.5 & 3.00-11 . & 75 . & 500 . \\ \mathrm{CO}_{2} & 42.000 & 0.4 & 0.4 & 2.00-11 . & 75 . & 500 .\end{array}$

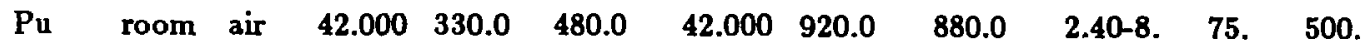

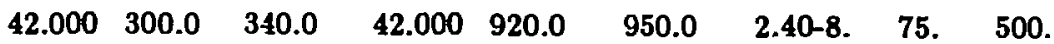

$\begin{array}{llllllllll}85^{\circ} \text {. air } & 42.000 & 440.0 & 940.0 & 42.000 & 620.0 & 830.0 & 2.40-8 . & 75 . & 500 .\end{array}$

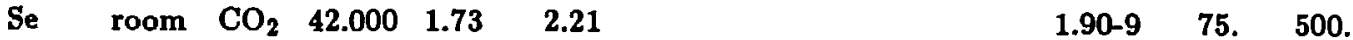

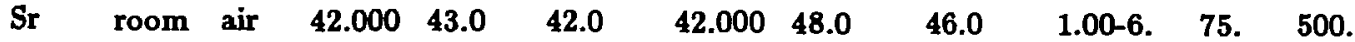

$\begin{array}{llllll}\text { Tc room air } & 42.000 & 0.02 & -0.03 & 1.00-11 . & 75 .\end{array}$

$\begin{array}{llllllll}\text { Th room } & \mathrm{CO}_{2} & 42.000 & 2000 & 1700 & 9.70-8 & 75 . & 500 .\end{array}$

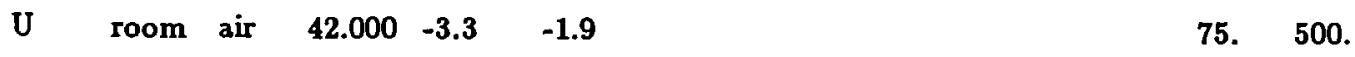

$\begin{array}{lllllll}\mathrm{CO}_{2} & 42.000 & 2.98 & 5.35 & 1.07-6 & 75 . & 500 .\end{array}$

Core

GU3-1301

$\begin{array}{llllllllll}\text { Am room air } & 42.000 & 1600.0 & 1400.0 & 42.000 & 3800.0 & 3200.0 & 2.40-7 . & 75 . & 500 .\end{array}$ $\begin{array}{lllllllll}42.000 & 2000.0 & 2050.0 & 42.000 & 1500.0 & 1500.0 & 2.40-7 . & 75 . & 500 .\end{array}$

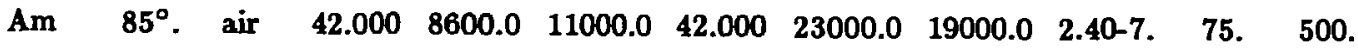

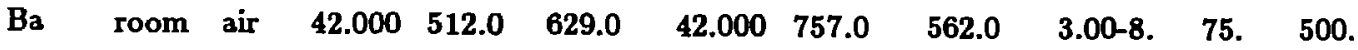

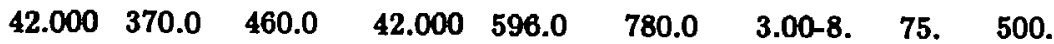


Element Temp Atm Stime srd1 srd2 dtime drd1 drd2 Conc pmin pmax

\section{Core}

GU3-1301 $\begin{array}{llllllllllll}\text { Cs } \quad \text { room } & \text { air } & 42.000 & 109.0 & 135.0 & 42.000 & 159.0 & 211.0 & 3.00-9 . & 75 . & 500 . \\ & & & 42.000 & 125.0 & 195.0 & 42.000 & 216.0 & 153.0 & 3.00-9 . & 75 . & 500 .\end{array}$

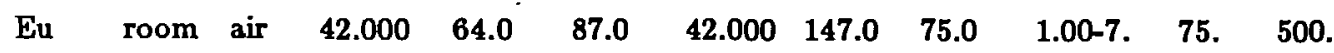
$\begin{array}{lllllllll}42.000 & 31.0 & 44.0 & 42.000 & 51.0 & 131.0 & 1.00-7 . & 75 . & 500 .\end{array}$

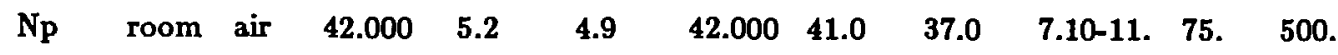
$\begin{array}{lllllllll}42.000 & 1.8 & 1.7 & 42.000 & 18.0 & 18.0 & 2.30-11 . & 75 . & 500 .\end{array}$ $91.000 \quad 2.1 \quad 1.9 \quad 6.00-11.75 . \quad 500$.

$\begin{array}{lllllllll}91.000 & 2.3 & 2.1 & 42.000 & 23.0 & 26.0 & 6.00-11 . & 75 . & 500 .\end{array}$

$\begin{array}{lllllll}188.000 & 2.2 & 2.3 & 6.00-11 . & 75 . & 500 .\end{array}$

$\begin{array}{llllll}288.000 & 1.9 & 1.8 & 6.00-11 . & 75 . & 500 .\end{array}$

$\begin{array}{lllllll}369.000 & 2.1 & 2.0 & 6.00-11 . & 75 . & 500 .\end{array}$

$\begin{array}{llllll}476.000 & 2.4 & 2.4 & 6.00-11 . & 75 . & 500 .\end{array}$

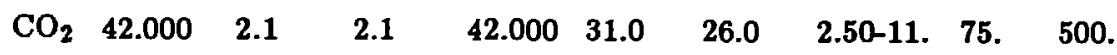

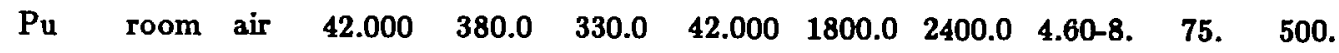
$\begin{array}{lllllllll}42.000 & 200.0 & 250.0 & 42.000 & 560.0 & 600.0 & 4.60-8 . & 75 . & 500 .\end{array}$ $\begin{array}{lllllllllll}85^{\circ} \text {. air } & 42.000 & 2500.0 & 7600.0 & 42.000 & 1300.0 & 1600.0 & 4.60-8 . & 75 . & 500 .\end{array}$

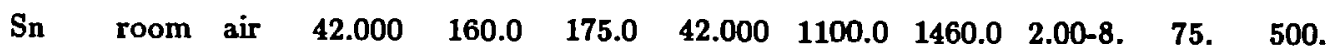

$\begin{array}{lllllllllll}\text { Sr } \quad \text { room } & \text { air } & 42.000 & 23.0 & 25.0 & 42.000 & 28.0 & 88.0 & 2.00-6 . & 75 . & 500 . \\ & & 42.000 & 25.0 & 40.0 & 42.000 & 110.0 & 76.0 & 2.00-6 . & 75 . & 500 .\end{array}$

Te room air $\quad 42.000 \quad 0.058 \quad 0.022$

$91.000 \quad 0.065 \quad 0.002$

7.00-10. 75 . 500.

$\begin{array}{llll}182.000 & -0.003 & 0.004\end{array}$

$\begin{array}{lll}273.000 & 0.013 & 0.031\end{array}$

$\begin{array}{lll}366.000 & 0.17 & 0.30\end{array}$

$\begin{array}{lll}480.000 & 0.04 & 0.20\end{array}$
7.00-10. 75 . 500 .

7.00-10. 75 . 500 .

7.00-10. 75. 500 .

7.00-10. 75 . 500 .

7.00-10 75. 500 . 
Element Temp Atm Stime srd1 srd2 dtime drd1 drd2 Conc pmin pmax

\section{Core}

GU3-1301

$$
\begin{array}{lllll}
U & \text { room } & \text { air } \quad 42.000 & -1.7 & -1.7
\end{array}
$$

75. 500 .

Core

GU3-1436

$$
\begin{array}{llll}
\text { Se } & \text { room air } & 42.000 \quad 3(0) \\
\mathrm{U} & \text { room air } & 42.000 & 20(2)
\end{array}
$$

75. 500.

75. 500 .

\section{Core}

GU3-1531

$$
\begin{array}{lllll}
\text { Se } & \text { room air } & 5(1) \\
U & \text { room } & \text { air } & 42.000 & 54(9)
\end{array}
$$

75. 500.

75. 500 .

Core

GU3-1937

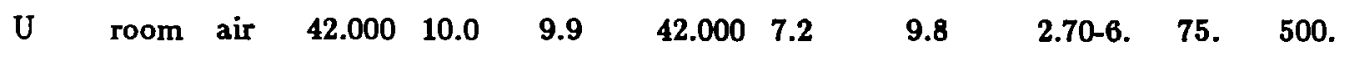

Core

JA-08 
Element Temp Atm Stime srd1 srd2 dtime drd1 drd2 Conc pmin pmax

\section{Core}

JA-18

$\begin{array}{clllll}\text { Am room air } \quad 7.000 & 310.0 & 63.000 & 810.0 \\ & 7.000 & 250.0 & & \\ 7.000 & 96.0 & & \\ 7.000 & 200.0 & 14.000 & 270.0 \\ 14.000 & 310.0 & 63.000 & 710.0 \\ 14.000 & 86.0 & 35.000 & 440.0 \\ 28.000 & 360.0 & 63.000 & 790.0 \\ 28.000 & 220.0 & & \\ 28.000 & 120.0 & & \\ 28.000 & 200.0 & 35.000 & 1200.0 \\ 56.000 & 100.0 & 35.000 & 2000.0 \\ & 56.000 & 85.0 & 63.000 & 2300.0 \\ 56.000 & 85.0 & & \\ & 56.000 & 57.0 & & \end{array}$

Ba room air

$14.000 \quad 3100.0$

$14.000 \quad 3100.0$

$14.000 \quad 2300.0$

21.00096000 .0

$21.000 \quad 4500.0$

$21.000 \quad 4500.0$

$21.000 \quad 3300.0$

$42.000 \quad 110000.0$

$42.000 \quad 4700.0$

$42.000 \quad 7100.0$

$77.000 \quad 6600.0$

$\begin{array}{ll}77.000 & 7100.0\end{array}$

$84.000 \quad 170000.0$
$98.000 \quad 40000.0$

$98.000 \quad 34000.0$

$21.000 \quad 24000.0$

21.00024000 .0

$21.000 \quad 8600.0$

$84.000 \cdot 240000.0$

$35.000 \quad 38000.0$

$35.000 \quad 38000.0$

35.00023000 .0

63.000220000 .0

$21.000 \quad 370000.0$
4.00-7. 106. 150 . 4.00-7. 106. 150 . 4.00-7. 106. 150 . 4.00-7. 106. 150 . 4.00-7. 106. 150 . 4.00-7. 106. 150 . 4.00-7. 106. 150 . 4.00-7. 106. 150 . 4.00-7. 106. 150 . 4.00-7. 106. 150 . 4.00-7. 106. 150. 4.00-7. 106. 150. 4.00-7. 106. 150 . 4.00-7. 106. 150 .

2.00-7. 106. 150 . 2.00-7. 355. 500 . 2.00-7. 106. 150. 2.00-7. 106. 150 . 2.00-7. 355. 500 . 8.00-10. 75. 500 . 2.00-7. 106. 150 . 2.00-7. 106. 150 . 2.00-7. 355. 500 . 8.00-10. 75. 500. 2.00-7. 106. 150 . 2.00-7. 355. 500 . 2.00-7. 106. 150 . 2.00-7. 355. 500 . 8.00-10. 75. 500 . 
Element Temp Atm Stime srd1 grd2 dtime drd1 drd2 Conc pmin pmax

Core

JA-18

Ba $70^{\circ}$. air

Ce room air

14.00026 .0

$14.000 \quad 20.0$

$21.000 \quad 1400.0$

$21.000 \quad 46.0$

$21.000 \quad 26.0$

$42.000 \quad 5700.0$

$42.000 \quad 43.0$

$42.000 \quad 41.0$

$\mathbf{7 7 . 0 0 0} \quad \mathbf{7 8 . 0}$

$77.000 \quad 70.0$

$84.000 \quad 1300.0$

$70^{\circ}$. air
98.000110000 .0

$98.000 \quad 170000.0$

14.00070000 .0

$14.000 \quad 91000.0$

$21.000 \quad 100000.0$

$21.000 \quad 67000.0$

$42.000 \quad 100000.0$

$42.000 \quad 150000.0$

$98.000 \quad 440.0$

$98.000 \quad 130.0$

$21.000 \quad 120.0$

$21.000 \quad 36.0$

$84.000 \quad 2000.0$

$35.000 \quad 250.0$

$35.000 \quad 110.0$

63.0001100 .0

$98.000 \quad 550.0$

$98.000 \quad 300.0$

$14.000 \quad 40.0$

$14.000 \quad 40.0$

$21.000 \quad 36.0$
$14.000 \quad 160.0$

$14.000 \quad 240.0$

$21.000 \quad 350.0$
2.00-7. 106 . 150 .

2.00-7. 355. 500 .

2.00-7. 106. 150.

2.00-7. 355. 500 .

2.00-7. 106.150 .

2.00-7. 355. 500 .

2.00-7. 106. 150 .

2.00-7. 355. 500 .

2.00-7. 106. 150 .

2.00-7. 355. 500 .

1.00-6. 106. 150.

1.00-8. 355. 500.

1.00-6. 106. 150 .

1.00-6. 355. 500 .

8.00-13. 75. 500.

1.00-6. 106. 150.

1.00-6. 355. 500 .

8.00-13. 75. 500 .

1.00-6. 106. 150.

1.00-6. 355. 500 .

1.00-6. 106. 150.

1.00-6. 355. 500 .

8.00-13. 75. 500 .

9.00-7. 106. 150 .

9.00-7. 355. 500 .

9.00-7. 106. 150.

9.00-7. 355. 500 .

9.00-7. 106.150. 
Element Temp Atm Stime srd1 srd2 dtime drd1 drd2 Conヶ pmin pmax

\section{Core}

JA-18

\begin{tabular}{|c|c|c|c|c|c|c|c|c|c|}
\hline \multirow[t]{5}{*}{$\mathrm{Ce}$} & $70^{\circ}$ & air & 21.000 & 45.0 & 21.000 & 120.0 & $9.00-7$ & 355. & 500. \\
\hline & & & 34.000 & 46.0 & 42.000 & 230.0 & $9.00-7$ & 106. & 150. \\
\hline & & & 35.000 & 40.0 & 42.000 & 220.0 & $9.00-7$ & 355. & 500. \\
\hline & & & 63.000 & 51.0 & & & $9.00-7$ & 106. & 150. \\
\hline & & & 63.000 & 42.0 & & & $9.00-7$ & 355. & 500. \\
\hline \multirow[t]{19}{*}{ Cs } & room & air & & & 98.000 & 15000.0 & $1.00-8$ & 106. & 150. \\
\hline & & & & & 98.000 & 15000.0 & $1.00-8$ & 355. & 500. \\
\hline & & & 14.000 & 12000.0 & 21.000 & 22000.0 & $1.00-8$ & 106. & 150. \\
\hline & & & 14.000 & 10000.0 & 21.000 & 16000.0 & $1.00-8$. & 355. & 500. \\
\hline & & & 21.000 & 16000.0 & 84.000 & 19000.0 & 3.00-9. & 75. & 500. \\
\hline & & & 21.000 & 13000.0 & 35.000 & 18000.0 & $1.00-8$ & 106. & 150. \\
\hline & & & 21.000 & 10000.0 & 35.000 & 17000.0 & $1.00-8$ & 355 & 500. \\
\hline & & & 42.000 & 15000.0 & 63.000 & 17000.0 & $3.00-9$ & 75. & 500. \\
\hline & & & 42.000 & 17000.0 & & & $1.00-8$ & 106. & 150. \\
\hline & & & 42.000 & 19000.0 & & & $1.00-8$ & 355. & 500. \\
\hline & & & 77.000 & 20000.0 & & & $1.00-8$ & 106. & 150. \\
\hline & & & 77.000 & 19000.9 & & & $1.00-8$ & 355. & 500. \\
\hline & & & 84.000 & 18000.0 & 21.000 & 19000.0 & $3.00-9$ & 75. & 500. \\
\hline & $70^{\circ}$ & air & & & 98.000 & 17000.0 & $1.00-8$ & 106. & 150. \\
\hline & & & & & 98.000 & 26000.0 & $1.00-8$ & 355. & 500. \\
\hline & & & 14.000 & 13000.0 & 14.000 & 14000.0 & $1.00-8$ & 106. & 150. \\
\hline & & & 14.000 & 21000.0 & 14.000 & 22000.0 & $1.00-8$ & 355. & 500. \\
\hline & & & 21.000 & 21000.0 & 21.000 & 17000.0 & $1.00-8$ & 106. & 150. \\
\hline & & & 21.000 & 18000.0 & 21.000 & 21000.0 & $1.00-8$ & 355. & 500. \\
\hline
\end{tabular}


Element Temp Atm Stime srd1 srd2 dtime drd1 drd2 Conc pmin pmax

\section{Core}

JA-18

\begin{tabular}{|c|c|c|c|c|c|c|c|c|c|}
\hline \multirow[t]{4}{*}{ Cs } & $70^{\circ}$ & air & 35.000 & 16000.0 & 42.000 & 17000.0 & $1.00-8$. & 106. & 150. \\
\hline & & & 35.000 & 19000.0 & 42.000 & 21000.0 & $1.00-8$ & 355. & 500. \\
\hline & & & 63.000 & 17000.0 & & & $1.00-8$ & 106. & 150. \\
\hline & & & 63.000 & 19000.0 & & & $1.00-8$ & 355. & 500. \\
\hline \multirow[t]{23}{*}{ Eu } & room & air & & & 98.000 & 350.0 & $6.00-7$ & 106. & 150. \\
\hline & & & & & 98.000 & 140.0 & $6.00-7$ & 355. & 500. \\
\hline & & & 14.000 & 14.0 & 21.000 & 120.0 & $6.00-7$ & 106. & 150. \\
\hline & & & 14.000 & 14.0 & 21.000 & 30.0 & $6.00-7$ & 355. & 500. \\
\hline & & & 21.000 & 1700.0 & 84.000 & 3000.0 & $1.00-10$ & 75. & 500. \\
\hline & & & 21.000 & 1700.0 & 84.000 & 3000.0 & $1.00-10$ & 75. & 500. \\
\hline & & & 21.000 & 30.0 & 35.000 & 210.0 & $6.00-7$ & 106. & 150. \\
\hline & & & 21.000 & 18.0 & 35.000 & 74.0 & $6.00-7$ & 355. & 500. \\
\hline & & & $\mathbf{4 2 . 0 0 0}$ & 1100.0 & 63.000 & 2300.0 & $1.00-10$ & 75. & 500. \\
\hline & & & 42.000 & 32.0 & & & $6.00-7$ & 106. & 150. \\
\hline & & & $\mathbf{4 2 . 0 0 0}$ & 26.0 & & & $6.00-7$ & 355. & 500. \\
\hline & & & 77.000 & 60.0 & & & $6.00-7$ & 106. & 50. \\
\hline & & & 77.000 & 37.0 & & & $6.00-7$ & 355. & 00. \\
\hline & & & 84.000 & 1400.0 & 21.000 & 2100.0 & $1.00-10$ & 75. & 500. \\
\hline & $70^{\circ}$ & air & & & 98.000 & 840.0 & 3.00-7. & 355. & 00. \\
\hline & & & 14.000 & 63.0 & 14.000 & 280.0 & $3.00-7$ & 106. & 150. \\
\hline & & & 14.000 & 61.0 & 14.000 & 440.0 & 3.00-7. & 355. & 00. \\
\hline & & & 21.000 & 76.0 & 21.000 & 780.0 & $3.00-7$ & 106. & 150. \\
\hline & & & 21.000 & 62.0 & 21.000 & 260.0 & $3.00-7$ & 355. & ). \\
\hline & & & 35.000 & 110.0 & 42.000 & 680.0 & $3.00-7$ & 106. & 150. \\
\hline & & & 35.000 & 76.0 & 42.000 & 500.0 & 3.00-7. & 355. & J. \\
\hline & & & 63.000 & 130.0 & & & $3.00-7$ & 106. & 0 . \\
\hline & & & 63.000 & 89.0 & & & 3.00-7. & 355. & \\
\hline
\end{tabular}


Core

JA-18

\begin{tabular}{|c|c|c|c|c|c|c|c|c|c|}
\hline \multirow[t]{2}{*}{ I } & \multirow[t]{2}{*}{ room } & 21.000 & \multicolumn{4}{|l|}{-1.5} & \multirow{2}{*}{$\begin{array}{l}1.00-13 \\
1.00-13\end{array}$} & \multirow{2}{*}{$\begin{array}{l}355 . \\
355 .\end{array}$} & \multirow{2}{*}{$\begin{array}{l}500 . \\
500 .\end{array}$} \\
\hline & & 28.000 & -0.5 & & & & & & \\
\hline Mo & room air & 21.000 & 4.3 & & & & $1.00-14$ & 355. & 500. \\
\hline \multirow[t]{6}{*}{$\mathbf{P u}$} & room air & 7.000 & 170.0 & 70.0 & 14.000 & 160.0 & 4.00-7. & 106. & 150. \\
\hline & & 14.000 & 110.0 & & 14.000 & 710.0 & $1.00-13$ & 106. & 150. \\
\hline & & 28.000 & 81.0 & & & & $4.00-7$ & 106. & 150. \\
\hline & & 28.000 & 120.0 & & 14.000 & 450.0 & $1.00-13$ & 106. & 150. \\
\hline & & 56.000 & 68.0 & & & & $4.00-7$ & 106. & 150. \\
\hline & & 56.000 & 220.0 & & 21.000 & 97.0 & $1.00-13$ & 106. & 150. \\
\hline \multirow[t]{2}{*}{$\mathbf{R u}$} & room air & 21.000 & 67.0 & & & & $3.00-12$ & 355. & 500. \\
\hline & & 28.000 & 32.0 & & & & $3.00-12$ & 355. & 500. \\
\hline \multirow[t]{2}{*}{$\mathbf{S b}$} & room air & 21.000 & -0.9 & & & & $6.00-12$ & 355. & 500. \\
\hline & & 28.000 & 0.2 & & & & $6.00-12$ & 355. & 500. \\
\hline \multirow[t]{13}{*}{$\mathbf{S r}$} & room air & & & & 98.000 & 13000.0 & $1.00-6$ & 106. & 150. \\
\hline & & & & & 98.000 & 16000.0 & $1.00-6$ & 355. & 500. \\
\hline & & 14.000 & 11000.0 & & 21.000 & 21000.0 & $1.00-6$ & 106. & 150. \\
\hline & & 14.000 & 8900.0 & & 21.000 & 13000.0 & $1.00-6$ & 355. & 500. \\
\hline & & 21.000 & 16000.0 & & 84.000 & 17000.0 & $8.00-11$ & 75. & 500. \\
\hline & & 21.000 & 13000.0 & & 35.000 & 5800.0 & $1.00-6$ & 106. & 150. \\
\hline & & 21.000 & 6500.0 & & 35.000 & 5500.0 & $1.00-6$ & 355. & 500. \\
\hline & & 42.000 & 45000.0 & & 63.000 & 16000.0 & $8.00-11$ & 75. & 500. \\
\hline & & 42.000 & 18000.0 & & & & $1.00-6$ & 106. & 150. \\
\hline & & 42.000 & 5800.0 & & & & $1.00-6$ & 355. & 500. \\
\hline & & 77.000 & 22000.0 & & & & $1.00-6$ & 106. & 150. \\
\hline & & 77.000 & 16000.0 & & & & $1.00-6$ & 355. & 500. \\
\hline & & 84.000 & 20000.0 & & 21.000 & 26000.0 & $8.00-11$ & 75. & 500. \\
\hline
\end{tabular}


Element Temp Atm Stime srd1 srd2 dtime drd1 drd2 Conc pmin pmax

Core

JA-18

\begin{tabular}{|c|c|c|c|c|c|c|c|c|c|}
\hline Sr & $70^{\circ}$ & air & & & 98.000 & 17000.0 & $1.00-6$ & 106. & 150. \\
\hline & & & & & 98.000 & 19000.0 & $1.00-6$ & 355. & 500. \\
\hline & & & 14.000 & 13000.0 & 14.000 & 22000.0 & $1.00-6$ & 106. & 150. \\
\hline & & & 14.000 & 19000.0 & 14.000 & 22000.0 & $1.00-6$ & 355. & 500. \\
\hline & & & 21.000 & 22000.0 & 21.000 & 30000.0 & $1.00-6$ & 106. & 150. \\
\hline & & & 21.000 & 15000.0 & 21.000 & 24000.0 & $1.00-6$ & 355. & 500. \\
\hline & & & 35.000 & 15000.0 & 42.000 & 18000.0 & $1.00-6$ & 106. & 150. \\
\hline & & & 35.000 & 22000.0 & 42.000 & 17000.0 & $1.00-6$ & 355. & 500. \\
\hline & & & 63.000 & 4700.0 & & & $1.00-6$ & 106. & 150. \\
\hline & & & 63.000 & 4300.0 & & & $1.00-6$ & 355. & 500. \\
\hline $\mathrm{U}$ & room & air & 7.000 & 4.9 & 21.000 & 13.0 & $1.00-7$ & 106. & 150. \\
\hline & & & 7.000 & 1.6 & 21.000 & 9.7 & $1.00-7$ & 355. & 500. \\
\hline & & & 14.000 & 3.5 & 14.000 & 12.0 & $1.00-7$ & 106. & 150. \\
\hline & & & 14.000 & 1.4 & 14.000 & 6.4 & $1.00-7$ & 355. & 500. \\
\hline & & & 21.000 & 12.0 & 7.000 & 4.4 & $1.00-7$ & 106. & 150. \\
\hline & & & 21.000 & 1.3 & 7.000 & 6.3 & $1.00-7$ & 355. & 500. \\
\hline & $70^{\circ}$ & air & 7.000 & 4.2 & 21.000 & 13.0 & $1.00-7$ & 355. & 500. \\
\hline & & & 14.000 & 3.6 & 14.000 & 9.5 & $1.00-7$ & 355. & 500. \\
\hline & & & 21.000 & 4.3 & 7.000 & 18.0 & $1.00-7$ & 355. & 500. \\
\hline
\end{tabular}

Core

JA-26

Ba room air

$21.000 \quad 490.0 \quad 480.0 \quad 1.00-9.75 . \quad 500$.

$\begin{array}{lllllllll}21.000 & 210.0 & 270.0 & 84.000 & 460.0 & 400.0 & 1.00-9 . & 75 . & 500 .\end{array}$

$\begin{array}{lllllllll}42.000 & 1200.0 & 1400.0 & 42.000 & 430.0 & 450.0 & 1.00-9 & 75 . & 500 .\end{array}$

Cs room air

$21.000 \quad 1700.0 \quad 1700.0 \quad 6.00-9$. $75 . \quad 500$.

$\begin{array}{lllllllll}21.000 & 420.0 & 720.0 & 84.000 & 1200.0 & 1500.0 & 6.00-9 & 75 . & 500 .\end{array}$

$\begin{array}{lllllllll}42.000 & 2900.0 & 1900.0 & 42.000 & 1600.0 & 1800.0 & 6.00-9 & 75 . & 500 .\end{array}$ 
Element Temp Atm Stime srd1 srd2 dtime drd1 drd2 Conc pmin pmax

Core

JA-26 Eu room air

$21.0002400 .0 \quad 3100.0 \quad 3.00-10.75 .500$.

$\begin{array}{lllllllll}21.000 & 220.0 & 47.0 & 84.000 & 3700.0 & 3300.0 & 3.00-10 & 75 . & 500 .\end{array}$

$\begin{array}{lllllllll}42.000 & 15000.0 & 1200.0 & 42.000 & 2100.0 & 3100.0 & 3.00-10 . & 75 . & 500 \text {. }\end{array}$

Sr room air

$21.00046 .0 \quad 46.0 \quad 2.00-11.75 .500$.

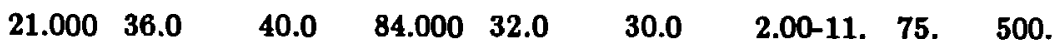

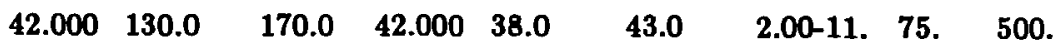

Core

JA-28

Ba room air

$21.000 \quad 1100.0 \quad 1100.0 \quad 1.00-9$. 75.500.

$\begin{array}{lllllllll}21.000 & 900.0 & 760.0 & 84.000 & 1200.0 & 1200.0 & 1.00-9 . & 75 . & 500 .\end{array}$

$\begin{array}{lllllllll}42.000 & 720.0 & 900.0 & 42.000 & 1200.0 & 1200.0 & 1.00-9 . & 75 . & 500 .\end{array}$

Cs room air

$21.000 \quad 2300.0 \quad 2700.0 \quad 6.00-9$. 75 . 500 .

$\begin{array}{lllllllll}21.000 & 1700.0 & 1200.0 & 84.000 & 3100.0 & 2500.0 & 6.00-9 . & 75 . & 500 .\end{array}$

$\begin{array}{lllllllll}42.000 & 2200.0 & 1500.0 & 42.000 & 2400.0 & 2200.0 & 6.00-9 . & 75 . & 500 .\end{array}$

Eu room air

$21.00011000 .014000 .0 \quad 1.00-10.75 .500$.

$\begin{array}{lllllllll}21.000 & 1500.0 & 1200.0 & 84.000 & 13000.0 & 13000.0 & 1.00-10 . & 75 . & 500 .\end{array}$

$\begin{array}{lllllllll}42.000 & 5200.0 & 600.0 & 42.000 & 11000.0 & 12000.0 & 1.00-10 & 75 . & 500 .\end{array}$

Sr room air

$21.000110 .0 \quad 110.0 \quad 2.00-11.75 .500$.

$\begin{array}{lllllllll}21.000 & 140.0 & 110.0 & 84.000 & 120.0 & 120.0 & 2.00-11 . & 75 . & 500 .\end{array}$

$\begin{array}{lllllllll}42.000 & 69.0 & 54.0 & 42.000 & 110.0 & 110.0 & 2.00-11 . & 75 . & 500 \text {. }\end{array}$

\section{Core}

JA-32

$\begin{array}{rllllllll}\text { Am rooñ } & \text { air } & 7.000 & 110.0 & 35.000 & 2800.0 & 1.00-6 . & 106 . & 150 . \\ & 14.000 & 110.0 & & & 1.00-6 . & 106 . & 150 . \\ & 28.000 & 140.0 & & & 1.00-6 . & 106 . & 150 . \\ & 28.000 & 230.0 & 35.000 & 1500.0 & 1.00-6 . & 106 . & 150 . \\ & 56.000 & 79.0 & & & 1.00-6 . & 106 . & 150 .\end{array}$


Element Temp Atm Stime srd1 srd2 dtime drd1 drd2 Conc pmin pmax

Core

JA-32

\begin{tabular}{|c|c|c|}
\hline Am & $70^{\circ}$. air & 7.000 \\
\hline & & 14.000 \\
\hline & & 28.000 \\
\hline & & 56.000 \\
\hline
\end{tabular}

Ba room air $\quad 7.000 \quad 370.0$

$7.000 \quad 270.0$

$21.000 \quad 370.0$

$21.000 \quad 310.0$

$35.000 \quad 420.0$

$35.000 \quad 370.0$

$\begin{array}{lll}56.000 & 440.0\end{array}$

$\mathbf{5 6 . 0 0 0} \quad \mathbf{5 2 0 . 0}$

$70^{\circ}$. air

$7.000 \quad 560.0$

$7.000 \quad 900.0$

$14.000 \quad 660.0$

$14.000 \quad 1000.0$

$28.000 \quad 940.0$

$28.000 \quad 1100.0$

$56.000 \quad 1300.0$

$56.000 \quad 1600.0$

$\mathrm{Ce}$

room air

$7.000 \quad 43.0$

$7.000 \quad 66.0$

$21.000 \quad 53.0$

$21.000 \quad 90.0$

$35.000 \quad 48.0$

$35.000 \quad 90.0$

$56.000 \quad 160.0$

$56.000 \quad 110.0$ \begin{tabular}{l}
$7.000 \quad 420.0$ \\
\hline
\end{tabular}

$14.000 \quad 360.0$

$21.000 \quad 430.0$

$28.000 \quad 390.0$

$35.000 \quad 560.0$

$42.000 \quad 560.0$

$77.000 \quad 510.0$

$84.000 \quad 700.0$

$21.000 \quad 970.0$

$21.000 \quad 1600.0$

$14.000 \quad 710.0$

$14.000 \quad 1100.0$

$21.000 \quad 940.0$

$21.000 \quad 950.0$

$42.000 \quad 1300.0$

$42.000 \quad 1800.0$

$14.000 \quad 1100.0$

$14.000 \quad 1200.0$

\begin{tabular}{ll}
$7.000 \quad 1300.0$ \\
\hline
\end{tabular}

$14.000 \quad 670.0$

$21.000 \quad 340.0$

$28.000 \quad 490.0$

$35.000 \quad 310.0$

42.000240 .0

$77.000 \quad 240.0$

84.000640 .0
1.00-6. 106.150.

1.00-6. 106. 150.

1.00-6. 106. 150.

1.00-6. 106. 150 .

1.00-6. 106. 150 .

1.00-6. 355. 500 .

1.00-6. 106. 150.

1.00-6. 355. 500 .

1.00-6. 106.150.

1.00-6. 355. 500.

1.00-6. 106. 150.

1.00-6. 355. 500.

1.00-6. 106. 150.

1.00-6. 355. 500 .

1.00-6. 106. 150.

1.00-6. 355. 500 .

1.00-6. 106. 150 .

1.00-5. 355. 500 .

1.00-6. 106. 150.

1.00-6. 355. 500 .

1.00-6. 106. 150 .

1.00-6. 355. 500 .

8.00-7. 106 . 150 .

8.00-7. 355. 500 .

8.00-7. 106. 150.

8.00-7, 355. 500 .

8.00-7. 106.150.

8.00-7. 355. 500 .

8.00-7. 106 . 150.

8.00-7. 355. 500. 
Element Temp Atm Stime grd1 srd2 dtime drd1 drd2 Conc pmin pmax

Core

JA-32

\begin{tabular}{|c|c|c|c|c|c|c|c|c|}
\hline \multirow{8}{*}{$\mathrm{Ce}$} & \multirow[t]{8}{*}{$70^{\circ}$} & & & 21.000 & 710.0 & $1.00-6$ & 106. & 150. \\
\hline & & & & 21.000 & 1100.0 & $1.00-6$ & 355. & 500. \\
\hline & & 7.000 & 53.0 & 14.000 & 360.0 & $1.00-6$ & 106. & 150. \\
\hline & & 7.000 & 51.0 & 14.000 & 750.0 & $1.00-6$ & 355. & 500. \\
\hline & & 14.000 & 64.0 & 21.000 & 600.0 & $1.00-6$ & 106. & 50. \\
\hline & & 14.000 & 61.0 & 21.000 & 310.0 & $1.00-6$ & 355. & 500. \\
\hline & & 56,000 & 67.0 & 14.000 & 460.0 & $1.00-6$ & 106. & 150. \\
\hline & & 56.000 & 170.0 & 14.000 & 800.0 & $1.00-6$ & 355. & 0. \\
\hline \multirow[t]{18}{*}{ Cs } & \multirow[t]{8}{*}{ room } & 7.000 & 120.0 & 7.000 & 170.0 & $1.00-9$ & 106. & 0. \\
\hline & & 7.000 & 110.0 & 14.000 & 200.0 & $1.00-9$ & 355. & 0. \\
\hline & & 21.000 & 120.0 & 21.000 & 230.0 & $1.00-9$ & 106. & 0. \\
\hline & & 21.000 & 120.0 & 28.000 & 150.0 & 1.00-9. & 355. & 0. \\
\hline & & 35.000 & 130.0 & 35.000 & 130.0 & $1.00-9$ & 106. & 0 . \\
\hline & & 35.000 & 140.0 & 42.000 & 200.0 & $1.00-9$ & 355. & \\
\hline & & 56.000 & 140.0 & 77.000 & 150.0 & $1.00-9$ & 106. & 0. \\
\hline & & 56.000 & 120.0 & 84.000 & 180.0 & $1.00-9$ & 355. & \\
\hline & \multirow[t]{10}{*}{$70^{\circ}$. air } & & & 21.000 & 130.0 & $2.00-9$ & 106. & \\
\hline & & & & 21.000 & 99.0 & 2.00-9. & 355. & \\
\hline & & 7.000 & 82.0 & 14.000 & 80.0 & $2.00-9$ & 106. & \\
\hline & & 7.000 & 82.0 & 14.000 & 89.0 & $2.00-9$ & 355. & \\
\hline & & 14.000 & 87.0 & 21.000 & 110.0 & 2.00-9. & 106. & \\
\hline & & 14.000 & 85.0 & 21.000 & 96.0 & 2.00-9 & 355. & \\
\hline & & 28.000 & 120.0 & 42.000 & 130.0 & 2.00-9. & 106. & \\
\hline & & 28.000 & 100.0 & 42.000 & 110.0 & 2.00-9. & 355. & \\
\hline & & 56.000 & 120.0 & 14.000 & 120.0 & 2.00-9. & 106. & \\
\hline & & 56.000 & 100.0 & 14.000 & 100.0 & 2.00-9. & 355. & \\
\hline \multirow[t]{4}{*}{$\mathbf{E u}$} & \multirow[t]{4}{*}{ room air } & 7.000 & 51.0 & 7.000 & 1600.0 & $6.00-7$ & 106. & \\
\hline & & 7.000 & 48.0 & 14.000 & 610.0 & $6.00-7$ & 355. & \\
\hline & & 21.000 & 69.0 & 21.000 & 600.0 & $6.00-7$ & 106. & \\
\hline & & 21.000 & 92.0 & 28.000 & 600.0 & $6.00-7$ & 355 . & \\
\hline
\end{tabular}


Element Temp Atm Stime srd1 srd2 dtime drd1 drd2 Conc pmin pmax

Core

JA-32

\begin{tabular}{|c|c|c|c|c|c|c|c|c|c|}
\hline \multirow{14}{*}{$\mathbf{E u}$} & room & air & 35.000 & 73.0 & 35.000 & 740.0 & $6.00-7$ & 106. & 150. \\
\hline & & & 35.000 & 88.0 & 42.000 & 570.0 & $6.00-7$ & 355. & 500. \\
\hline & & & $\mathbf{5 6 . 0 0 0}$ & 190.0 & 77.000 & 1300.0 & $6.00-7$ & 106. & 150. \\
\hline & & & 56.000 & 120.0 & 84.000 & 780.0 & $6.00-7$ & 355. & 500. \\
\hline & $70^{\circ}$ & air & & & 21.000 & 1300.0 & $6.00-7$ & 106. & 150. \\
\hline & & & & & 21.000 & 1100.0 & $6.00-7$ & 355. & 500. \\
\hline & & & 7.000 & 120.0 & 14.000 & 880.0 & $6.00-7$ & 106. & 150. \\
\hline & & & 7.000 & 93.0 & 14.000 & 1700.0 & $6.00-7$ & 355. & 500. \\
\hline & & & 14.000 & 180.0 & 21.000 & 1500.0 & $6.00-7$ & 106. & 150. \\
\hline & & & 14.000 & 130.0 & 21.000 & 890.0 & $6.00-7$ & 355. & 500. \\
\hline & & & 28.000 & 220.0 & 42.000 & 1600.0 & $6.00-7$ & 106. & 150. \\
\hline & & & 28.000 & 380.0 & 42.000 & 3200.0 & $6.00-7$ & 355. & 500. \\
\hline & & & 56.000 & 240.0 & 14.000 & 2000.0 & $6.00-7$ & 106. & 150. \\
\hline & & & 56.000 & 130.0 & 14.000 & 4000.0 & $6.00-7$ & 355. & 500. \\
\hline \multirow[t]{2}{*}{ I } & room & air & 21.000 & 0.35 & & & $1.00-13$ & 355. & 500. \\
\hline & & & 28.000 & -0.2 & & & $1.00-13$ & 355. & 500. \\
\hline Mo & room & air & 21.000 & 8.2 & & & $1.00-14$ & 355. & 500. \\
\hline $\mathbf{P u}$ & room & air & 14.000 & 110.0 & & & $1.00-6$ & 106. & 150. \\
\hline \multirow[t]{2}{*}{ Ru } & room & air & 21.000 & 88.0 & & & $3.00-12$ & 355. & 500. \\
\hline & & & 28.000 & 44.0 & & & $3.00-12$ & 355. & 500. \\
\hline \multirow[t]{2}{*}{ Sb } & room & air & 21.000 & 0.12 & & & $6.00-12$ & 355. & 00. \\
\hline & & & 28.000 & -0.88 & & & $6.00-12$ & 355. & \\
\hline
\end{tabular}


Element Temp Atm Stime srd1 srd2 dtime drd1 drd2 Cone pmin pmax

Core

JA-32

\begin{tabular}{|c|c|c|c|c|c|c|c|c|c|}
\hline \multirow[t]{18}{*}{ Sr } & room & air & 7.000 & 48.0 & 7.000 & 48.0 & $2.00-6$ & 106. & 150. \\
\hline & & & 7.000 & 50.0 & 14.000 & $\mathbf{5 5 . 0}$ & $2.00-6$ & 355. & 500. \\
\hline & & & 21.000 & 50.0 & 21.000 & 41.0 & $2.00-6$ & 106. & 150. \\
\hline & & & 21.000 & 52.0 & 28.000 & 52.0 & $2.00-6$ & 355. & 500. \\
\hline & & & 35.000 & 72.0 & 35.000 & 50.0 & $2.00-6$ & 106. & 150. \\
\hline & & & 35.000 & 56.0 & 42.000 & $\mathbf{5 8 . 0}$ & $2.00-6$ & 355. & 500. \\
\hline & & & 56.000 & 55.0 & 77.000 & 50.0 & $2.00-6$ & 106. & 150. \\
\hline & & & 56.000 & 71.0 & 84.000 & 72.0 & $2.00-6$ & 355. & 500. \\
\hline & $70^{\circ}$ & air & 21.000 & & 120.0 & & $2.00-6$ & 106. & 150. \\
\hline & & & & & 21.000 & 110.0 & $2.00-6$ & 355. & 500. \\
\hline & & & 7.000 & 82.0 & 14.000 & 80.0 & $2.00-6$ & 106. & 150. \\
\hline & & & 7.000 & 93.0 & 14.000 & 80.0 & $2.00-6$ & 355. & 500. \\
\hline & & & 14.000 & 92.0 & 21.000 & 110.0 & $2.00-6$ & 106. & 150. \\
\hline & & & 14.000 & 110.0 & 21.000 & 80.0 & $2.00-6$ & 355. & 500. \\
\hline & & & 28.000 & 120.0 & 42.000 & 140.0 & $2.00-6$ & 106. & 150. \\
\hline & & & $\mathbf{2 8 . 0 0 0}$ & 110.0 & 42.000 & 120.0 & $2.00-6$ & 355. & 500. \\
\hline & & & 56.000 & 160.0 & 14.000 & 93.0 & $2.00-6$ & 106. & 150. \\
\hline & & & 56.000 & 140.0 & 14.000 & 70.0 & $2.00-6$ & 355. & 500. \\
\hline \multirow[t]{9}{*}{$\mathbf{U}$} & room & air & 7.000 & 3.5 & 21.000 & 15.0 & $1.00-7$ & 106. & 150. \\
\hline & & & 7.000 & 1.4 & 21.000 & 0.2 & $1.00-7$ & 355. & 500. \\
\hline & & & 14.000 & 2.9 & 14.000 & 12.0 & $1.00-7$ & 106. & 150. \\
\hline & & & 14.000 & 1.3 & 14.000 & 5.4 & $1.00-7$ & 355. & 500. \\
\hline & & & 21.000 & 2.5 & 7.000 & 9.6 & $1.00-7$ & 106. & 150. \\
\hline & & & 21.000 & 1.3 & 7.000 & 5.2 & $1.00-7$ & 355. & 500. \\
\hline & $70^{\circ}$ & air & 7.000 & 10.0 & 21.000 & 23.0 & $1.00-7$ & 355. & 500. \\
\hline & & & 14.000 & 11.0 & 14.000 & 19.0 & $1.00-7$ & 355. & 500 \\
\hline & & & 21.000 & 15.0 & 7.000 & 20.0 & $1.00-7$ & 355. & \\
\hline
\end{tabular}

Core

JA-37

$\begin{array}{lllllllll}\text { Am room air } & 7.000 & 430.0 & 35.00 & 14000.0 & 1.00-6 . & 106 . & 150 . \\ & & 14.000 & 370.0 & 35.000 & 14000.0 & 1.00-6 . & 106 . & 150 . \\ & & 21.000 & 18000.0 & 84.000 & 54000.0 & 1.00-7 . & 106 . & 250 . \\ & & 28.000 & 430.0 & & & 1.00-6 . & 106 . & 150 . \\ & 28.000 & 1500.0 & 35.000 & 21000.0 & 1.00-6 . & 106 . & 150 .\end{array}$


Element Temp Atm Stime srd1 srd2 dtime drd1 drd2 Conc pmin pmax

\section{Core}

JA-37

$\begin{array}{llllll}\text { Am room air } \quad 42.000 & 37000.0 & 63.000 & 59000.0 \\ & & 56.000 & 640.0 & & \\ & & 84.000 & 46000.0 & 21.000 & 43000.0 \\ 70^{\circ} . \quad \text { air } \quad & 7.000 & 520.0 & & \\ & & 14.000 & 2100.0 & & \\ & & 14.000 & 680.0 & & \\ & 28.000 & 960.0 & & \\ & & 56.000 & 730.0 & & \\ & 56.000 & 800.0 & \end{array}$

1.00-7. 106.250.

1.00-6. 106. 150 .

1.00-7. 106. 250.

1.00-6. 106. 150 .

1.00-6. 106. 150 .

1.00-6. 106. 150.

1.00-6. 106. 150.

1.00-6. 106. 150 .

1.00-6. 106. 150 .

Ba room air

84.0001100 .0

2.00-6. 106. 150 .

$28.000 \quad 750.0$

2.00-6. 106. 150 .

$28.000 \quad 950.0$

2.00-6. 355. 500 .

84.000990 .0

2.00-6. 355. 500 .

$14.000 \quad 700.0$

$14.000 \quad 810.0$

2.00-6. 106.150.

$14.000 \quad 600.0$

$14.000 \quad 840.0$

2.00-6. 355. 500 .

$21.000 \quad 750.0$

$21.000 \quad 1000.0$

2.00-6. 106. 150 .

$21.000 \quad 660.0$

$21.000 \quad 860.0$

2.00-6. 355. 500 .

$35.000 \quad 710.0$

42.000900 .0

2.00-6. 106. 150 .

$35.000 \quad 830.0$

$42.000 \quad 1100.0$

$\begin{array}{ll}70.000 & 1000.0\end{array}$

$\mathbf{7 0 . 0 0 0} \quad \mathbf{7 6 0 . 0}$

$70^{\circ}$. air

$91.000 \quad 12000.0$

$21.000 \quad 3500.0$

$91.000 \quad 9900.0$

$21.000 \quad 3000.0$

$7.000 \quad 2000.0$

$14.000 \quad 3300.0$

2.00-6. 355. 500 .

2.00-6. 106. 150.

2.00-6. 355. 500 .

2.00-6. 106. 150 .

2.00-6. 106. 150.

1.00-6. 355. 500 .

1.00-3. 355. 500.

2.00-6. 106. 150 .

$\begin{array}{rllllllll}\text { Ba } \quad 70^{\circ} \text { air } & 7.000 & 1700.0 & 14.000 & 2500.0 & 1.00-6 . & 355 . & 500 . \\ & 14.000 & 2500.0 & 21.000 & 4800.0 & 2.00-6 . & 106 . & 150 . \\ & 14.000 & 2400.0 & 21.000 & 4400.0 & 1.00-6 . & 355 . & 500 . \\ & 21.000 & 4200.0 & 42.000 & 7600.0 & 2.00-6 . & 106 . & 150 . \\ & 21.000 & 3400.0 & 42.000 & 6300.0 & 1.00-6 . & 355 . & 500 . \\ & 49.000 & 6600.0 & 21.000 & 7500.0 & 2.00-6 . & 106 . & 150 . \\ & 49.000 & 6600.0 & 21.000 & 5900.0 & 1.00-6 . & 355 . & 500 .\end{array}$


Element Temp Atm Stime srd1 srd2 dtime drd1 drd2 Conc pmin pmax

Core

JA-37

Cs room air

$14.000 \quad 530.0$

14.000700 .0

$21.000 \quad 490.0$

$21.000 \quad 480.0$

$35.000 \quad 510.0$

$35.000 \quad 650.0$

$\mathbf{7 0 . 0 0 0} \quad \mathbf{7 8 0 . 0}$

$70.000 \quad 750.0$

70'. air

$7.000 \quad 1100.0$

$7.000 \quad 1100.0$

$14.000 \quad 1300.0$

$14.000 \quad 1300.0$

$21.000 \quad 1400.0$

$21.000 \quad 1400.0$

$49.000 \quad 1800.0$

$49.000 \quad 1600.0$

Eu room air

$\begin{array}{ll}28.000 & 600.0 \\ 84.000 & 1000.0 \\ 28.000 & 950.0 \\ 84.000 & 1100.0 \\ 14.000 & 640.0 \\ 14.000 & 880.0 \\ 21.000 & 800.0 \\ 21.000 & 800.0 \\ 42.000 & 720.0 \\ 42.000 & 970.0 \\ & \\ & \\ 21.000 & 1600.0 \\ 91.000 & 5800.0 \\ 21.000 & 1500.0 \\ 91.000 & 4400.0 \\ 14.000 & 1200.0 \\ 14.000 & 1300.0 \\ 21.000 & 4600.0 \\ 21.000 & 4700.0 \\ 42.000 & 1500.0 \\ 42.000 & 1800.0 \\ 21.000 & 1400.0 \\ 21.000 & 1800.0\end{array}$

$84.000 \quad 24000.0$

$84.000 \quad 18000.0$

28.0006700 .0

14.0002100 .0

$14.000 \quad 4100.0$

$21.000 \quad 7600.0$

$21.000 \quad 4000.0$

$28.000 \quad 13000.0$

$35.000 \quad 7300.0$

$35.000 \quad 6400.0$

$63.000 \quad 51000.0$

$63.000>26000.0$
1.00-7. 106. 150 .

1.00-7. 106. 150 .

1.00-7. 355. 500.

1.00-7. 355. 500 .

1.00-7. 106. 150.

1.00-7. 355. 500 .

1.00-7. 106 . 150.

1.00-7. 355. 500 .

1.00-7. 106.150.

1.00-7. 355. 500 .

1.00-7. 106. 150.

1.00-7. 355. 500 .

4.00-8. 106. 150.

4.00-8. 106. 150 .

4.00-8. 355. 500 .

4.00-8. 355. 500 .

4.00-8. 106. 150.

4.00-8. 355. 500 .

4.00-8. 106. 150.

4.00-8. 355. 500 .

4.00-8. 106. 150.

4.00-8. 355. 500 .

4.00-8. 106. 150 .

4.00-8. 355. 500 .

3.00-7. 106. 150 .

3.00-7. 355. 500 .

3.00-7. 355. 500 .

3.00-7. 106. 150 .

3.00-7. 355. 500 .

3.00-7. 106. 150.

3.00-7. 355. 500 .

3.00-8. 250. 355.

3.00-7. 106. 150.

3.00-7. 355. 500 .

3.00-8. 250. 355 .

8.00-9. 250. 355 . 
Element Temp Atm Stime srd1 srd2 dtime drd1 drd2 Conc pmin pmax

Core

JA-37

\begin{tabular}{|c|c|c|c|c|c|c|c|c|c|c|c|}
\hline \multirow[t]{14}{*}{ Eu } & room & air & 70.000 & 9500.0 & & & & & 3.00-7. & 106. & 150. \\
\hline & & & 70.000 & 6900.0 & & & & & $3.00-7$ & 355. & 500. \\
\hline & $70^{\circ}$ & air & & & & 91.000 & 24000.0 & & $1.00-7$ & 106. & 150. \\
\hline & & & & & & 21.000 & 19000.0 & & $1.00-7$ & 106. & 150. \\
\hline & & & & & & 21.000 & 11000.0 & & $1.00-7$ & 355. & 500. \\
\hline & & & & & & 91.000 & 13000.0 & & $1.00-7$ & 355. & 500. \\
\hline & & & 7.000 & 4000.0 & & 14.000 & 9700.0 & & $1.00-7$ & 106. & 150. \\
\hline & & & 7.000 & 2100.0 & & 14.000 & 7600.0 & & $1.00-7$ & 355. & 500. \\
\hline & & & 14.000 & 4100.0 & & 21.000 & 7700.0 & & $1.00-7$ & 106. & 150. \\
\hline & & & 14.000 & 4400.0 & & 21.000 & 12000.0 & & $1.00-7$ & 355. & 500. \\
\hline & $70^{\circ}$ & air & 21.000 & 4000.0 & & 42.000 & 17000.0 & & $1.00-7$ & 106. & 150. \\
\hline & & & 21.000 & 4500.0 & & 42.000 & 19000.0 & & $1.00-7$ & 355. & 500. \\
\hline & & & 49.000 & 5200.0 & & 21.000 & 13000.0 & & $1.00-7$ & 106. & 150. \\
\hline & & & 49.000 & 5500.0 & & 21.000 & 18000.0 & & $1.00-7$ & 355. & 500. \\
\hline \multirow[t]{2}{*}{ I } & room & air & 21.000 & -0.9 & & & & & $1.00-13$ & 355. & 500. \\
\hline & & & 28.000 & -0.2 & & & & & $1.00-13$ & 355. & 500. \\
\hline Mo & room & air & 21.000 & 10.0 & & & & & $1.00-14$ & 355. & 500. \\
\hline \multirow[t]{3}{*}{$\mathbf{N p}_{p}$} & room & air & 21.000 & 20.0 & & 84.000 & 230.0 & & $8.00-11$ & 106. & 250. \\
\hline & & & 42.000 & 22.0 & & 63.000 & 65.0 & & $8.00-11$ & 106. & 250. \\
\hline & & & 91.000 & 42.0 & & 21.000 & 210.0 & & $8.00-11$ & 106. & 250. \\
\hline \multirow[t]{6}{*}{$\mathbf{P u}$} & room & air & 7.000 & 390.0 & & & & & $1.00-6$ & 106. & 150. \\
\hline & & & 21.000 & 300.0 & & 84.000 & 870.0 & & $4.00-12$ & 106. & 250. \\
\hline & & & 28.000 & 180.0 & & & & & $1.00-6$ & 106. & 150. \\
\hline & & & 42.000 & 420.0 & 560.0 & 56.000 & 890.0 & 1700.0 & $4.00-12$ & 106. & 250. \\
\hline & & & 91.000 & 760.0 & 1900.0 & 21.000 & 1300.0 & 2400.0 & $4.00-12$ & 106. & 250. \\
\hline & $70^{\circ}$ & air & 7.000 & 240.0 & & & & & $1.00-6$ & 106. & 150. \\
\hline \multirow[t]{2}{*}{$\mathbf{R u}$} & room & air & 21.000 & 67.0 & & & & & $3.00-12$ & 355. & 500. \\
\hline & & & 28.000 & 65.0 & & & & & $3.00-12$ & 355. & 500. \\
\hline \multirow[t]{2}{*}{ Sb } & room & air & 21.000 & 0.5 & & & & & $6.00-12$ & 355. & 500. \\
\hline & & & 28.000 & 0.1 & & & & & $6.00-12$ & 355. & 500. \\
\hline
\end{tabular}




\section{Element Temp Atm Stime ard1 srd2 dtime drd1 drd2 Conc pmin pmax}

$\underline{\text { Core }}$

JA-37

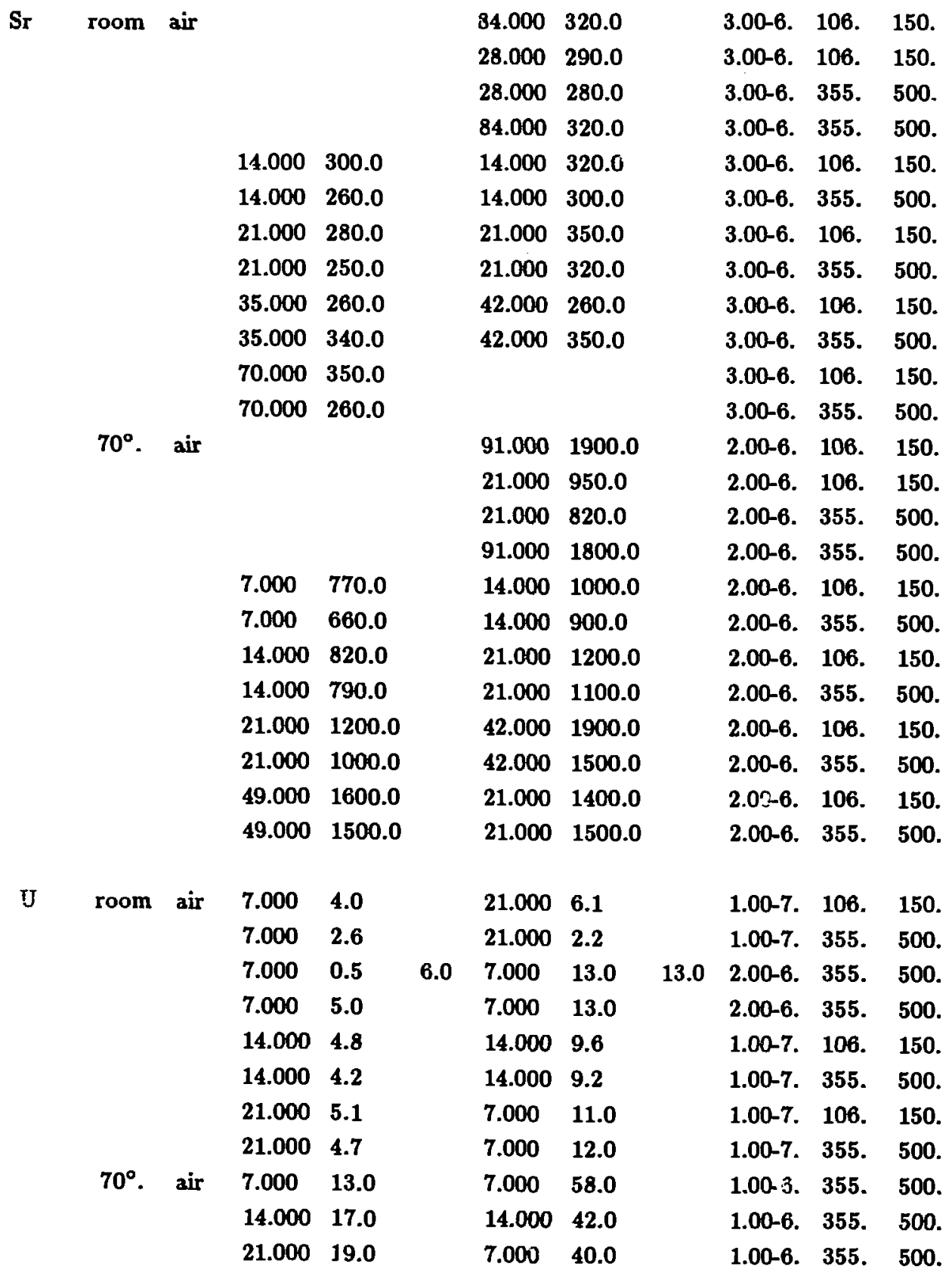


Element Temp Atm Stime srd1 srd2 dtime drd1 drd2 Conc pmin pmax

\section{$\underline{\text { Core }}$}

YM-22

\begin{tabular}{|c|c|c|c|c|c|c|c|c|c|c|c|}
\hline \multirow[t]{13}{*}{ Am } & \multirow[t]{13}{*}{ room } & \multirow[t]{7}{*}{ air } & 21.000 & 6500.0 & & 84.000 & 6700.0 & & $1.00-7$ & & 75. \\
\hline & & & 21.000 & 1500.0 & & 84.000 & 2400.0 & & $1.00-7$ & \multirow[t]{3}{*}{75.} & 500. \\
\hline & & & 42.000 & 6800.0 & & 63.000 & 6500.0 & & $1.00-7$ & & 75. \\
\hline & & & 42.000 & 6800.0 & & 63.000 & 6500.0 & & $1.00-7$ & & 75. \\
\hline & & & 42.000 & 1100.0 & & 63.000 & 1900.0 & & $1.00-7$ & \multirow[t]{2}{*}{75.} & 500. \\
\hline & & & 84.000 & 6900.0 & & 21.000 & 7300.0 & & $1.00-7$ & & 75. \\
\hline & & & 84..J0 & 1100.0 & & 21.000 & 3100.0 & & $1.00-7$ & \multirow[t]{2}{*}{75.} & 500. \\
\hline & & \multirow[t]{6}{*}{ ca } & 21.000 & 1400.0 & & 84.000 & 2500.0 & & $3.00-8$ & & 75. \\
\hline & & & 21.000 & 750.0 & & 84.000 & 2300.0 & & $3.00-8$ & \multirow[t]{2}{*}{75.} & 500. \\
\hline & & & 42.000 & 2100.0 & & 63.000 & $\mathbf{3 1 0 0 . 0}$ & & $3.00-8$ & & 75. \\
\hline & & & 42.000 & 960.0 & & 63.000 & 2300.0 & & $3.00-8$ & \multirow[t]{2}{*}{75.} & 500. \\
\hline & & & 84.000 & 1800.0 & & 21.000 & 7500.0 & & $3.00-8$ & & 75. \\
\hline & & & 84.000 & 1200.0 & & 21.000 & 4300.0 & & $3.00-8$ & 75. & 500. \\
\hline \multirow[t]{18}{*}{$\mathrm{Ba}$} & \multirow[t]{18}{*}{ rocis } & \multirow[t]{14}{*}{ air } & 21.000 & 1200.0 & & & & & 4.00-7 & & 75. \\
\hline & & & 21.000 & 1300.0 & & & & & $3.00-7$ & & 75. \\
\hline & & & 21.000 & 1000.0 & & & & & $3.00-7$ & & 75. \\
\hline & & & 21.000 & 760.0 & & & & & $1.00-5$ & & 75. \\
\hline & & & 21.000 & 400.0 & & & & & $1.00-4$ & & 75. \\
\hline & & & 21.000 & 600.0 & & & & & $3.00-7$ & 75 . & 500. \\
\hline & & & 21.000 & 210.0 & & & & & $1.00-4$ & 75. & 500. \\
\hline & & & $2 i .000$ & 470.0 & & & & & $1.00-5$ & 75. & 500. \\
\hline & & & 21.000 & 670.0 & & & & & $3.00-7$ & 75. & 500. \\
\hline & & & 21.000 & 790.0 & & & & & $4.00-7$ & 75. & 500. \\
\hline & & & 21.000 & 910.0 & & 42.000 & 650.0 & & $3.00-7$ & 106. & 500. \\
\hline & & & 21.000 & 850.0 & & & & & $3.00-7$ & 106. & 500. \\
\hline & & & 42.000 & 1300.0 & & 21.000 & 1600.0 & & $3.00-7$ & & 106. \\
\hline & & & 42.000 & 980.0 & 850.0 & 21.000 & 990.0 & 830.0 & $3.00-7$ & 106. & 500. \\
\hline & & \multirow[t]{4}{*}{ ca } & 21.000 & 660.0 & & 42.000 & 1100.0 & & $3.00-7$ & & 75. \\
\hline & & & 21.000 & 200.0 & & 42.000 & 470.0 & & $3.00-7$ & \multirow[t]{2}{*}{75.} & 500. \\
\hline & & & 42.000 & 900.0 & & 21.000 & 1300.0 & & 3.00-7 & & 75. \\
\hline & & & 42.000 & 300.0 & & 21.000 & 460.0 & & $3.00-7$ & 75. & 500. \\
\hline
\end{tabular}


Element Temp Atm Stime srd1 srd2 dtime drd1 drd2 Conc pmin pmax

\section{Core}

YM-22

\begin{tabular}{|c|c|c|c|c|c|c|c|c|c|c|c|}
\hline & & & 84.000 & 1000.0 & & & & & $3.00-7$ & & 75. \\
\hline & & & 84.000 & 300.0 & & & & & $3.00-7$ & 75. & 500. \\
\hline \multirow[t]{10}{*}{$\mathrm{Ce}$} & room & air & 21.000 & 1200.0 & & & & & $7.00-7$ & 106. & 500. \\
\hline & & & 21.000 & 1400.0 & & 42.000 & 6100.0 & & $7.00-7$ & 106. & 500. \\
\hline & & & 42.000 & 1600.0 & & 21.000 & 4900.0 & & $7.00-7$ & & 106. \\
\hline & & & 42.000 & 1300.0 & 1200.0 & 21.000 & 8100.0 & 5400.0 & $7.00-7$ & 106. & 500. \\
\hline & & ca & & & & 21.000 & 2100.0 & & $2.00-8$ & 75. & 500. \\
\hline & & & 21.000 & 630.0 & & 42.000 & 2400.0 & & 2.00-8. & & 75. \\
\hline & & & 21.000 & 760.0 & & 42.000 & 2700.0 & & $2.00-8$ & 75. & 500. \\
\hline & & & 42.000 & 860.0 & & 21.000 & 2100.0 & & $2.00-8$ & & 75. \\
\hline & & & 84.000 & 760.0 & & & & & $2.00-8$ & & 75. \\
\hline & & & 84.000 & 1600.0 & & & & & $2.00-8$ & 75. & 500. \\
\hline \multirow[t]{15}{*}{$\mathrm{Cs}$} & room & air & 21.000 & 610.0 & & & & & 2.00-7. & & 75. \\
\hline & & & 21.000 & 12.0 & & & & & $2.00-3$ & & 75. \\
\hline & & & 21.000 & 380.0 & & & & & $3.00-9$ & & 75. \\
\hline & & & 21.000 & 130.0 & & & & & $2.00-5$ & & 75. \\
\hline & & & 21.000 & 260.0 & & & & & $2.00-7$ & 75. & 500. \\
\hline & & & 21.000 & 550.0 & & & & & $3.00-10$ & 75. & 500. \\
\hline & & & 21.000 & 10.0 & & & & & $2.00-3$ & 75. & 500. \\
\hline & & & 21.000 & 110.0 & & & & & $2.00-5$ & 75. & 500. \\
\hline & & & 21.000 & 660.0 & & & & & $3.00-9$ & 75. & 500. \\
\hline & & & 21.000 & 260.0 & & 42.000 & 360.0 & & $1.00-9$ & 106. & 500. \\
\hline & & & 21.000 & 380.0 & & & & & $1.00-9$ & 106. & 500. \\
\hline & & & 42.000 & 540.0 & & 21.000 & 500.0 & & $1.00-9$ & & 106. \\
\hline & & & 42.000 & 270.0 & 240.0 & 21.000 & 380.0 & 360.0 & $1.00-9$ & 106. & 500. \\
\hline & & $\mathbf{c a}$ & 21.000 & 380.0 & & 42.000 & 550.0 & & $2.00-9$ & & 75. \\
\hline & & & 21.000 & 200.0 & & 42.000 & 340.0 & & $2.00-9$ & 75. & 500. \\
\hline
\end{tabular}


Element Temp Atm Stime srd1 srd2 dtime drd1 drd2 Conc pmin pmax

Core

YM-22

\begin{tabular}{|c|c|c|c|c|c|c|c|c|c|c|c|}
\hline \multirow{4}{*}{ Cs } & \multirow{4}{*}{ room } & \multirow[t]{4}{*}{ ca } & 42.000 & \multicolumn{2}{|l|}{440.0} & \multirow{2}{*}{$\begin{array}{l}21.000 \\
21.000\end{array}$} & \multirow{2}{*}{$\begin{array}{l}490.0 \\
280.0\end{array}$} & \multicolumn{3}{|c|}{ 2.00-9. } & 75. \\
\hline & & & 42.000 & 210.0 & & & & & $2.00-9$ & 75. & 500. \\
\hline & & & 84.000 & 480.0 & & & & & $2.00-9$ & & 75. \\
\hline & & & 84.000 & 250.0 & & & & & $2.00-9$ & 75. & 500. \\
\hline \multirow[t]{19}{*}{ Eu } & room & air & 21.000 & 1900.0 & & & & & $1.00-8$ & & 75. \\
\hline & & & 21.000 & 1900.0 & & & & & $4.00-8$ & & 75. \\
\hline & & & 21.000 & 5800.0 & & & & & $9.00-6$ & & 75. \\
\hline & & & 21.000 & 690.0 & & & & & $3.00-6$ & & 75. \\
\hline & & & 21.000 & $2100.0 \overline{0}$ & & & & & $3.00-9$ & 75. & 500. \\
\hline & & & 21.000 & 1900.0 & & & & & $1.00-8$ & 75. & 500. \\
\hline & & & 21.000 & 1900.0 & & & & & $4.00-8$ & 75. & 500. \\
\hline & & & 21.000 & 1100.0 & & & & & $9.00-6$ & 75. & 500. \\
\hline & & & 21.000 & 1200.0 & & & & & $3.00-6$ & 75. & 500. \\
\hline & & & 21.000 & 1200.0 & & & & & $5.00-8$ & 106. & 500. \\
\hline & & & 21.000 & 1300.0 & & 42.000 & 3300.0 & & $5.00-8$ & 106. & 500. \\
\hline & & & 42.000 & 1500.0 & & 21.000 & 4000.0 & & $5.00-8$ & & 106. \\
\hline & & & 42.000 & 1700.0 & 1400.0 & 21.000 & 3900.0 & 3100.0 & $5.00-8$ & 106. & 500. \\
\hline & & ca & & & & 42.000 & 3100.0 & & $2.00-8$ & 75. & 500. \\
\hline & & & 21.000 & 800.0 & & 42.000 & 2200.0 & & $2.00-8$ & & 75. \\
\hline & & ca & 21.000 & 710.0 & & 42.000 & 2500.0 & & $2.00-8$ & 75. & 500. \\
\hline & & & 42.000 & 990.0 & & 21.000 & 1900.0 & & $2.00-8$ & & 75. \\
\hline & & & 84.000 & 1000.0 & & & & & $2.00-8$ & & 75. \\
\hline & & & 84.000 & 1300.0 & & & & & $2.00-8$ & 75. & 500. \\
\hline \multirow[t]{6}{*}{$\mathbf{N p}_{\mathbf{p}}$} & room & air & 21.000 & 5.1 & & 84.000 & 26.0 & & $1.00-10$ & 75. & 500. \\
\hline & & & 42.000 & 5.8 & & 63.000 & 30.0 & & $1.00-10$ & 75. & 500. \\
\hline & & & 84.000 & 7.0 & & 21.000 & 42.0 & & $1.00-10$ & 75. & 500. \\
\hline & & ca & 28.000 & 6.1 & 7.0 & 84.000 & 18.0 & 18.0 & $3.00-11$ & 75. & 500. \\
\hline & & & 56.000 & 9.5 & 9.5 & 49.000 & 19.0 & 17.0 & $3.00-11$ & 75. & 500. \\
\hline & & & 84.000 & 9.5 & 10.0 & 21.000 & 34.0 & 34.0 & $3.00-11$ & 75. & 500. \\
\hline
\end{tabular}


Element Temp Atm Stime srd1 srd2 dtime drd1 drd2 Conc pmin pmax

\section{Core}

YM-22

\begin{tabular}{|c|c|c|c|c|c|c|c|c|}
\hline \multirow{21}{*}{\multicolumn{2}{|c|}{ room air }} & 21.000 & 54.0 & 21.000 & 990.0 & $2.00-10$ & & 75. \\
\hline & & 21.000 & 66.0 & 21.000 & 1100.0 & $2.00-9$ & & 75. \\
\hline & & 21.000 & 63.0 & 21.000 & 1200.0 & $3.00-11$ & & 75. \\
\hline & & 21.000 & 34.0 & 21.000 & 280.0 & $1.00-8$ & & 75. \\
\hline & & 21.000 & 60.0 & 21.000 & 1100.0 & $8.00-12$ & & 75. \\
\hline & & 21.000 & 130.0 & 84.000 & 1400.0 & $4.00-12$ & & 75. \\
\hline & & 21.000 & 41.0 & 21.000 & 920.0 & $2.00-9$ & 75. & 500. \\
\hline & & 21.000 & 54.0 & 21.000 & 470.0 & $2.00-10$ & 75. & 500. \\
\hline & & 21.000 & 16.0 & 21.000 & 916.0 & $1.00-8$ & 75. & 500. \\
\hline & & 21.000 & 47.0 & 21.000 & 1800.0 & $2.00-11$ & 75. & 500. \\
\hline & & 21.000 & 37.0 & 84.000 & 1300.0 & $4.00-12$ & 75. & 500. \\
\hline & & 21.000 & 65.0 & 21.000 & 960.0 & $8.00-12$ & 75. & 500. \\
\hline & & 21.000 & 70.0 & 21.000 & 1900.0 & $6.00-10$ & 75. & 500. \\
\hline & & 21.000 & 120.0 & 21.000 & 2800.0 & $6.00-13$ & 75. & 500. \\
\hline & & 21.000 & 62.0 & 21.000 & 580.0 & $3.00-11$ & 75. & 500. \\
\hline & & 21.000 & 79.0 & 21.000 & 1400.0 & $1.00-10$ & 75. & 500. \\
\hline & & 21.000 & 17.0 & 21.000 & 730.0 & $1.00-8$ & 75. & 500. \\
\hline & & 42.000 & 210.0 & 63.000 & 1300.0 & $4.00-12$ & & 75. \\
\hline & & 42.000 & 64.0 & 63.000 & 1300.0 & $4.00-12$ & 75. & 300. \\
\hline & & 84.000 & 280.0 & 21.000 & 1900.0 & $4.00-12$ & & 75. \\
\hline & & 84.000 & 100.0 & 21.000 & 1400.0 & $4.00-12$ & 75. & 500. \\
\hline & $\mathrm{ca}$ & 21.000 & 85.0 & 84.000 & 1000.0 & $4.00-13$ & & 75. \\
\hline & & 21.000 & 120.0 & 84.000 & 970.0 & $4.00-13$ & 75. & 500. \\
\hline & & 42.000 & 260.0 & 63.000 & 1500.0 & $4.00-13$ & & 75. \\
\hline & & 42.000 & 400.0 & 63.000 & 1800.0 & $4.00-13$ & 75. & 500. \\
\hline & & 84.000 & 190.0 & 21.000 & 3100.0 & $4.00-13$ & & b. \\
\hline & & 84.000 & 250.0 & 21.000 & 1200.0 & $4.00-13$ & 75. & 0. \\
\hline
\end{tabular}


Element Temp Atm Stime grd1 srd2 dtime drd1 drd2 Conc pmin pmax

Core

YM-22

\begin{tabular}{|c|c|c|c|c|c|c|c|c|c|c|c|}
\hline \multirow{20}{*}{ Sr } & room & air & 21.000 & 70.0 & & & & & $6.00-7$ & & 75. \\
\hline & & & 21.000 & 20.0 & & & & & $3.00-3$ & & 75. \\
\hline & & & 21.000 & 81.0 & & & & & $5.00-7$ & & 75. \\
\hline & & & 21.000 & 54.0 & & & & & $3.00-5$ & & 75. \\
\hline & & & 21.000 & 65.0 & & & & & $6.00-7$ & & 75. \\
\hline & & & 21.000 & 95.0 & & & & & $6.00-7$ & 75. & 500. \\
\hline & & & 21.000 & 65.0 & & & & & $6.00-7$ & 75. & 500. \\
\hline & & & 21.000 & 71.0 & & & & & $5.00-7$ & 75. & 500. \\
\hline & & & 21.000 & 9.4 & & & & & $3.00-3$ & 75. & 500. \\
\hline & & & 21.000 & 55.0 & & & & & $3.00-5$ & 75. & 500. \\
\hline & & & 21.000 & 48.0 & & 42.000 & 59.0 & & $7.00-7$ & 106. & 500. \\
\hline & & & 21.000 & 48.0 & & & & & $7.00-7$ & 106. & 500. \\
\hline & & & 42.000 & 66.0 & & 21.000 & 74.0 & & $7.00-7$ & & 106. \\
\hline & & & 42.000 & 55.0 & 62.0 & 21.000 & 63.0 & 57.0 & $7.00-7$ & 106. & 500. \\
\hline & & $\mathrm{ca}$ & 21.000 & 73.0 & & 42.000 & 120.0 & & $7.00-7$ & & 75. \\
\hline & & & 21.000 & 48.0 & & 42.000 & 120.0 & & $7.00-7$ & 75. & 500. \\
\hline & & & 42.000 & 75.0 & & 21.000 & 100.0 & & 7.00-7. & 75. & \\
\hline & & & 42.000 & 53.0 & & 21.000 & 70.0 & & $7.00-7$ & 75. & 500. \\
\hline & & & 84.000 & 81.0 & & & & & $7.00-7$ & & 75. \\
\hline & & & 84.000 & 46.0 & & & & & $7.00-7$ & 75. & 500. \\
\hline \multirow[t]{10}{*}{$\mathrm{Tc}$} & room & air & 42.000 & 0.13 & & 63.000 & 0.47 & & $1.00-3$ & 106. & 500. \\
\hline & & & 42.000 & 0.17 & & 63.000 & 1.2 & & $1.00-6$ & 106. & 500. \\
\hline & & & 42.000 & 0.72 & & 63.000 & 1.2 & & $1.00-12$ & 106. & 500. \\
\hline & & & 42.000 & 0.16 & & 63.000 & 1.9 & & $1.00-9$ & 106. & 500. \\
\hline & & ca & 21.000 & 3.8 & & 84.000 & 37.0 & & $1.00-12$ & & 75. \\
\hline & & & 21.000 & 0.4 & & 84.000 & 12.0 & & $1.00-12$ & 75. & 500. \\
\hline & & ca & 42.000 & 6.5 & & 63.000 & 14.0 & & $1.00-12$ & & 75. \\
\hline & & & 42.000 & 0.3 & & 63.000 & 9.5 & & $1.00-12$ & 75. & 500. \\
\hline & & & 84.000 & 3.2 & & 21.000 & 32.0 & & $1.00-12$ & & 5. \\
\hline & & & 84.000 & 1.5 & & 21.000 & 5.3 & & $1.00-12$ & 75. & D. \\
\hline
\end{tabular}


Element Temp Atm Stime ord1 ord2 dtime drd1 drd2 Conc pmin pmax

\section{Core}

YM-22

$\begin{array}{lllll}\text { U room air } & 7.000 & 2.0 & 14.000 & 15.0 \\ & 7.000 & 1.0 & 14.000 & 0 \\ & 14.000 & 2.0 & 7.000 & 8.0 \\ 14.000 & 2.0 & 7.000 & 8.0 \\ & 21.000 & 2.0 & & \\ & 21.000 & 2.0 & & \\ \text { ca } & 7.000 & 0 & & \\ & 14.000 & 0.9 & & \\ & 14.000 & 0 & \\ & 21.000 & 1.2 & \\ & 21.000 & 0.8 & \end{array}$

1.00-6.

106.

1.00- 6. 106. 500 .

1.00-6. 106 .

1.00-6. 106. 500.

1.00-6. 106 .

1.00-6. 106. 500 .

1.00-6. 75 .

1.00-6. 75 .

1.00-6. 75. 500 .

1.00-6. 75 .

1.00-6. 75. 500 .

Core

YM-30

\begin{tabular}{|c|c|c|c|c|c|c|c|c|c|}
\hline \multirow[t]{3}{*}{$\mathrm{Ba}$} & room & air & 21.000 & 2000.0 & 84.000 & 4200.0 & $8.00-10$ & 75. & 500. \\
\hline & & & 42.000 & 1800.0 & 63.000 & 2000.0 & $8.00-10$ & 75. & 500. \\
\hline & & & 84.000 & 6400.0 & 21.000 & 3100.0 & $8.00-10$ & 75. & 500. \\
\hline \multirow[t]{3}{*}{$\mathrm{Ce}$} & room & air & 21.000 & 130000 & 84.000 & 200000 & $8.00-13$ & 75. & 500. \\
\hline & & & 42.000 & 1100000 & 63.000 & 160000 & $8.00-13$ & 75. & 500. \\
\hline & & & 84.000 & 330000 & 21.000 & 150000 & $8.00-13$ & 75. & 500. \\
\hline \multirow[t]{3}{*}{$\mathrm{cs}$} & room & air & 21.000 & 850.0 & 84.000 & 1600.0 & $3.00-9$ & 75. & 500. \\
\hline & & & 42.000 & 860.0 & 63.000 & 1700.0 & $3.00-9$ & 75. & 500. \\
\hline & & & 84.000 & 2000.0 & 21.000 & 1300.0 & $3.00-9$ & 75. & 500. \\
\hline \multirow[t]{3}{*}{ Eu } & room & air & 21.000 & 94000.0 & 84.000 & 10000.0 & $1.00-10$ & 75. & 500. \\
\hline & & & 42.000 & 120000.0 & 63.000 & 10000.0 & $1.00-10$ & 75. & 500. \\
\hline & & & 84.000 & 260000.0 & 21.000 & 12000.0 & $1.00-10$ & 75. & 500. \\
\hline \multirow[t]{3}{*}{ Sr } & room & air & 21.000 & 100.0 & 84.000 & 210.0 & $8.00-11$ & 75. & 500. \\
\hline & & & 42.000 & 320.0 & 63.000 & 260.0 & $8.00-11$ & 75. & 500. \\
\hline & & & 84.000 & 360.0 & 21.000 & 160.0 & $8.00-11$ & 75. & \\
\hline
\end{tabular}


Element Temp Atm Stime srd1 srd2 dtime drd1 drd2 Conc pmin pmax

Core

YM-38

$$
\begin{aligned}
& \text { Am room air } 21.000 \quad 9500.0 \\
& 21.000 \quad 6100.0 \\
& 42.0007300 .0 \\
& 42.000 \quad 5200.0 \\
& 84.0002600 .0 \\
& 84.0002500 .0 \\
& \text { ca } \quad 21.000 \quad 4600.0 \\
& 21.0003400 .0 \\
& 42.000 \quad 8800.0 \\
& 42.000 \quad 3600.0 \\
& \text { ca } \quad 84.000 \quad 8200.0 \\
& 84.000 \quad 5000.0
\end{aligned}
$$

Ba room air $21.000 \quad 69000.0$

21.000190000 .0

21.00093000 .0

21.00072000 .0

21.000100000 .0

21.00097000 .0

$21.000 \quad 81000.0$

$21.000 \quad 100000.0$

$21.000 \quad 120000.0$

$21.000 \quad 33000.0$

$21.000 \quad 79000.0$

$21.000 \quad 36000.0$

21.00068000 .0

$21.000 \quad 75000.0$

$21.000 \quad 77000.0$

$21.000 \quad 57000.0$

21.000100000 .0

$42.000 \quad 40000.0$

42.00081000 .0

$\begin{array}{ll}84.000 & 9900.0 \\ 84.000 & 5900.0 \\ 63.000 & 14000.0 \\ 63.000 & 9600.0 \\ 28.000 & 12000.0 \\ 28.000 & 5800.0 \\ 84.000 & 18000.0 \\ 84.000 & 18000.0 \\ 63.000 & 10000.0 \\ 63.000 & 8400.0 \\ 21.000 & 19000.0 \\ 21.000 & 9100.0\end{array}$

1.00-7. 75.

1.00-7. 75. 500 .

1.00-7.

75.

1.00-7. 75. 500 .

1.00-7.

75.

1.00-7. 75. 500 .

3.00-8.

75.

3.00-8. 75. 500 .

3.00-8. 75 .

3.00-8. 75. 500 .

3.00-8.

75.

3.00-8. 75. 500 .

4.00-7.

38.

4.00-\%.

38.

1.00-5.

75.

4.00-7.

75.

1.00-4.

75.

2.00-6.

75.

6.00-7.

75.

4.00-7. 38. 106.

4.00-7. 38. 106.

4.00-7. 75 . 500 .

1.00-4. 75. 500 .

2.00-6. 75. 500 .

6.00-7. 75. 500 .

1.00-5. 75. 500 .

4.00-7. 106. 500.

4.00-7. 106. 500 .

4.00-7. 106. 500 .

$21.000110000 .0 \quad 4.00-7$. 106.

21.000260000 .0

4.00-7. 106. 500 . 


\section{Core}

YM-38

$\begin{array}{lll}\text { Ba room ca } \quad 21.000 & 57000.0 \\ & 21.000 & 34000.0 \\ 42.000 & >210000.0 \\ 42.000 & 41000.0 \\ 84.000 & 22000.0 \\ 84.000 & 11000.0\end{array}$

Ce room air $21.000 \quad 900.0$

42.000950 .0

42.000620 .0

21.000650 .0

$21.000 \quad 560.0$

$42.000 \quad 320.0$

42.000850 .0

$84.000 \quad 740.0$

$84.000 \quad 320.0$

Cs room air $21.000 \quad 11000.0$

$21.000 \quad 20000.0$

$21.000 \quad 3500.0$

$21.000 \quad 3700.0$

$21.000 \quad 6300.0$

$21.000 \quad 3200.0$

$21.000 \quad 2700.0$

$21.000 \quad 17000.0$

$21.000 \quad 15000.0$

$21.000 \quad 3400.0$

$21.000 \quad 6000.0$

$21.000 \quad 4000.0$

$21.000 \quad 4200.0$

$21.000 \quad 3500.0$

21.00014000 .0

$\begin{array}{lllll}42.000 & 63000.0 & 4.00-7 . & & 75 . \\ 42.000 & 58000.0 & 4.00-7 . & 75 . & 500 . \\ 21.000 & 46000.0 & 4.00-7 . & & 75 . \\ 21.000 & 89000.0 & 4.00-7 . & 75 . & 500 . \\ & & 4.00-7 . & & 75 . \\ & & 4.00-7 . & 75 . & 500 .\end{array}$

1.00-6. 106.500.

$\begin{array}{llll}21.000 & 4900.0 & 1.00-6 . & 106 .\end{array}$

$21.0002600 .0 \quad 1.00-6$. 106.500.

$\begin{array}{llll}42.000 & 21000.0 & 7.00-8 . & 75 .\end{array}$

$\begin{array}{lllll}42.000 & 1300.0 & 7.00-8 . & 75 . & 500 .\end{array}$

$\begin{array}{llll}21.000 & 660.0 & 7.00-8 . & 75 .\end{array}$

$\begin{array}{lllll}21.000 & 3200.0 & 7.00-8 . & 75 . & 500 .\end{array}$

7.00-8. 75 .

7.00-8. 75.500.

4.00-9. 38 .

4.00-9. 38 .

3.00-3. 75 .

3.00-5. 75 .

3.00-7. 75 .

2.00-10. 75 .

2.00-9. 75 .

4.00-9. 38. 106.

4.00-9. 38. 106.

3.00-3. 75. 500 .

3.00-5. 75. 500 .

2.00-9. 75. 500 .

3.00-7. 75. 500.

2.00-10. 75 . 500.

4.00-9. 106. 500 . 
Element Temp Atm Stime srd1 srd2 dtime drd1 drd2 Cone pmin pmax

\section{Core}

YM-38

$\begin{array}{rll}\text { Cs room air } \quad 21.000 & 12000.0 \\ & 21.000 & 14000.0 \\ & 42.000 & 5900.0 \\ & 42.000 & 8200.0 \\ \text { ca } & 21.000 & 9500.0 \\ & 21.000 & 7900.0 \\ 42.000 & 14000.0 \\ 42.000 & 10000.0 \\ 84.000 & 9000.0 \\ 84.000 & 5400.0\end{array}$

Eu room air 21.0002200 .0

21.0003000 .0

21.0003700 .0

21.0005000 .0

21.0007100 .0

21.0002600 .0

$21.000 \quad 3100.0$

$21.000 \quad 1300.0$

$21.000 \quad 1300.0$

$21.000 \quad 13000.0$

$21.000 \quad 13000.0$

$42.000 \quad 12000.0$

$42.000 \quad 15000.0$

$21.000 \quad 8000.0$

$21.000 \quad 15000.0$

1.00-9. 106.500.

4.00-9. 106. 500 .

1.00-9.

106.

1.00-9. 106. 500 .

3.00-9.

75.

3.00-9. 75. 500 .

3.00-9. 75 .

3.00-9. 75. 500 .

3.00-9.

75.

3.00-9. 75. 500 .

$21.000 \quad 3700.0$

7.00-8.

38.

7.00-8.

38.

6.00-8.

75.

6.00-9.

75.

6.00-6.

75.

3.00-6. 75 .

4.00-8. 75 .

7.00-8. 38. 106.

7.00-8. 38. 106 .

$21.000 \quad 4600.0$

6.00-9. 75. 500 .

21.0001700 .0

6.00-6. 75. 500 .

21.0001700 .0

4.00-6. 75. 500 .

21.0002700 .0

6.00-8. 75. 500.

$21.000 \quad 1300.0$

21.0001500 .0

42.00021060 .0

4.00-8. 75. 500 .

$21.000 \quad 2600.0$

$42.000 \quad 4900.0$

$21.000 \quad 10000.0$

42.0001500 .0

$21.000 \quad 7300.0$

7.00-8. 106. 500 .

7.00-8. 106. 500 .

7.00-8. 106. 500 .

7.00-8. 106 .

7.00-8. 106. 500 . 
Element Temp Atm Stime srd1 srd2 dtime drd1 drd2 Conc pmin pmax

Core

YM-38

ca $\begin{array}{llll}21.000 & 1100.0 & 42.000 & 21000.0 \\ 21.000 & 840.0 & 42.000 & 1300.0 \\ 42.000 & 560.0 & 21.000 & 820.0 \\ 42.000 & 1000.0 & 21.000 & 4300.0 \\ 84.000 & 1000.0 & & \\ 84.000 & 470.0 & & \end{array}$

$N_{p} \quad$ room air $\quad 28.000 \quad 9.3$

28.0009 .4

42.00011 .0

84.00012 .0

ca $\quad 28.000 \quad 14.0$

$56.000 \quad 120.0$

$84.000 \quad 190.0$

Pu

$91.000 \quad 1700.0$

$\begin{array}{lllllll} & 84.000 & 17.0 & & 4.00-11 . & 75 . & 500 . \\ & 84.000 & 22.0 & & 4.00-11 . & 75 . & 500 . \\ 11.0 & 63.000 & 23.0 & 24.0 & 4.00-11 . & 75 . & 500 . \\ 14.0 & 21.000 & 28.0 & 33.0 & 4.00-11 . & 75 . & 500 . \\ 19.0 & 84.000 & 22.0 & 250.0 & 2.00-11 . & 75 . & 500 . \\ 160.0 & 49.000 & 310.0 & 500.0 & 2.00-11 . & 75 . & 500 . \\ 77.0 & 21.000 & 2100.0 & 250.0 & 2.00-11 . & 75 . & 500 .\end{array}$

$91.000 \quad 1100.0$

63.0002200 .0

$63.000 \quad 1000.0$

$21.000 \quad 4300.0$

21.0001800 .0

84.0002200 .0

$91.000 \quad 2400.0$

56.0002000 .0

$56.000 \quad 2200.0$

21.0002600 .0

21.0002300 .0
9.00-8. $\quad 75$.

9.00-8. 75. 500 .

9.00-8. 75 .

9.00-8. 75. 500.

9.00-8. 75 .

9.00-8. 75. 500 .

4.00-12. 75 .

4.00-12. 75. 500 .

4.00-12. 75 .

4.00-12. 75. 500 .

4.00-12. 75 .

4.00-12. 75. 500 .

2.00-13. 75 .

2.00-13. 75. 500 .

2.00-13. 75 .

2.00-13. 75. 500 .

2.00-13. 75 .

2.00-13. 75. 500 . 
Element Temp Atm Stime srd1 srd2 dtime drd1 drd2 Conc pmin pmax

\section{Core}

YM-38

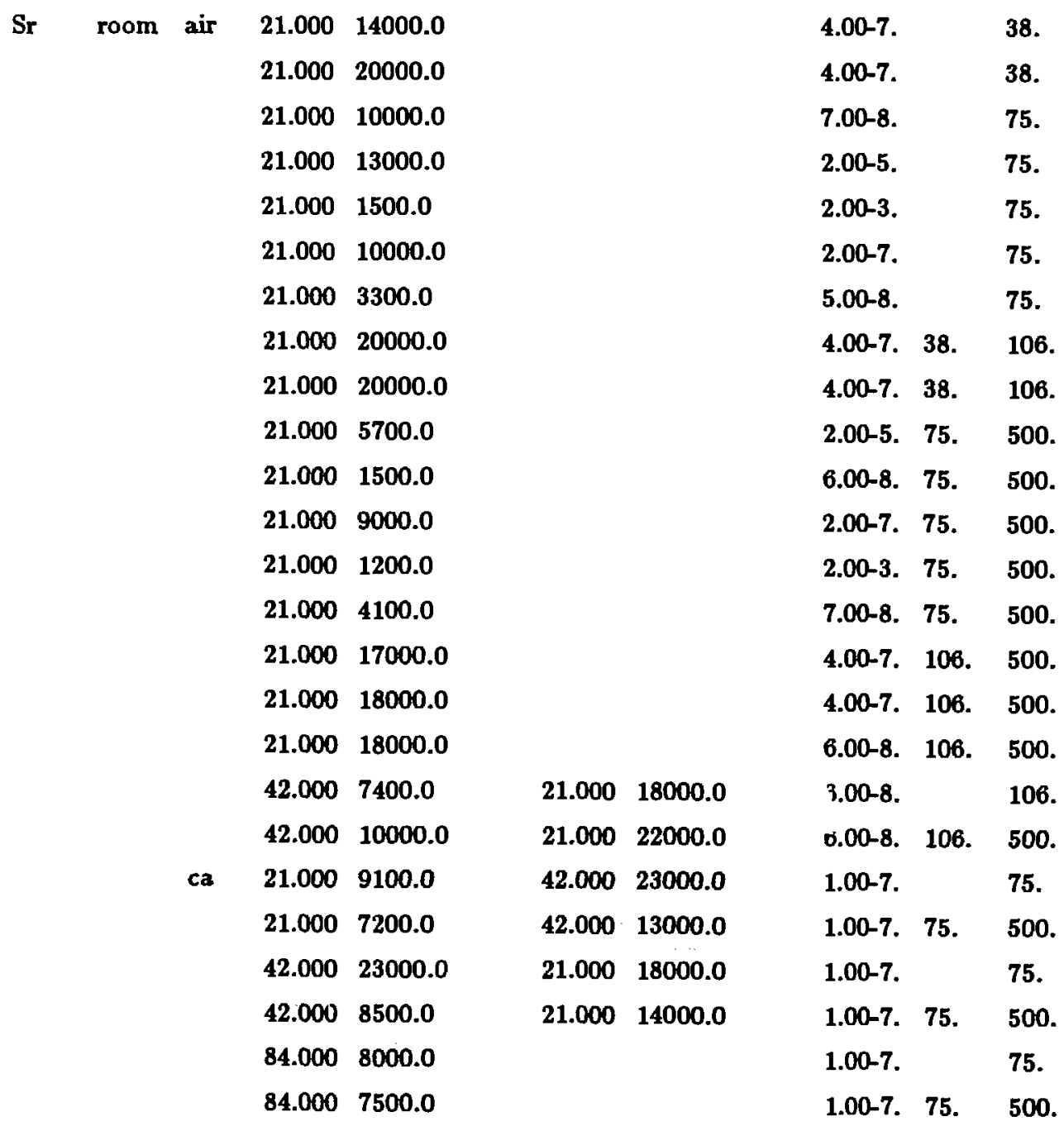


Element Temp Atm Stime ord1 srd2 dtime drd1 drd2 Conc pmin pmax

Core

YM-38

\begin{tabular}{|c|c|c|c|c|c|c|c|c|}
\hline \multirow[t]{6}{*}{ room } & \multirow[t]{6}{*}{ ca } & 21.000 & 3.0 & 84.000 & 160.0 & $1.00-12$ & & 75. \\
\hline & & 21.000 & 2.6 & 84.000 & 180.0 & $1.00-12$ & \multirow[t]{2}{*}{75.} & 500. \\
\hline & & 42.000 & 17.0 & 63.000 & 160.0 & $1.00-12$ & & 75. \\
\hline & & 42.000 & 7.3 & 63.000 & 87.0 & $1.00-12$ & \multirow[t]{2}{*}{75.} & 500. \\
\hline & & 84.000 & 29.0 & 21.000 & 46.0 & $1.00-12$ & & 75. \\
\hline & & 84.000 & 21.0 & 21.000 & 73.0 & $1.00-12$ & \multirow[t]{2}{*}{75.} & 500. \\
\hline \multirow[t]{12}{*}{ room } & \multirow[t]{6}{*}{ air } & 7.000 & 5.0 & 7.000 & 16.0 & $1.00-6$ & & 106. \\
\hline & & 7.000 & 5.0 & 7.000 & 16.0 & $1.00-6$ & \multirow[t]{2}{*}{106.} & 500. \\
\hline & & 14.000 & 6.0 & 14.000 & 15.0 & $1.00-6$ & & 106. \\
\hline & & 14.000 & 5.0 & 14.000 & 12.0 & $1.00-6$ & 106. & 500. \\
\hline & & 21.000 & 6.0 & & & $1.00-6$ & & 106. \\
\hline & & 21.000 & 5.0 & & & $1.00-6$ & 106. & 500. \\
\hline & \multirow[t]{6}{*}{$\mathbf{c a}$} & 7.000 & 17.0 & & & $1.00-6$ & & 75. \\
\hline & & 7.000 & 11.0 & & & $1.00-6$ & \multirow[t]{2}{*}{75.} & 500. \\
\hline & & 14.000 & 20.0 & & & $1.00-6$ & & 75. \\
\hline & & 14.000 & 14.0 & & & $1.00-6$ & 75. & 500. \\
\hline & & 21.000 & 14.0 & & & $1.00-6$ & & 75. \\
\hline & & 21.000 & 15.0 & & & $1.00-6$ & 75. & 500. \\
\hline
\end{tabular}

$\underline{\text { Core }}$

YM-42

$\begin{array}{llllllllll}\text { Ba room } & \text { air } & 21.000 & 72000.0 & 84.000 & 42000.0 & 8.00-10 . & 75 . & 500 . \\ & & 42.000 & 90000.0 & 63.000 & 83000.0 & 8.00-10.75 . & 500 . \\ & & 84.000 & 120000.0 & 21.000 & 150000.0 & 8.00-10 . & 75 . & 500 . \\ & & & & & & & & \\ \text { Ce room air } & 21.000 & 35000.0 & 84.000 & 46000.0 & 8.00-13 . & 75 . & 500 . \\ & & & 42.000 & 47000.0 & 63.000 & 35000.0 & 8.00-13 . & 75 . & 500 . \\ & & 84.000 & 29900.0 & 21.000 & 52000.0 & 8.00-13 . & 75 . & 500 .\end{array}$


Element Temp Atm Stime srd1 srd2 dtime drd1 drd2 Conc pmin pmax

Core

YM-42

\begin{tabular}{|c|c|c|c|c|c|c|c|c|c|}
\hline \multirow[t]{3}{*}{$\mathrm{Cs}$} & room & air & 21.000 & 16000.0 & 84.000 & 19000.0 & $3.00-9$ & 75. & 500. \\
\hline & & & 42.000 & 17000.0 & 63.000 & 19000.0 & $3.00-9$ & 75. & 500. \\
\hline & & & 84.000 & 19000.0 & 21.000 & 25000.0 & $3.00-9$ & 75. & 500. \\
\hline \multirow[t]{3}{*}{ Eu } & room & air & 21.000 & 45000.0 & 84.000 & 64000.0 & $1.00-10$ & 75. & 500. \\
\hline & & & 42.000 & 58000.0 & 63.000 & 59000.0 & $1.00-10$ & 75. & 500. \\
\hline & & & 84.000 & 53000.0 & 21.000 & 70000.0 & $1.00-10$ & 75. & 500. \\
\hline \multirow[t]{3}{*}{$\mathrm{Sr}$} & room & air & 21.000 & 2900.0 & 84.000 & 3300.0 & $8.00-11$ & 75. & 500. \\
\hline & & & 42.000 & 3900.0 & 63.000 & 3000.0 & $8.00-11$ & 75. & 500. \\
\hline & & & 84.000 & 5000.0 & 21.000 & 6000.0 & $8.00-11$ & 75. & 500. \\
\hline
\end{tabular}

$\underline{\text { Core }}$

YM-45

\begin{tabular}{|c|c|c|c|c|c|c|c|c|}
\hline \multirow[t]{4}{*}{$\mathbf{B a}$} & \multirow[t]{4}{*}{ room air } & 21.000 & 970.0 & 42.000 & 1200.0 & $3.00-7$. & \multirow{3}{*}{106.} & 106. \\
\hline & & 21.000 & 1200.0 & 42.000 & 1500.0 & $3.00-7$. & & 500. \\
\hline & & 42.000 & 1200.0 & 21.000 & 1300.0 & $3.00-7$. & & 106. \\
\hline & & 42.000 & 1400.0 & 21.000 & 1200.0 & $3.00-7$. & 106. & 500. \\
\hline \multirow[t]{4}{*}{$\mathrm{Ce}$} & \multirow[t]{4}{*}{ room air } & 21.000 & 540.0 & 42.000 & 4100.0 & $9.00-7$. & \multirow{3}{*}{106.} & 106. \\
\hline & & 21.000 & 1000.0 & 42.000 & 7400.0 & $9.00-7$. & & 500. \\
\hline & & 42.000 & 670.0 & 21.000 & 6800.0 & $9.00-7$. & & 106. \\
\hline & & 42.000 & 710.0 & 21.000 & 4700.0 & $9.00-7$. & 106. & 500. \\
\hline
\end{tabular}


Element Temp Atm Stime srd1 srd2 dtime drd1 drd2 Conc pmin pmax

$\begin{array}{rrr}\text { Cs room air } \quad 21.000 & 740.0 \\ & 21.000 & 480.0 \\ & 42.000 & 550.0 \\ & 42.000 & 320.0\end{array}$

$42.000 \quad 780.0$

$42.000 \quad 450.0$

$21.000 \quad 840.0$

$21.000 \quad 430.0$

Eu room air $21.000 \quad 990.0$

21.0002100 .0

$42.000 \quad 1700.0$

$42.000 \quad 1600.0$

Sr room air $21.000 \quad 220.0$

$21.000 \quad 170.0$

42.000220 .0

$42.000 \quad 170.0$
$42.000 \quad 5800.0$

$42.000 \quad 7100.0$

$21.000 \quad 9700.0$

$21.000 \quad 6400.0$

$42.000 \quad 240.0$

$\$ 2.000 \quad 190.0$

21.000230 .0

$21.000 \quad 180.0$
1.0G-9.

1.00-9. 106 .

1.00-9.

$1.00-9$.

1.00-7.

106.

1.00-7. 106 . 500 .

1.00-7.

106.

1.00-7. 106.500.

6.00-7.

6.00-7. 106.500 .

6.00-7. 106.

6.00-7. 106.500 .

\section{Core}

YM-46

$\mathrm{Ba}$ room air $21.000 \quad 6500.0$

$42.000 \quad 11000.0$

84.00025000 .0

Ce room air $\quad 21.000 \quad 97000.0$

$42.000 \quad 360000.0$

$84.000 \quad 470000.0$

Cs room air 21.000 500.0

$42.000 \quad 320.0$

$84.000 \quad 1700.0$

Eu air

$21.000 \quad 110000.0$

$42.000 \quad 320000.0$

$84.000 \quad 490000.0$
$84.000 \quad 23000.0$

63.00025000 .0

$21.000 \quad 16000.0$

$84.000 \quad 370000.0$

$63.000 \quad 400000.0$

21.000230000 .0

$84.000 \quad 1800.0$

63.0002200 .0

$21.000 \quad 1300.0$

84.00027000 .0

$63.000 \quad 35000.0$

$21.000 \quad 310000.0$
8.00-10. 75. 500 .

8.00-10. 75. 500 .

8.00-10. 75. 500 .

8.00-13. 75. 500 .

8.00-13. 75 . 500.

8.00-13. 75. 500 .

3.00-9. $75 . \quad 500$.

3.00-9. 75 . 500 .

3.C0-9. 75 . 500 .

1.00-10. $75 . \quad 500$.

1.00-10. 75 . 500 .

1.00-10. 75. 500 . 
Element Temp Atm Stime srd1 srd2 dtime drd1 drd2 Conc pmin pmax

$\begin{array}{lllllllll}\text { Sr room air } & 21.000 & 90.0 & 84.000 & 280.0 & 8.00-11 . & 75 . & 500 . \\ & & 42.000 & 170.0 & 63.000 & 290.0 & 8.00-11 . & 75 . & 500 . \\ & & 84.000 & 300.0 & 21.000 & 220.0 & 8.00-11 . & 75 . & 500 .\end{array}$

Core

YM-48

\begin{tabular}{|c|c|c|c|c|c|c|c|c|c|c|}
\hline \multirow[t]{3}{*}{$\mathrm{Ba}$} & \multirow[t]{3}{*}{ air } & \multirow[t]{3}{*}{21.000} & \multicolumn{5}{|l|}{12000.0} & \multirow{2}{*}{$\begin{array}{l}4.00-7 \\
4.00-7\end{array}$} & \multirow[t]{2}{*}{106.} & \multirow{2}{*}{$\begin{array}{l}500 . \\
106 .\end{array}$} \\
\hline & & & 42.000 & 10000.0 & 21.C0O & 27000.0 & & & & \\
\hline & & & 42.000 & 23000.0 & 21.000 & 41000.0 & & $4.00-7$ & 106. & 500. \\
\hline \multirow[t]{3}{*}{$\mathrm{Ce}$} & room & air & 21.000 & 870.0 & & & & $7.00-7$ & 106. & $5 Q Q$. \\
\hline & & & 42.000 & 2900.0 & 21.000 & 13000.0 & & $7.00-7$ & & 106. \\
\hline & & & 42.000 & 1900.0 & 21.000 & 12000.0 & & $7.00-7$. & 106. & 500. \\
\hline \multirow[t]{3}{*}{ Cs } & room & air & 21.000 & 15000.0 & & & & $1.00-9$ & 106. & 500. \\
\hline & & & 42.000 & 6900.0 & 21.000 & 23000.0 & & $1.00-9$ & & 106. \\
\hline & & & 42.000 & 22000.0 & 21.000 & 30000.0 & & $1.00-9$ & 106. & 500. \\
\hline \multirow[t]{3}{*}{$\mathbf{E u}$} & room & air & 21.000 & 1700.0 & & & & $5.00-8$ & 106. & 500. \\
\hline & & & 42.000 & 3100.0 & 21.000 & 6800.0 & & $5.00-8$ & & 106. \\
\hline & & & 42.000 & 2700.0 & 21.000 & 9300.0 & & $5.00-8$ & 106. & 500. \\
\hline \multirow[t]{3}{*}{$\mathrm{Sr}$} & rcom & air & 21.000 & 15000.0 & & & & $7.00-8$ & 106. & 500. \\
\hline & & & 42.000 & 1200.0 & 21.000 & 4200.0 & & $7.00-8$ & & 106. \\
\hline & & & 42.000 & 2500.0 & 21.000 & 2900.0 & & $7.00-8$ & 106. & 500. \\
\hline \multirow[t]{4}{*}{$\mathrm{Tc}$} & room & air & 4.2 .000 & 0.11 & 63.000 & 2.3 & & $1.00-9$ & 106. & 500. \\
\hline & & & 42.000 & 0.14 & 63.000 & 1.2 & & $1.00-6$ & 106. & 500. \\
\hline & & & 42.000 & 0.16 & 63.000 & & 1.5 & $1.00-3$ & 106. & 00. \\
\hline & & & 42.000 & 0.2 & 63.000 & 1.6 & & $1.00-12$ & 106. & \\
\hline
\end{tabular}


Element Temp Atm Stime grd1 ord2 dtime drd1 drd2 Conc pmin pmax

Core

YM-49

\begin{tabular}{|c|c|c|c|c|c|c|c|c|c|c|c|}
\hline \multirow[t]{3}{*}{ Am } & \multirow[t]{3}{*}{ room } & \multirow[t]{3}{*}{ air } & 21.000 & \multicolumn{2}{|l|}{2900.0} & 84.000 & \multicolumn{2}{|l|}{19000.0} & \multirow{2}{*}{$\begin{array}{l}1.00-7 \\
1.00-7\end{array}$} & \multirow{2}{*}{$\begin{array}{l}106 . \\
106 .\end{array}$} & \multirow{2}{*}{$\begin{array}{l}250 . \\
250 .\end{array}$} \\
\hline & & & 42.000 & 2800.0 & & 63.000 & 3800.0 & & & & \\
\hline & & & 84.000 & 7100.0 & & 21.000 & 3000.0 & & $1.00-7$ & 106. & 250. \\
\hline \multirow[t]{5}{*}{$\mathbf{B a}$} & room & air & 21.000 & 17000.0 & & 42.000 & 28000.0 & & $4.00-7$ & & 106. \\
\hline & & & 21.000 & 26000.0 & & 42.000 & 51000.0 & & $4.00-7$ & 106. & 500. \\
\hline & & & 21.000 & 30000.0 & & & & & $4.00-7$ & 106. & 500. \\
\hline & & & 42.000 & 9200.0 & & & & & $4.00-7$ & & 106. \\
\hline & & & 42.000 & 59000.0 & 54000.0 & 21.000 & 69000.0 & 76000.0 & $4.00-7$ & 106. & 500. \\
\hline \multirow[t]{5}{*}{$\mathrm{Ce}$} & room & air & 21.000 & 570.0 & & 42.000 & 1400.0 & & $3.00-7$ & & 100. \\
\hline & & & 21.000 & 560.0 & & 42.000 & 1000.0 & & $3.00-7$ & 106. & 500. \\
\hline & & & 21.000 & 490.0 & & & & & $3.00-7$ & 106. & 500. \\
\hline & & & 42.000 & 530.0 & & & & & $3.00-7$ & & 106. \\
\hline & & & 42.000 & 810.0 & 350.0 & 21.000 & 1100.0 & 970.0 & $3.00-7$ & 106. & 500. \\
\hline \multirow[t]{5}{*}{ Cs } & room & air & 21.000 & 22000.0 & & 42.000 & 15000.0 & & $1.00-9$ & & 106. \\
\hline & & & 21.000 & 29000.0 & & 42.000 & 38000.0 & & $1.00-9$ & 106. & 500. \\
\hline & & & 21.000 & 37000.0 & & & & & $1.00-9$ & 106. & 500. \\
\hline & & & 42.000 & 8700.0 & & & & & $1.00-9$ & & 106. \\
\hline & & & 42.000 & 36000.0 & 43000.0 & 21.000 & 40000.0 & 40000.0 & $1.00-9$ & 106. & 500. \\
\hline \multirow[t]{5}{*}{$\mathbf{E u}$} & room & air & 21.000 & 1400.0 & & 42.000 & 2200.0 & & $1.00-7$ & 106 & \\
\hline & & & 21.000 & 1200.0 & & & & & $1.00-7$ & 106. & 500. \\
\hline & & & 21.000 & 1000.0 & & 42.000 & 1600.0 & & $1.00-7$ & 106. & 500. \\
\hline & & & 42.000 & 1300.0 & & & & & $1.00-7$ & & 106. \\
\hline & & & 42.000 & 1500.0 & 1000.0 & 21.000 & 3100.0 & 1600.0 & $1.00-7$ & 106. & 500. \\
\hline \multirow[t]{3}{*}{$N_{p}$} & room & air & 21.000 & 15.0 & & 84.000 & 6.7 & & $7.00-11$ & 106. & 250. \\
\hline & & & 42.000 & 5.3 & & 63.000 & 9.2 & & $7.00-11$ & 106. & 250. \\
\hline & & & 84.000 & 6.3 & & 21.000 & 20.0 & & $i .00-11$. & 106. & $25 n$. \\
\hline
\end{tabular}




\section{Element Temp Atm Stime srd1 srd2 dtime drd1 drd2 Conc pmin pmax}

\begin{tabular}{|c|c|c|c|c|c|c|c|c|c|c|}
\hline \multirow{18}{*}{ Pu } & \multirow[t]{18}{*}{ room air } & 21.000 & \multirow{2}{*}{\multicolumn{2}{|c|}{$\begin{array}{l}270.0 \\
170.0\end{array}$}} & 21.000 & \multirow{2}{*}{\multicolumn{2}{|c|}{$\begin{array}{l}690.0 \\
700.0\end{array}$}} & $3.00-8$ & \multicolumn{2}{|l|}{75.} \\
\hline & & 21.000 & & & 21.000 & & & $2.00-12$ & & 75. \\
\hline & & 21.000 & 180.0 & & 21.000 & 490.0 & & $4.00-10$ & & 75. \\
\hline & & 21.000 & 130.0 & & 21.000 & 780.0 & & $1.00-10$ & & 75. \\
\hline & & 21.000 & 160.0 & & 21.000 & 840.0 & & $8.00-12$ & & 75. \\
\hline & & 21.000 & 140.0 & & 21.000 & 590.0 & & $1.00-10$ & 75. & 500. \\
\hline & & 21.000 & 390.0 & & 21.000 & 1300.0 & & $1.00-10$ & 75. & 500. \\
\hline & & 21.000 & 150.0 & & 21.000 & 670.0 & & $2.00-12$ & 75. & 500. \\
\hline & & 21.000 & 220.0 & & 21.000 & 620.0 & & $4.00-10$ & 75. & $50 n$. \\
\hline & & 21.000 & 89.0 & & 21.000 & 790.0 & & $8.00-12$ & 75. & 500. \\
\hline & & 21.000 & 2000.0 & & 21.000 & 1700.0 & & $8.00-10$ & 75. & 500. \\
\hline & & 21.000 & 130.0 & & 21.000 & 720.0 & & $3.00-12$ & 75. & 500. \\
\hline & & 21.000 & 120.0 & & 21.000 & 560.0 & & $1.00-8$ & 75. & 500. \\
\hline & & 21.000 & 240.0 & & 21.000 & 700.0 & & $2.00-11$ & 75. & 500. \\
\hline & & 21.000 & 240.0 & & 21.000 & 340.0 & & $3.00-8$ & 75. & 500. \\
\hline & & 21.000 & 140.0 & & 84.000 & 390.0 & & $3.00-12$ & 108. & 250. \\
\hline & & 42.000 & 160.0 & 200.0 & 63.000 & 410.0 & 440.0 & $3.00-12$ & 106. & 250. \\
\hline & & 84.000 & 210.0 & 820.0 & 21.000 & 660.0 & 930.0 & $3.00-12$ & 106. & 250. \\
\hline $\mathbf{S r}$ & room air & 21.000 & 1500.0 & & 42.000 & 2400.0 & & $6.00-8$ & & 106. \\
\hline & & 21.000 & 2700.0 & & 42.000 & 4400.0 & & $6.00-8$ & 106. & 500 \\
\hline & & 21.000 & 2600.0 & & & & & $6.00-8$ & 106. & 500. \\
\hline & & 42.000 & 2400.0 & & & & & $6.00-8$ & & 106. \\
\hline & & 42.000 & 3800.0 & 3800.0 & 21.000 & 4400.0 & 4300.0 & $6.00-8$. & 106. & 500. \\
\hline
\end{tabular}

$\begin{array}{llllllll}\text { Te room air } & 42.000 & 0.23 & 63.000 & 2.3 & 1.00-12 . & 106 . & 500 \\ & 42.000 & 0.25 & 63.000 & 2.7 & 1.00-9 . & 106 . & 500 \\ & 42.000 & 0.2 & 63.000 & 1.5 & 1.00-6 . & 106 . & 500 . \\ & 42.000 & 0.16 & 63.000 & 1.3 & 1.00-3 . & 106 . & 500 .\end{array}$


Element Temp Atm Stime srd1 srd2 dtime drd1 d:d2 Conc pmin pmax

\section{Core}

YM-54

\begin{tabular}{|c|c|c|c|c|c|c|c|c|c|}
\hline \multirow{12}{*}{ Am } & \multirow[t]{12}{*}{ room } & \multirow[t]{6}{*}{ air } & 21.000 & 900.0 & 84.000 & 690.0 & $1.00-7$ & & 75. \\
\hline & & & 21.000 & 150.0 & 84.000 & 400.0 & $1.00-7$ & \multirow[t]{2}{*}{75.} & 500. \\
\hline & & & 42.000 & 1300.0 & 63.000 & 670.0 & $1.00-7$ & & 75. \\
\hline & & & 42.000 & 150.0 & 63.000 & 680.0 & $1.00-7$ & \multirow[t]{2}{*}{75.} & 500. \\
\hline & & & 84.000 & 900.0 & 21.000 & 560.0 & $1.00-7$ & & 75. \\
\hline & & & 84.000 & 160.0 & 21.000 & 570.0 & $1.00-7$ & \multirow[t]{2}{*}{75.} & 500. \\
\hline & & \multirow[t]{6}{*}{$\mathrm{ca}$} & 21.000 & 1000.0 & 84.000 & 2400.0 & $1.00-7$ & & 75. \\
\hline & & & 21.000 & 650.0 & 84.000 & 1400.0 & $1.00-7$ & \multirow[t]{2}{*}{75.} & 500. \\
\hline & & & 42.000 & 1400.0 & 63.000 & 3200.0 & $1.00-7$ & & 75. \\
\hline & & & 42.000 & 620.0 & 63.000 & 1600.0 & $1.00-7$ & \multirow[t]{2}{*}{75.} & 500. \\
\hline & & & 84.000 & 1900.0 & 21.000 & 3800.0 & $1.00-7$ & & 75. \\
\hline & & & $8 \dot{4} .000$ & 660.0 & 21.000 & 2900.0 & $1.00-7$ & 75. & 500. \\
\hline \multirow[t]{16}{*}{$\mathrm{Ba}$} & \multirow[t]{16}{*}{ room } & \multirow[t]{10}{*}{ air } & 21.000 & 1700.0 & & & 3.00-7. & & 38. \\
\hline & & & 21.000 & 1600.0 & & & $3.00-7$ & & 38. \\
\hline & & & 21.000 & 520.0 & 42.000 & 690.0 & $3.00-7$ & & 106. \\
\hline & & & 21.000 & 480.0 & & & $3.00-7$ & 38. & 106. \\
\hline & & & 21.000 & 470.0 & & & 3.00-7. & 38. & 106. \\
\hline & & & 21.000 & 130.0 & & & $3.00-7$ & 106. & 500. \\
\hline & & & 21.000 & 150.0 & & & $3.00-7$ & 106. & 500. \\
\hline & & & 21.000 & 720.0 & 42.000 & 620.0 & $3.00-7$ & \multirow[t]{2}{*}{106.} & 500. \\
\hline & & & 42.000 & 650.0 & 21.000 & 680.0 & 3.00-7. & & 106. \\
\hline & & & 42.000 & 590.0 & 21.000 & 640.0 & $3.00-7$ & \multirow[t]{2}{*}{106.} & 500. \\
\hline & & \multirow[t]{6}{*}{ ca } & 21.000 & 610.0 & 42.000 & 630.0 & $1.00-7$ & & 75. \\
\hline & & & 21.000 & 870.0 & 42.000 & 470.0 & $1.00-7$ & \multirow[t]{2}{*}{75.} & 500. \\
\hline & & & 42.000 & 740.0 & 21.000 & 660.0 & $1.00-7$ & & 75. \\
\hline & & & 42.000 & 620.0 & 21.000 & 640.0 & $1.00-7$ & \multirow[t]{2}{*}{75.} & 500. \\
\hline & & & 84.000 & 660.0 & & & $1.00-7$ & & 75. \\
\hline & & & 84.000 & 350.0 & & & $1.00-7$ & \multirow[t]{2}{*}{75.} & 500. \\
\hline \multirow[t]{2}{*}{$\mathrm{Ce}$} & \multirow[t]{2}{*}{ room } & \multirow[t]{2}{*}{ air } & 21.000 & 110.0 & 42.000 & 1000.0 & $9.00-7$ & & 6. \\
\hline & & & 21.000 & 180.0 & 42.000 & 1500.0 & $9.00-7$ & 106. & \\
\hline
\end{tabular}




\section{Core}

YM-54

\begin{tabular}{|c|c|c|c|c|c|c|c|c|c|}
\hline \multirow[t]{8}{*}{$\mathrm{Ce}$} & room & air & 42.000 & 170.0 & 21.000 & 690.0 & $9.00-7$ & & 106. \\
\hline & & & 42.000 & 110.0 & 21.000 & 720.0 & 9.00-7. & 106. & 500. \\
\hline & & ca & 21.000 & 150.0 & 42.000 & 840.0 & $1.00-7$ & & 75. \\
\hline & & & 21.000 & 110.0 & 42.000 & 680.0 & $1.00-7$ & 75. & 500. \\
\hline & & & 42.000 & 860.0 & 21.000 & 2400.0 & $1.00-7$ & & 75. \\
\hline & & & 42.000 & 540.0 & 21.000 & 2100.0 & $1.00-7$ & 75. & 500. \\
\hline & & & 84.000 & 970.0 & & & $1.00-7$ & & 75 \\
\hline & & & 84.000 & 490.0 & & & $1.00-7$ & 75 & 500. \\
\hline \multirow[t]{16}{*}{ Cs } & room & air & 21.000 & 890.0 & & & $3.00-9$ & & 38. \\
\hline & & & 21.000 & 940.0 & & & $3.00-9$ & & 38. \\
\hline & & & 21.000 & 270.0 & 42.000 & 270.0 & $2.00-9$ & & 106. \\
\hline & & & 21.000 & 190.0 & & & $3.00-9$ & 38. & 106. \\
\hline & & & 21.000 & 190.0 & & & $3.00-9$ & 38. & 106. \\
\hline & & & 21.000 & 130.0 & & & $3.00-9$ & 106. & 500. \\
\hline & & & 21.000 & 290.0 & 42.000 & 290.0 & $2.00-9$ & 106. & 500. \\
\hline & & & 21.000 & 110.0 & & & $3.00-9$ & 106. & 500. \\
\hline & & & 42.000 & 230.0 & 21.000 & 320.0 & $2.00-9$ & & 106. \\
\hline & & & 42.000 & 200.0 & 21.000 & 350.0 & $2.00-9$ & 106. & 500. \\
\hline & & ca & 21.000 & 360.0 & 42.000 & 460.0 & $3.00-9$ & & 75. \\
\hline & & & 21.000 & 210.0 & 42.000 & 260.0 & $3.00-9$ & 75. & 500. \\
\hline & & & 42.000 & 370.0 & 21.000 & 420.0 & $3.00-9$ & & 75. \\
\hline & & & 42.000 & 260.0 & 21.000 & 310.0 & $3.00-9$ & 75. & 500. \\
\hline & & & 84.000 & 390.0 & & & $3.00-9$ & & 75. \\
\hline & & & 84.000 & 240.0 & & & $3.00-9$ & 75. & 500. \\
\hline \multirow[t]{4}{*}{ Eu } & room & air & 21.000 & 1600.0 & & & $4.00-8$ & & 38. \\
\hline & & & 21.000 & 1600.0 & & & $4.00-8$ & & 38. \\
\hline & & & 21.000 & 390.0 & 42.000 & 1900.0 & $1.00-7$ & & 106. \\
\hline & & & 21.000 & 420.0 & & & $4.00-8$ & 38. & 106. \\
\hline
\end{tabular}


Core

YM-54

$\begin{array}{rllll}\text { Eu room air } \quad 21.000 & 260.0 & & \\ & 21.000 & 440.0 & & \\ & 21.000 & 580.0 & 42.000 & 2100.0 \\ & 21.000 & 490.0 & & \\ 42.000 & 700.0 & 21.000 & 1700.0 \\ & 42.000 & 370.0 & 21.000 & 1700.0 \\ \text { ca } \quad 21.000 & 530.0 & 42.000 & 1700.0 \\ & 21.000 & 330.0 & 42.000 & 1500.0 \\ & 42.000 & 1400.0 & 21.000 & 2600.0 \\ 42.000 & 850.0 & 21.000 & 2100.0 \\ 84.000 & 1500.0 & & \\ & 84.000 & 770.0 & & \end{array}$

Pu room air 21.00 66.0

$21.000 \quad 52.0$

42.00064 .0

42.00081 .0

$84.000 \quad 76.0$

$84.000 \quad 160.0$

ca $\quad 21.000 \quad 65.0$

$21.000 \quad 110.0$

42.000100 .0

$49.000 \quad 205.0$

$84.000 \quad 120.0$

84.000190 .0

Sr room air $21.000 \quad 280.0$

$21.000 \quad 270.0$

21.00095 .0

$21.000 \quad 56.0$

$21.000 \quad 57.0$

$21.000 \quad 42.0$
4.00-8. 38. 106.

4.00-8. 106 . 500 .

1.00-7. 106 . 500.

4.00-8. 106 . 500 .

1.00-7. 106.

1.00-7. 106. 500 .

2.00-7. 75 .

2.00-7. 75 . 500 .

$2.00-7$. 75 .

2.00-7. 75 . 500 .

2.00-7. 75 .

2.00-7. 75. 500 .

$\begin{array}{llll}84.000 & 830.0 & 5.00-12 . & 75 .\end{array}$

$84.000660 .0 \quad 5.00-12.75 .500$.

$\begin{array}{llll}63.000 & 590.0 & 5.00-12 . & 75 .\end{array}$

$\begin{array}{lllll}63.000 & 600.0 & 5.00-12 . & 75 . & 500 .\end{array}$

$\begin{array}{llll}21.000 & 670.0 & 5.00-12 . & 75 .\end{array}$

$21.000660 .0 \quad 5.00-12$. $75 . \quad 500$.

$\begin{array}{llll}84.000 & 1000.0 & 3.00-13 . & 75 .\end{array}$

$84.000850 .0 \quad 3.00-13.75$. 500 .

$\begin{array}{llll}63.000 & 780.0 & 3.00-13 . & 75 .\end{array}$

$\begin{array}{lllll}56.000 & 1600.0 & 3.00-13 . & 75 . & 500 .\end{array}$

$\begin{array}{llll}21.000 & 1900.0 & 3.00-13 . & 75 .\end{array}$

$21.0001500 .0 \quad 3.00-13.75 .500$.

6.00-7. 38 .

6.00-7. 38 .

6.00-7. 106 .

6.00-7. 38. 106 .

6.00-7. 38. 106.

6.00-7. 106. 500 . 
Element Temp Atm Stime srd1 srd2 dtime drd1 drd2 Conc pmin pmax

Core

YM-54

\begin{tabular}{|c|c|c|c|c|c|c|c|c|c|}
\hline \multirow{10}{*}{$\mathrm{Sr}$} & \multirow[t]{10}{*}{ room } & \multirow[t]{8}{*}{ air } & 21.000 & 88.0 & 42.000 & 80.0 & $6.00-7$ & 106. & 500. \\
\hline & & & 21.000 & 37.0 & & & $6.00-7$ & 106. & 500. \\
\hline & & & 42.000 & 97.0 & 21.000 & 110.0 & $6.00-7$ & & 106. \\
\hline & & & 42.000 & 80.0 & 21.000 & 84.0 & $6.00-7$ & 106. & 500. \\
\hline & & & 42.000 & 150.0 & 21.000 & 120.0 & $8.00-8$ & & 75. \\
\hline & & & 42.000 & 130.0 & 21.000 & 120.0 & $8.00-8$ & 75. & 500. \\
\hline & & & 84.000 & 130.0 & & & $8.00-8$. & & 75. \\
\hline & & & 84.000 & 70.0 & & & $8.00-8$. & 75. & 500. \\
\hline & & \multirow[t]{2}{*}{ ca } & 21.000 & 100.0 & 42.000 & 150.0 & $8.00-8$ & & 75. \\
\hline & & & 21.000 & 76.0 & 42.000 & 110.0 & $8.00-8$ & 75. & 500. \\
\hline \multirow[t]{6}{*}{$\mathrm{Tc}$} & \multirow[t]{6}{*}{ room } & \multirow[t]{6}{*}{ ca } & 21.000 & 0.7 & 84.000 & 37.0 & $1.00-12$ & & 75. \\
\hline & & & 21.000 & 4.7 & 84.000 & 140.0 & $1.00-12$ & 75. & 500. \\
\hline & & & 42.000 & 0.8 & 63.000 & 13.0 & $1.00-12$ & & 75. \\
\hline & & & 42.000 & 3.8 & 63.000 & 38.0 & $1.00-12$ & 75. & 500. \\
\hline & & & 84.000 & 3.4 & 21.000 & 5.0 & $1.00-12$ & & 75. \\
\hline & & & 84.000 & 33.0 & 21.000 & 240.0 & $1.00-12$ & 75. & 500. \\
\hline \multirow[t]{12}{*}{$U$} & \multirow[t]{12}{*}{ room } & \multirow[t]{6}{*}{ air } & 7.000 & 2.0 & 14.000 & 14.0 & $1.00-6$ & & 106. \\
\hline & & & 7.000 & 1.0 & 14.000 & 4.0 & $1.00-6$ & 106. & 500. \\
\hline & & & 14.000 & 2.0 & 7.000 & 15.0 & $1.00-6$ & & 106. \\
\hline & & & 14.000 & 2.0 & 7.000 & 19.0 & $1.00-6$ & 106. & 500. \\
\hline & & & 21.000 & 2.0 & & & $1.00-6$ & & 106. \\
\hline & & & 21.000 & 1.0 & & & $1.00-6$ & 106. & 500. \\
\hline & & \multirow[t]{6}{*}{ ca } & 7.000 & 1.0 & & & $1.00-6$ & & 75. \\
\hline & & & 7.000 & .8 & & & $1.00-6$ & 75. & 500. \\
\hline & & & 14.000 & 1.8 & & & $1.00-6$ & & 75. \\
\hline & & & 14.000 & 1.4 & & & $1.00-6$ & 75. & 500. \\
\hline & & & 21.000 & 2.3 & & & $1.00-6$ & & 75. \\
\hline & & & 21.000 & 1.7 & & & $1.00-6$ & 75. & 500. \\
\hline
\end{tabular}

